\title{
Reducing the Risks of Herbicide Resistance: Best Management Practices and Recommendations
}

Jason K. Norsworthy, Sarah M. Ward, David R. Shaw, Rick S. Llewellyn, Robert L. Nichols, Theodore M. Webster, Kevin W. Bradley, George Frisvold, Stephen B. Powles, Nilda R. Burgos, William W. Witt, and Michael Barrett*

\section{Table of Contents}

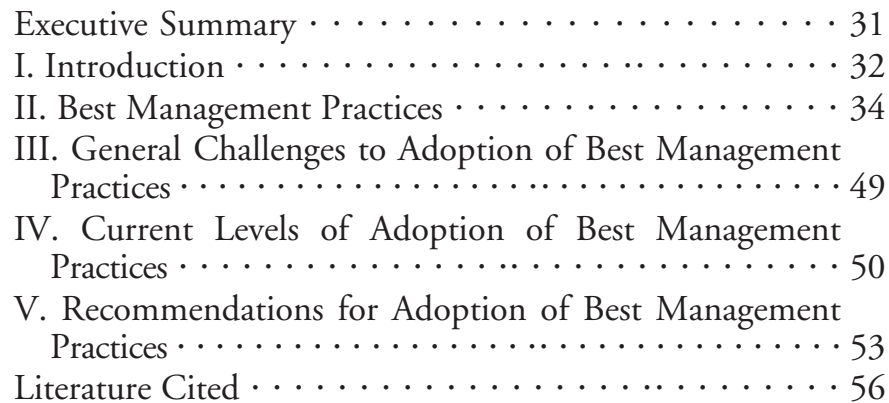

\section{Executive Summary}

Herbicides are the foundation of weed control in commercial crop-production systems. However, herbicide-resistant (HR) weed populations are evolving rapidly as a natural response to selection pressure imposed by modern agricultural management activities. Mitigating the evolution of herbicide resistance depends on reducing selection through diversification of weed control techniques, minimizing the spread of resistance genes and genotypes via pollen or propagule dispersal, and eliminating additions of weed seed to the soil seedbank. Effective deployment of such a multifaceted approach will require shifting from the current concept of basing weed management on single-year economic thresholds.

Programs for herbicide-resistance management must consider use of all cultural, mechanical, and herbicidal options available for effective weed control in each situation and employ the following best management practices (BMPs):

1. Understand the biology of the weeds present.

2. Use a diversified approach toward weed management focused on preventing weed seed production and reducing the number of weed seed in the soil seedbank.

\footnotetext{
DOI: 10.1614/WS-D-11-00155.1

* First, second, and tenth authors: Associate Professor, Associate Professor, and Professor, Department of Crop, Soil, and Environmental Sciences, University of Arkansas, 1366 West Atheimer Drive, Fayetteville, AR 72704; third author: Giles Distinguished Professor, GeoResources Institute, Mississippi State University, Mississippi State, MS 39762; fourth author: CSIRO Sustainable Ecosystems, Private Bag 2, Glen Osmond, South Australia 5064, Australia; fifth author: Cotton Incorporated, 6399 Weston Parkway, Cary, NC 27513; sixth author: Research Agronomist, Crop Protection and Management Research Unit, USDAAgricultural Research Service, Tifton, GA 31794; seventh author: Assistant Professor, Division of Plant Sciences, University of Missouri, Columbia, MO 65211; eighth author: Professor and Extension Specialist, Department of Agricultural and Resource Economics, 319 Economics Building, University of Arizona, Tucson, AZ 85721; ninth author: Professor, Western Australian Herbicide Resistance Initiative, University of Western Australia, 35 Stirling Highway, Crawley, WA 6009, Australia; eleventh and twelfth authors: Professor and Professor, Department of Plant and Soil Sciences, 105 Plant Science Building, University of Kentucky, Lexington, KY 40546. Corresponding author's E-mail: jnorswor@uark.edu
}

3. Plant into weed-free fields and then keep fields as weed free as possible.

4. Plant weed-free crop seed.

5. Scout fields routinely.

6. Use multiple herbicide mechanisms of action (MOAs) that are effective against the most troublesome weeds or those most prone to herbicide resistance.

7. Apply the labeled herbicide rate at recommended weed sizes.

8. Emphasize cultural practices that suppress weeds by using crop competitiveness.

9. Use mechanical and biological management practices where appropriate.

10. Prevent field-to-field and within-field movement of weed seed or vegetative propagules.

11. Manage weed seed at harvest and after harvest to prevent a buildup of the weed seedbank.

12. Prevent an influx of weeds into the field by managing field borders.

The long-term economic benefits of avoiding additional costs associated with managing $\mathrm{HR}$ weeds are clear. Nevertheless, widespread adoption of these BMPs must overcome several real barriers. In particular, growers' focus on immediate economic returns must be overcome as well as their beliefs that the evolution of herbicide resistance in weeds is unavoidable and that continued availability of novel herbicide technologies will solve the problem. There is, at present, no single database collating information on weed management practices employed by U.S. growers, so the extent of the adoption of BMPs for HR weeds must be inferred by combining data from multiple sources. Available survey data show that, although many U.S. soybean [Glycine max (L.) Merr], corn (Zea mays L.), and cotton (Gossypium hirsutum L.) growers employ at least some BMPs, a significant proportion of growers are not practicing adequate, proactive herbicide-resistance management. Two key recommendations, in particular, must be more widely implemented: diversifying weed management practices and using multiple herbicide MOAs. Growers need to be educated about MOAs and be made aware that discovery of new herbicide chemistries is rare, that the existing herbicide resource is exhaustible, and that indiscriminate herbicide use leading to rapid evolution of HR weeds may result in the loss of herbicide options for all.

To address the increasingly urgent problem of herbicide resistance, we make the following recommendations:

1. Reduce the weed seedbank through diversified programs that minimize weed seed production.

2. Implement a herbicide MOA labeling system for all herbicide products and conduct an awareness campaign.

3. Communicate that discovery of new, effective herbicide MOAs is rare and that the existing herbicide resource is exhaustible. 
4. Demonstrate the benefits and costs of proactive, diversified weed-management systems for the mitigation of HR weeds.

5. Foster the development of incentives by government agencies and industry that conserve critical herbicide MOAs as a means to encourage adoption of best practices.

6. Promote the application of full-labeled rates at the appropriate weed and crop growth stage. When tank mixtures are employed to control the range of weeds present in a field, each product should be used at the specified label rate appropriate for the weeds present.

7. Identify and promote individual BMPs that fit specific farming segments with the greatest potential impact.

8. Engage the public and private sectors in the promotion of BMPs, including those concerning appropriate herbicide use.

9. Direct federal, state, and industry funding to research addressing the substantial knowledge gaps in BMPs for herbicide resistance and to support cooperative extension services as vital agents in education for resistance management.

In some instances, short-term costs may not favor implementation of BMPs that provide insufficient immediate economic benefit, even though their adoption will delay the evolution of HR weed populations over time. In such cases, consideration should be given to providing incentives and expert advice for growers to develop and implement riskreducing weed management plans, following the precedent set by similar incentives for the conservation of soil and water resources in agriculture.

\section{Introduction}

The evolution of herbicide-resistant (HR) weed populations is a natural response to selection pressure imposed by modern agricultural management activities. This response in weeds was predicted by Harper (1956), when he stated "the most effective intensity of selection is that which reduces a population to a small resistant residue which is capable of rapid reproduction" (page 182). The two key principles implicit in Harper's observation are fundamental to herbicideresistance management today: (1) reducing the intensity of selection, and (2) preventing reproduction by the surviving, resistant individuals. Herbicide applications that eliminate susceptible weeds before they reproduce create a selective advantage for any rare, resistant individuals in the weed population. Reproduction by these escapees then transmits the resistance trait to their offspring, facilitating their survival when exposed to the same herbicide mechanism of action (MOA). Sustained, unidirectional selection pressure, which occurs with repeated use of either the same herbicide or, in some cases, the same MOA, favors survival and reproduction of these resistant biotypes, leading to a weed population in which resistant plants predominate. Repeating the same control tactics at a given timing, whether a herbicide application or a nonchemical control methods, may also result in the evolution of avoidance mechanisms in a weed population by selecting for biotypes that have not emerged, or are outside the optimal growth stage, when control is implemented (Reddy and Norsworthy 2010). For example, repeated hand-weeding in rice (Oryza sativa L.) systems in
Asia has resulted in selection for barnyardgrass [Echinochloa crus-galli (L.) Beauv.] populations that are phenotypically similar to rice, making them harder to differentiate at vegetative growth stages (Barrett 1983). Thus, the evolution of resistance or avoidance is favored when a particular management practice is repeated without any diversification.

For herbicides, factors that affect how rapidly weed populations shift to predominantly resistant individuals include (1) the intensity of the selection (which is a function of herbicide dose, frequency, and timing of application), (2) mutation rate and the initial frequency of resistant individuals in the population exposed to the herbicide, (3) the genetic basis of the resistance (mode of inheritance, dominance), (4) life-history characteristics of the weed species (such as annual vs. perennial life cycle, self fertilization vs. cross-pollination, fecundity, extent of seed dormancy), and (5) the rate of reproduction and potential for recruitment of susceptible or resistant individuals from outside the population (e.g., from the soil seedbank or by immigration).

Among these factors, producers can influence intensity of selection and, to a lesser extent, seed production of escapees, seedbank dynamics, and recruitment of resistant individuals. Effective management of herbicide resistance-whether proactive to mitigate resistance evolution or reactive to restore weed control after resistance has evolved-depends on two key strategies: (1) reducing herbicide selection pressure and diversifying weed control techniques so as to minimize preferential survival and reproduction by resistant individuals, and (2) minimizing the spread of resistance by means of pollen movement, seed production, and propagule dispersal. Strategies that eliminate annual additions of weed seed to the soil seedbank will be particularly effective, although such an approach is incompatible with the use of management based on single-year economic thresholds (Coble and Mortensen 1992; Cousens 1987).

The first incidences of evolved herbicide resistance were reported in wild carrot (Daucus carota L.), which evolved resistance to the auxin analog class of herbicides after several seasons of consecutive use of 2,4-D (Switzer 1957; Whitehead and Switzer 1967), and common groundsel (Senecio vulgaris L.), which evolved resistance to simazine and atrazine after receiving either one or two annual applications of these herbicides for 10 consecutive yr (Ryan 1970). Since then, 362 confirmed instances of weed resistance have been reported in 198 species (115 dicots and 83 monocots)(Heap 2011b). More than one-third of these resistant weeds are found in the United States, primarily in the north-central and southern regions, where arable crop production is concentrated (Heap 2011b; Vencill et al. 2011). Persistent herbicide selection across a vast crop area on multiple populations of genetically diverse weeds has led, and will continue to lead, to the widespread evolution of HR weed populations (Powles and $\mathrm{Yu}$ 2010). Although herbicides will continue to dominate weed-control practices because of their economic utility, the sustainability of herbicide use depends on their diversification and integration with nonchemical weed-control strategies. Only by implementing diverse weed-management practices will herbicides be conserved as a valuable agricultural resource.

Transgenic Crops. Since 1996, glyphosate-resistant (GR) crops have had a major effect on agriculture, particularly in the United States, Brazil, Argentina, and Canada (Brookes 
and Barfoot 2011). The introduction of GR crops in the United States helped solve a major weed-management problem that was developing at that time-the evolution of weeds resistant to the acetolactate synthase (ALS)-inhibiting and protoporphyrinogen oxidase (PPO)-inhibiting herbicides. However, the introduction of GR crops also prompted concerns about potential transfer of herbicide resistance to weed populations via crop-to-weed gene flow (Dale 1994; Warwick et al. 1999). This has been experimentally demonstrated for a small number of weed species in North America that can hybridize with a closely related crop: examples are described later in this document (see BMP 1). However, for full introgression of a herbicide-resistance gene from a crop into a weed population, the initial weed by crop hybrid must be fertile and repeated transmission of the HR gene via backcrossing to the weedy parent must take place. There are few reports of this occurring in the field. Warwick et al. (2008) described stable introgression of a HR transgene from GR canola (Brassica napus L.) to weedy birdsrape mustard (Brassica rapa L.) under field conditions, and Zapiola et al. (2008) reported persistence of a GR transgene in populations of weedy creeping bentgrass (Agrostis stolonifera L.) following accidental pollen and propagule transfer from experimental plantings of GR ornamental bentgrass (Agrostis palustris Huds.). However, none of the confirmed field reports of glyphosate resistance in North American weed species listed to date by Heap (2011b) have been traced to gene transfer from GR crops. Although there is a possibility of weeds acquiring HR genes from crops in a few cases, the accumulating evidence to date strongly suggests that a much greater risk is posed by spontaneous evolution of herbicide resistance in weed populations under selection pressure from repeated herbicide applications in HR cropping systems. The wide-scale adoption of any single herbicidal MOA contributes to the evolution of resistance to that $\mathrm{MOA}$, and the unprecedented scale of glyphosate use in GR crops has clearly contributed to the number of GR weeds identified in recent years (Powles et al. 1997; Vencill et al. 2011).

In parts of North and South America, transgenic GR crops have dramatically reduced the diversity of herbicides used for weed management in those crops (Young 2006). Glyphosateresistant crop cultivars now dominate corn (Zea mays L.), soybean [Glycine $\max$ (L.) Merr.], cotton (Gossypium hirsutum L.), and canola production in the United States (Nichols et al. 2003). As new HR crops become available, management of novel HR weeds will continue to be a challenge. Glufosinateresistant soybean, corn, cotton, and canola are now commercialized, and, in the near future, crops resistant to the herbicides 2,4-D, dicamba, hydroxyphenylpyruvate dioxygenase (HPPD) inhibitors, and possibly to the PPOinhibiting herbicides are expected to reach the marketplace (Green et al. 2008). Further, transgenic crops with resistance to more than one herbicide MOA (i.e., stacked traits) have also been commercialized in recent times. Strategies for managing resistant weed populations in the context of these new technologies must be developed and adopted (Duke and Powles 2008; Owen 2008; Owen and Zelaya 2005).

Although glyphosate resistance in weeds currently has a large effect on U.S. agriculture, the discussion and recommendations in this document pertain to all current and future herbicide technologies. All herbicide technologies, if used repeatedly, are at risk of losing efficacy because of herbicide resistance in weed populations. Two recent examples are the identification of goosegrass [Eleusine indica (L.) Gaertn.] populations with resistance to glufosinate (Jalaludin et al. 2010; Seng et. al. 2010) and tall waterhemp [Amaranthus tuberculatus (Moq.) Sauer] populations with resistance to the HPPD-inhibiting herbicides (Hausman et al. 2011; McMullan and Green 2011); resistance had not previously been reported to either of these two herbicide MOAs.

Consequence of Overreliance on a Single Mechanism of Action. Although a number of factors determine the frequency of resistance events in weed populations, consideration of reported incidents strongly suggests that the single most important factor leading to the evolution of herbicide resistance is overreliance on a single herbicide (or group of herbicides with the same MOA) without using other weed management options (Heap 2011b). For example, GR rigid ryegrass (Lolium rigidum Gaudin) and Italian ryegrass [Lolium perenne L. ssp. multiflorum (Lam.) Husnot] populations were identified in orchards where glyphosate had been used continually for at least 14 consecutive yr (Perez-Jones et al. 2005; Powles et al. 1997; Simarmata et al. 2005). Glyphosate-resistant horseweed [Conyza canadensis (L.) Cronq.] and common ragweed (Ambrosia artemisiifolia L.) were confirmed after continuous applications of glyphosate on GR soybean for 3 and 6 yr, respectively (Pollard et al. 2004; VanGessel 2001). Likewise, glyphosate resistance in Palmer amaranth (Amaranthus palmeri S. Wats.) and common waterhemp (Amaranthus rudis Sauer) was discovered after only 4 and $6 \mathrm{yr}$ of consecutive glyphosate use (Culpeppper et al. 2006; Legleiter and Bradley 2008). This phenomenon is not unique to glyphosate. Prickly lettuce (Lactuca serriola L.), for example, evolved resistance after $5 \mathrm{yr}$ of consecutive application of chlorsulfuron (Mallory-Smith et al. 1990). Other evidence includes, but is not limited to, 2,4-D resistance in wild carrot (Switzer 1957; Whitehead and Switzer 1967), common groundsel resistance to atrazine (Ryan 1970), and barnyardgrass resistance to propanil (Carey et al. 1995).

Costs of Resistance. Because herbicides are the primary means of weed management in many economically developed countries, herbicide resistance causes greater short-term cost to manage a weed population, especially with the absence of new herbicide chemistries. Implicit in the measurement of the costs of HR weeds are crop yield loss, reduced commodity prices because of weed-seed contamination, reduced land values, costs of mechanical and cultural controls, and ultimately the additional expense of alternative herbicides or cropping systems or both for managing the resistant weed. Several recent studies have described the added costs associated with the management of HR weeds. In the United States, the occurrence of GR horseweed resulted in a net increase in production cost of $\$ 28.42 \mathrm{ha}^{-1}$ in soybean (Mueller et al. 2005). The additional cost of managing GR Palmer amaranth in Georgia and Arkansas cotton production systems was estimated at $\$ 48 \mathrm{ha}^{-1}$ (Vencill et al. 2011). In Missouri, Legleiter et al. (2009) reported similar net cost increases in controlling GR common waterhemp in soybean. Similarly in Arkansas rice, the additional cost involved in controlling propanil- and quinclorac-resistant barnyardgrass was estimated at $\$ 64 \mathrm{ha}^{-1}$ (Norsworthy et al. 2007a). 
Limitations to Implementation of Practices to Prevent Resistance. Although there is a significant cost to managing resistant weeds, growers are often hesitant to implement proactive measures to reduce the risk of resistance evolution in their fields. A key factor negatively influencing producer adoption of practices that will mitigate herbicide-resistance evolution is the expectation that there will be new herbicides available in the future (Foresman and Glasgow 2008; Llewellyn et al. 2002, 2007). With invasive plant populations, Finnoff et al. (2007) demonstrated quantitatively how managers who are cautious or financially risk averse are less likely to adopt preventive measures because prevention only reduces the risk, rather than eliminating it. This perception is perhaps true with growers weighing the value of prevention vs. control of HR weeds. For example, in a survey of more than 1,000 corn, cotton, and soybean growers in the United States, Frisvold et al. (2009) found that using multiple herbicides with different MOAs was one of the least-adopted practices for resistance management, despite this strategy being frequently advocated by weed scientists as an effective means to reduce the risk of herbicide-resistance evolution. A number of related factors may account for this. The overarching reason is that using diverse MOAs can increase current weed-control costs (Hurley et al. 2009), whereas the benefits of delaying resistance accrue in the future and are more uncertain. Some growers believe that mitigating weed resistance is beyond their control, depending more on their neighbor's behavior or natural factors (Llewellyn 2006; Wilson et al. 2008). Growers may also believe that industry will develop new chemistries, reducing the benefits of resistance management (Llewellyn et al. 2002, 2007). Finally, even when using diverse MOAs provides short-term returns comparable to current weed-management programs, growers will be less certain about the new, diversified programs.

Herbicide resistance-management strategies are typically implemented reactively when a resistant weed population has grown to problematic levels and must be controlled. Far less often are proactive management strategies implemented to mitigate the evolution of herbicide resistance. Introduction of new HR crop cultivars can provide options for managing weed populations resistant to other herbicide MOAs, but good resistance-management practices must be employed to avoid evolving resistance to the new herbicide as well.

Rationale for Best Management Practices (BMPs) and Recommendations. Herbicides constitute the key means of weed management and are the primary means for reducing soil tillage practices. Just as conservation of soil, water, and genetic diversity are fundamental for agricultural production, conservation of herbicide resources underlies the sustainability of contemporary agriculture. As such, herbicide molecules and MOAs (and other pesticides) are scarce resources upon which the public largely relies for food, feed, fiber, and energy security. Management practices that mitigate the evolution of resistance have been identified and will be invaluable in preserving these vital resources. Resistance management begins with good agronomic practices, including the implementation of integrated weed management (IWM) strategies that use diverse control tactics to reduce the frequency of herbicide applications and lessen the selection pressure they exert on weed populations. The BMPs we propose are discussed below in the context of the currently available literature documenting their effectiveness.

\section{Best Management Practices}

BMP 1: Understand the Biology of the Weeds Present. Integrating an understanding of weed biology into current weed-management systems, with emphasis on reducing the soil seedbank, is paramount for developing sustainable weedmanagement programs (Bhowmik 1997; Walsh and Powles 2007). By understanding weed emergence patterns, length of developmental stages, fecundity, dispersal mechanisms, and persistence of weed seed in the soil seedbank, practitioners can devise a strategy that targets the life stages most sensitive to management. Knowledge of weed biology in agricultural systems allows development of weed management programs that leverage weaknesses in the life cycle of the weed to alter the competitive relationship with the crop (Neve et al. 2003a,b). Agroecosystems typically contain diverse weed species, each with different life histories and different responses to control measures. Effective herbicide-resistance management combines a variety of chemical and nonchemical management tactics to diversify selection pressure on weed populations and minimize spread of resistance genes. Development of such strategies requires an understanding of the biology and ecology of weeds and the agroecosystems in which they occur (Mortensen et al. 2000).

In any growing season, the soil weed seedbank governs the size and species composition of the weed community (Forcella et al. 1993). In Iowa, efficacy of weed control in corn is inversely correlated with population size the previous year (Hartzler and Roth 1993). Hence, reducing current and future weed populations is not only a general goal of weed management, but also a key component in herbicideresistance management. The greater the number of plants exposed to a herbicide, the higher the probability of selection for resistance, enriching the gene pool with an increased frequency of previously rare resistance alleles (Gressel and Levy 2006).

Long-term herbicide-resistance management, therefore, requires more than weed control aimed only at minimizing crop loss in any one season. It is also essential to reduce the number of individual weeds exposed to herbicide selection, to prevent propagation by $\mathrm{HR}$ weeds, and to reduce the seedbank in future years. Knowledge of the following biological characteristics of weed species allows targeted management of life stages that affect population and seedbank size, as well as more-accurate assessment of the risk of resistance evolution.

Germination Requirements and Emergence Pattern. Delayed emergence or emergence over an extended period can allow later weed cohorts to escape control measures, especially when in-crop herbicide applications lack residual control (Neve et al. 2003a; Reddy and Norsworthy 2010). Late-emerging weeds may also be subjected to selection by progressively diminishing doses of soil-applied herbicides that dissipate slowly, or they can be exposed to sublethal doses of POST herbicides because of spray interception by the crop, reducing coverage of the targeted weeds (Zhang et al. 2000). Recurrent selection under reduced or sublethal herbicide doses over several generations has been shown to shift the weed populations toward higher tolerance levels (Manalil et al. 2011; Norsworthy 2012).

Understanding how environmental factors affect seed germination and emergence is vital to knowing at what time 
in the growing season weeds are most likely to emerge and the length of time that weed-control measures must be maintained to provide effective control. Seasonal changes in seed dormancy influence seed germination and ultimately emergence patterns under field conditions (Baskin and Baskin 1977, 1987; Honek et al. 1999; Omami et al. 1999). Many weeds have an annual cycle of dormancy, with the requirements for germination changing over time (BenechArnold et al. 1988; Gallagher and Cardina 1998a,b; Jha et al. 2010; Leon et al. 2007; Norsworthy and Oliveria 2007a,b). With an understanding of germination and emergence requirements, emergence in the field has been predicted for many weeds with great reliability (Forcella 1993; Forcella et al. 2000; Harvey and Forcella 1993; King and Oliver 1994; Masin et al. 2005; Norsworthy and Oliveira 2007c). Such knowledge can be used to determine the appropriate timing and selection of control measures to prevent the escape of resistant or potentially resistant weeds. For example, information on Palmer amaranth emergence pattern incorporated in a resistance-simulation model was vital in revealing the need for residual herbicides in achieving season-long weed control and preventing seed production in GR Palmer amaranth plants (Jha and Norsworthy 2009; Neve et al. 2011a).

The initiation of weed emergence can differ among years and locations; however, the emergence sequence among weed species is generally consistent (Cardina et al. 2007; Hartzler et al. 1999). The initiation of emergence is often predictable when temperature and moisture availability in the microsite are known. The base temperature requirement typically varies among weed species and ecotypes, leading to differences in the initiation of weed emergence in the field. For instance, Forcella et al. (1997) observed that the initiation of emergence of giant foxtail (Setaria faberi Herm.) across years and locations is closely linked to the time at which the soil temperature reaches $16 \mathrm{C}$ (i.e., base temperature) at a 5- to 10-cm depth.

Weed communities also differ in emergence periodicity, with some exhibiting continuous emergence throughout the growing season, requiring weed management tactics to be extended well beyond crop establishment (Hartzler et al. 1999). Late-emerging weeds cause less interference with the crop and experience lower reproductive success than early emerging cohorts; however, seed production from these lateseason escapees, even at low levels, must be considered when developing resistance-management strategies (Hartzler et al. 2004; Jha et al. 2008; Norsworthy et al. 2007b). For some weeds, such as Benghal dayflower (Commelina benghalensis L.), whose emergence typically occurs after cotton is planted and growing, manipulation of planting date could be effective. The benefits of planting cotton before the peak emergence of Benghal dayflower are twofold: (1) it reduces potential cotton yield loss by 50\% (Webster et al. 2009) and (2) it allows for cotton emergence before the use of metolachlor, leading to effective control of germinating Benghal dayflower seed while avoiding injury to cotton (Culpepper et al. 2004). As such, knowledge on weed-emergence requirements and emergence patterns is fundamental to devising management programs.

Reproductive Biology and Life Cycle. Life histories of a weed species influence the rate of both herbicide-resistance evolution and spread. Herbicide resistance evolves far more frequently in annual than in perennial weed species (Heap 2011a). This is at least partly due to the predominance of annual weeds in cropping systems with intensive herbicide application, especially in tilled systems where perennial weeds are less common. However, repeated herbicide application on a highly prolific, annual weed with short life cycle exposes a large number of individuals to selection for rare resistance alleles (Gressel and Levy 2006). In perennial weed species, fewer individuals are exposed to such selection within the same period, potentially slowing the rate of resistance evolution.

Breeding behavior (i.e., the degree of self-pollination vs. outcrossing) is another key factor affecting the evolution and spread of herbicide resistance. In self-pollinating populations, dominant or recessive resistance alleles are likely to equally increase in frequency under selection pressure (Jasieniuk et al. 1996). However, in outcrossing weed populations, the frequency of dominant resistance alleles will increase more rapidly than will recessive alleles exposed to herbicide selection pressure, especially highly dominant resistance alleles that confer a significant fitness advantage in heterozygotes (Gould 1995). Weed species with a high degree of outcrossing and genetic recombination are also at greater risk of evolving multigene herbicide resistance (Neve 2008; Neve and Powles 2005b).

Herbicide-resistance alleles can be transferred to susceptible weed populations via pollen movement (Busi et al. 2008) or exported from resistant populations in seed or other propagules (Dauer et al. 2007). Such transport also includes gene flow among overlapping generations of weeds with extended seed dormancy, potentially allowing resistance alleles selected for in one generational cohort to be transmitted to the next. An understanding of pollen and seed biology, factors affecting pollen or seed viability and longevity, and dispersal distances, including vectors, is, therefore, essential for managing gene flow that might lead to resistance acquisition or export by a weed population (Roux et al. 2008).

Stages within the life cycle of weeds most sensitive to management must be identified for the most resistant-prone or troublesome weeds within a field. In general, annual plants tend to have more weedy characteristics and are more likely to evolve resistance than are those having longer life spans (Heap 2011a; Sutherland 2004). For annual weeds, seed production and seedbank persistence is of more importance for population growth than it is for that of biennial or perennial weeds. As a result, seed rain by uncontrolled annual weeds has the greatest influence on population size. Selective spraytopping of weeds, i.e., preventing seed maturation, through application of herbicides at early stages of reproductive development has been effective at killing weed seed and minimizing viable seed return to the soil seedbank (Medd et al. 1992; Steadman et al. 2006; Walker and Oliver 2008), although the reproductive stage at which weeds are most sensitive to spray-topping differs by herbicide and species (Steadman et al. 2006).

Duration of Reproductive Development. Rapid completion of reproductive stages favors perpetuation through the soil seedbank. Initiation of different developmental stages within a growing season is linked to time of emergence, with the duration of reproductive development correlated to accumulated heat units or photoperiod or both. Delayed emergence typically hastens the onset of reproductive development (Norsworthy et al. 2010a; Shrestha and Swanton 2007). In 
addition, photoperiodic sensitivity also influences the transition to, and the duration of, reproductive development. Weeds that flower in response to short days may quickly produce seed before the first killing frost when emerging in late summer. Under these conditions, prevention of weed seed production by late-emerging weeds that can complete their life cycle in as few as 6 wk can be extremely challenging. For example, tall waterhemp needs less than $10 \mathrm{~d}$ to produce viable seed following pollination (Bell and Tranel 2010). Likewise, prickly sida (Sida spinosa L.) and Benghal dayflower are capable of producing viable seed within only 12 to $16 \mathrm{~d}$ after anthesis (Egley 1976) and $42 \mathrm{~d}$ after seedling emergence (Webster et al. 2005), respectively.

Although a shorter reproductive development ensures reproductive success and seedbank replenishment, an extended flowering period provides greater opportunity for the spread of resistance genes via pollen movement in outcrossing weed species. In situations in which a weed species and a related HR crop are cross-compatible, extended periods of flowering synchrony increases the risk of resistance-gene transfer via weed-crop hybridization. Such transfer of herbicide-resistance genes has been reported from canola to birdsrape mustard, wheat (Triticum aestivum L.) to jointed goatgrass (Aegilops cylindrica Host), ornamental bentgrass to weedy creeping bentgrass, and cultivated rice to weedy rice (Brown and Brown 1996; Mallory-Smith and Zapiola 2008; Seefeldt et al. 1998; Shivrain et al. 2009c).

Mode of Dispersal. Some weeds possess specialized adaptations that aid long-distance dispersal. For instance, horseweed and dandelion (Taraxacum officinale G.H. Weber ex Wiggers) seed are equipped with a pappus that allows for dispersal by wind. Horseweed seed regularly disperse $500 \mathrm{~m}$ from source populations and have been recovered from atmospheric currents at about $140 \mathrm{~m}$ above ground level (Shields et al. 2006). Barnyardgrass seed typically float in water and can be transported through irrigation water for up to several miles (Norsworthy, unpublished observations). The role of birds and herbivores on weed seed dispersal has also been well established (Vander Wall et al. 2005). This evidence challenges the idea that single-field management practices would limit introduction of HR weeds. For weeds lacking such long-distance dispersal mechanisms and those with limited pollen movement, single-field resistance-management practices can be effective. In addition, anthropogenic processes can lead to weed introduction, and efforts must be put forth to minimize the risks of introducing HR weeds, as discussed in later sections.

Persistence in Soil Seedbank. The length of time that seed or other propagules remain viable in the soil dictates how long control measures must be maintained to reduce the overall seedbank and any reservoir of resistant seed (Matthews 1994; Powles et al. 1992). Management requires knowledge of how factors, such as crop type, canopy formation, crop rotation, soil type, tillage, and irrigation, affect seedbank dynamics, including key processes, such as germination, herbivory, and decay (Gallandt 2006). Small-seeded grass and broadleaf weeds, especially those that lack physical dormancy, often exhibit shorter persistence in the soil seedbank compared with large, hard-seeded weeds. Out of 20 weed species buried for $5.5 \mathrm{yr}$, Egley and Chandler (1983) found that velvetleaf
(Abutilon theophrasti Medik.), purple moonflower (Ipomoea turbinata Lag.), spurred anoda [Anoda cristata (L.) Schlecht.], hemp sesbania [Sesbania herbacea (P. Mill.) McVaugh], and pitted morningglory (Ipomoea lacunosa L.), all large, hardseeded broadleaves, and johnsongrass [Sorghum halepense (L.) Pers], a large, hard-seeded grass, were more persistent than most small-seeded weeds.

Challenges. A continuing challenge in weed management is an incomplete understanding of the biology of weeds across the myriad of environments they occur. Grouping weed species into functional groups (e.g., small-seeded broadleaf weeds vs. large-seeded broadleaf weeds) allows for generalizations about each group to be evaluated. An example is the longer persistence of large-seeded broadleaf weeds in the soil seedbank as opposed to the relatively shorter persistence of small-seeded broadleaf weeds (Egley and Chandler 1983). The challenge to this is to determine the appropriate biological characteristics by which weeds can be grouped (e.g., germination requirements, flowering duration, breeding systems, mode of pollination, seed size, seed dispersal, and seedbank persistence), and then selecting representative species from each group to study. Additional research on the biology and ecology of a diverse group of problematic weeds is critical for the development of effective and economical weed management strategies. In the context of herbicide-resistance management, such knowledge is vital for parameterizing herbicide-resistance simulation models that aid in devising suitable resistance management strategies (Maxwell et al. 1990; Neve et al. 2011a). Evolution of HR weed populations has highlighted substantial gaps in our understanding of weed biology and ecology, especially factors that affect composition and persistence of the weed seedbank, the germination and emergence for different species, and the extent of gene flow via pollen and seed dispersal among weed populations. Improved knowledge of these areas will be critical for effective and proactive resistance management.

BMP 2: Use a Diversified Approach to Weed Management Focused on Reducing Weed Seed Production and the Number of Weed Seeds in the Soil Seedbank. Frequently HR weeds evolve in crop production systems where weed management strategies have not been diverse (Nichols et al. 2009; Talbert and Burgos 2007; Walsh and Powles 2007). One of the most recent weeds to affect a vast area of crops across the southern United States is GR Palmer amaranth (Nichols et al. 2009). Palmer amaranth is a genetically diverse, obligate, outcrossing weed, and the adoption of no-till or reduced-tillage production practices; minimal crop rotation, especially in cotton; and almost sole reliance on a single herbicide (i.e., glyphosate) has led to the rapid evolution of glyphosate resistance. Recent simulation modeling has shown that integration of diversified management tactics, with particular focus on reducing the soil seedbank, greatly reduces the risk of new GR Palmer amaranth populations evolving (Neve et al. 2011a,b).

For a production system to remain sustainable, the soil weed seedbank must be static or declining. An increasing seedbank is evidence of a weed that is escaping the current management regime through herbicide resistance or some other adaptation. Furthermore, the risk of resistance evolution is shown to be positively associated with the initial seedbank 
size (Neve et al. 2011a); therefore, keeping the soil seedbank at low levels reduces the risk of future evolution of herbicide resistance. Soil seedbank size varies considerably among fields, often because of the relative effectiveness of weed management practices. For example, overall weed seedbank densities across the Corn Belt varied from 600 to 162,000 viable seed $\mathrm{m}^{-2}$ (Forcella et al. 1992). In Arkansas, barnyardgrass seedbank size in cotton, soybean, and rice fields varied from 0 to 121,000 viable seed $\mathrm{m}^{-2}$, indicating the highly dynamic nature of soil seedbanks (Bagavathiannan et al. 2011b). Farming practices directly influence weed populations by affecting quantity of seed removed from and returned to the soil seedbank (Wilson 1988). The soil seedbank could be effectively reduced through preventing weed seed production and reducing the germinable fraction of weed seed in the soil through specific tillage techniques, such as stale seedbed, along with practices that encourage seed loss via herbivory.

The lasting consequences of allowing weed seed production have long been acknowledged, as stated in an old English proverb: "One year's seeding makes seven years' weeding." Nevertheless, the idea that a limited amount of weed seed production each year is acceptable is strongly embedded in weed management strategies based on annual economic thresholds. Problems with this approach, especially the longterm effects of subthreshold weed populations, have been repeatedly demonstrated, independent of the increased risk of herbicide-resistance evolution (Cardina and Norquay 1997; Hartzler 1996; Jones and Medd 2000; Norris 1999). For example, Cardina and Norquay (1997) observed a linear increase in the soil seedbank when the annual subthreshold densities of velvetleaf plants were allowed to escape control in corn. The risks of herbicide-resistance evolution have been shown to increase with every increase in initial seedbank size (Neve et al. 2011a). Although economic thresholds have typically been calculated only to achieve an effect on crop returns on an annual basis, the long-term effects of subthreshold, noncontrolled weed populations on the soil seedbank and resistance evolution requires management considerations that aim beyond a single growing season (Gallandt 2006).

A few studies have followed an ecological approach to understanding and establishing thresholds. Jones and Medd (2000) suggested a population-based approach to weed management decisions that views weeds as more than an annual production problem. In their "economic optimum threshold" approach, seed production and subsequent additions to the soil seedbank are evaluated along with future management implications and costs. Although economic optimum thresholds are lower than annual economic thresholds (Bauer and Mortensen 1992), this approach still fails to consider the effects of weed population dynamics, such as the initial frequency of resistant alleles in the soil seedbank before herbicide use and changes in the genotypes under selection on herbicide-resistance evolution. As such, economic optimum thresholds ignore future costs associated with herbicide-resistance management. Thresholds that fail to consider the evolution of HR weeds are unsound and have long-term economic and environmental consequences. The concept of what constitutes an acceptable level of weed seed production must be abandoned in favor of a zero or near-zero threshold if the current rate of herbicide-resistance evolution is to be slowed. An increasing number of weed scientists have emphasized the need for a near-zero threshold, especially for highly competitive, prolific seed-producing weeds (Cardina and Norquay 1997; Norris 1999; Sattin et al. 1992; Swanton et al. 1999). However, with the exception of work by a small number of researchers, such as Shrestha (2004), and modeling by Neve et al. (2011a), management of the soil seedbank to delay resistance evolution has not been a major consideration in planning or assessing long-term weed management programs, which is regrettable. Modeling and field evidence indicate the long-term value of preventing weed seed production to minimize weed selection to herbicides and reduce the risk of herbicide-resistance evolution and spread (Griffith et al. 2010; Neve et al. 2011a).

The rapid spread of GR Palmer amaranth in cotton illustrates the fallacy of permitting subthreshold weed populations to produce seed. Although a density of 0.13 Palmer amaranth plants $\mathrm{m}^{-2}$ will not cause yield loss in cotton (Keeley et al. 1987; Smith et al. 2000), those Palmer amaranth plants can produce in excess of 500,000 seed per female plant, with an annual seedbank addition of more than 16 million seed ha ${ }^{-1}$ at that subthreshold level of infestation. Within $3 \mathrm{yr}$ of a single GR Palmer amaranth plant escaping control in cotton, the crop field can be overwhelmed by resistance (Griffith et al. 2010). Hence, at its minimum, the goal of all weed management programs must be an aim to eliminate weed seed production from the most competitive, resistance-prone weeds in a field, including any weeds on the global list of resistance-prone weeds as identified by Heap (2011a).

Intensive use of herbicides alone may not be sufficient to prevent weed seed production and to maintain a low soil seedbank (Griffith et al. 2010; Hartzler 1996; Jones and Medd 2000; Schweizer and Zimdahl 1984). Proactively, some U.S. producers are hand-roguing fields as part of a zero seedproduction approach to address the increasing occurrence of GR weeds, mainly Palmer amaranth. The expenses these producers have incurred are far less than those who allowed a few plants to escape and are later confronted with sizeable soil seedbanks of resistant weeds that must be rogued multiple times each year to achieve a harvestable crop (Culpepper et al. 2010). Methods to minimize late-season weed-seed production, such as elevated crop seeding rate and crop-topping and removing weed seed from equipment during harvest, are widely practiced in areas of Australia with major HR weed problems (Walsh and Powles 2007). Although preventing weed seed production adds to short-term management costs, it is instrumental in mitigating the evolution of herbicide resistance. Considering the long-term costs associated with future resistance management, these short-term expenses are still economically viable.

Challenges. Eradication of weed seedbanks is a goal that growers have tried to attain and failed at throughout history. The largest challenge involves the practicality of preventing seed return over large areas of land that contain diverse soil seedbanks filled with dormant, and often long-lived, weed seed (Buhler et al. 1998). The prolific reproduction potential of weeds, with some species producing hundreds of thousands of seed per plant, makes it difficult to effectively eliminate seed return to the soil seedbank. Previous studies have demonstrated that the soil weed seedbank reserves can be reduced by $95 \%$ after 5 yr of weed-free management, but quickly revert to $90 \%$ of their original weed seedbank 
population after only a single year of no herbicide use (Burnside et al. 1986). A total prevention of seed return to the soil seedbank is an enormous challenge that will increase management costs and will often require the use of multiple tools (e.g., herbicides, mechanical control, cultural strategies, physical weeding, and plant residue burning, among others). Unavailability of the full spectrum of tools and a lack of knowledge on weed biology may limit the efforts to prevent weed seed production. For instance, late-season herbicide applications were shown to reduce seed production and seed viability of Palmer amaranth, sicklepod [Senna obtusifolia (L.) H.S. Irwin \& Barneby], prickly sida, pitted morningglory, barnyardgrass, and rigid ryegrass (Isaacs et al. 1989; Steadman et al. 2006; Taylor and Oliver 1997; Walker and Oliver 2008); however, current knowledge of the efficacy of this practice is limited to a small number of weed species, and additional research is needed before making suitable recommendations. In particular, knowledge of the earliest time in the growing season when viable seed are produced is vital for timing late-season applications. Some nonherbicidal approaches to weed-seed prevention create additional management problems. For example, weeds must be removed mechanically or physically before seed maturity, and rogued weeds should be buried in a deep pit or otherwise disposed of appropriately, not stacked along field margins because reinfestation can occur due to seed shatter during periods of rainfall (see BMP 10). Diversified weed management systems are, by nature, more complex, requiring a larger set of tools and skills than were required in herbicide-dominated systems. These systems will often constitute greater costs (real or perceived) and labor requirements, demand increased sophistication on the part of the practitioner, and require fieldspecific or cropping system-specific strategies based on weed species composition and risk of herbicide resistance.

BMP 3: Plant into Weed-Free Fields and Keep Fields as Weed Free as Possible. Herbicide-resistance management plans must commence before planting because control options become limited once the crop is planted and weeds begin to emerge. At crop planting time, crop fields should be free of weeds, achieved by a range of control tools. Crops planted into established weeds are risky because even herbicide mixtures with multiple MOAs may not provide effective control. Failure of preplant measures to control emerged weeds is devastating to crop yield and even more devastating if resistance evolves.

To keep crop fields as weed-free as possible, especially in conservation-tillage systems where preplant tillage is not feasible, residual herbicides can be used before or at planting (PRE). Additional applications of residual herbicides in slowgrowing or open-canopy crops, before the efficacy of the initial residual herbicide has dissipated, reduces selection pressure associated with sole reliance on POST herbicides (Neve et al. 2003b, 2011b). Crops differ in rates of growth; thus, some crops will require longer periods of residual control than will others for efficacious weed control. Once a dense crop canopy has formed, emergence of most weeds typically ceases because of changes in thermal amplitude and in the quality and quantity of light in the zone of seed germination (Egley 1999; Norsworthy 2004a). Throughout the remainder of the growing season, focus should be on removing any weeds that have escaped control measures or have emerged in safe sites after the final late-season herbicide application, including those that emerge after crop harvest, if seed production is possible before a killing frost (see BMPs 2 and 11).

Challenges. The nature of the production system can complicate weed control by limiting the number of tools available. For instance, tillage as a means of weed control is not a viable option in many dryland systems and may be prohibited by government-sponsored programs aimed at conserving soil resources. Similarly, burning fields may pose an environmental hazard limited by local regulations. Preplant, weed-smothering techniques, such as mulches or cover crops can be cost-effective for small areas of high-value production, but are not economically viable for large areas. Where herbicide options are available, there may be time restrictions on how soon the crop can be planted following application because of potential crop injury. Furthermore, environmental conditions, such as temperature, rainfall, and soil moisture, may influence the application or activation of residual herbicides. Finally, once the crop is planted, the number of weed management options becomes more limited.

BMP 4: Plant Weed-Free Crop Seed. Planting weed-free crop seed is the first step to preventing the introduction of new weeds into fields and also an important tactic in preventing the spread of herbicide resistance into new areas (Thill and Mallory-Smith 1997). Separating weed seed from crop seed can be costly and often challenging because of the similarity in size and shape of some weed and crop seed. For example, jointed goatgrass and wild oat (Avena fatua L.) seed are often difficult to separate from wheat seed, making them a common contaminant in wheat seed lots. Through an extensive seed lot survey in Utah, Dewey and Whitesides (1990) found that wild oat seed contaminated about $14 \%$ of seed samples collected, with an average of 21 seed $\mathrm{kg}^{-1}$ of wheat seed. Herbicide-resistant wild oat in southeastern Idaho is thought to have immigrated from an adjacent state via contaminated crop seed (Thill and Mallory-Smith 1997). A recent survey of grower-saved crop seed in Australia revealed that about $73 \%$ of samples were contaminated with weed seed, with an average of 62 weed seed $10 \mathrm{~kg}^{-1}$ of wheat, barley (Hordeum vulgare L.), or lupine (Lupinus spp.) seed (Michael et al. 2010). Among the weed seed recovered from these samples, rigid ryegrass had resistance to four different herbicides, whereas wild radish (Raphanus raphanistrum L.) and wild oat were each resistant to one herbicide (Michael et al. 2010). Herbicide-resistant rigid ryegrass seed were also found as a contaminant of Australian wheat exported to Japan, demonstrating the potential for international dispersal of resistance genes via weed seed contamination of grain shipments. In these shipments, about 4,500 resistant ryegrass seed were detected in a 20-kg wheat sample in 2006 and 2007, about 35 and $15 \%$ of which were resistant to diclofopmethyl, 5 and $6 \%$ were resistant to sethoxydim, and 56 and $60 \%$ were resistant to chlorsulfuron, respectively (Shimono et al. 2010).

Challenges. The grower practice of saving seed from one harvest to plant the following year could be a potential challenge to ensuring that weed-free seed is planted. Seed from some crops, including cotton, soybean, rice, and wheat, can be saved, but convincing farmers to purchase weed-free 
seed from companies rather than saving their own can be challenging. There are also challenges associated with cleaning grower-saved seed, especially if appropriate equipment is not available. As resistance becomes an increasing problem, our challenge is to educate producers about the importance of weed-free crop seed and to discourage use of saved seed that contains weed seed.

BMP 5: Scout Fields Routinely. Effective scouting (i.e., moving through fields systematically to evaluate weed populations) is a vital component of any successful weed management program, including one aimed at mitigating or managing HR weeds. Timely scouting and maintaining an inventory of weed species, location, density, and size allow for subsequent assessment of the effectiveness of prescribed practices. Numerous field-sampling schemes or strategies can be used when scouting, with the strategy chosen based upon how and when the data will be used (Clay and Johnson 2002; Gold et al. 1996). Regardless of the technique used, records should document the management tools used during previous seasons along with the effectiveness of each tool on some of the most problematic weeds present. These data will be instrumental in determining the efficacy of existing weed management programs and in monitoring whether weed species shifts are occurring. A single herbicide is rarely effective against all weeds present within a field. As a result, effective scouting allows for recognizing the most efficacious herbicide for the weed spectrum present and following it with additional treatment options.

Many chemical weed-management programs aimed at reducing the risk of herbicide resistance begin with a residual herbicide, which should be chosen based on the previous year's weed spectrum from recorded inventory. In particular, weeds present at harvest are a good indicator of species that are not effectively controlled season-long and that may need further attention in the following year's crop (Reddy and Norsworthy 2010). It is imperative that in-season scouting begin soon after crop planting to determine whether preplanting measures, such as tillage or residual herbicide application, have provided the anticipated level of weed control. Further action, such as additional residual herbicide application, can be taken before the first residual herbicide has dissipated. However, timely scouting is vital in making such decisions.

The effectiveness of most POST herbicides is a function of the application rate, application timing, and size of the weed at application; in most field crop settings, a large weed is one that exceeds $10 \mathrm{~cm}$ in height. To ensure proper timing of POST herbicides, fields should be scouted routinely for weed sizes and spectrum. Failure to scout and apply POST herbicides in a well-timed manner could reduce the efficacy and increase the risk of herbicide resistance (see BMP 7).

Scouting allows for early identification of a lack of herbicide efficacy, which may indicate the evolution of resistance. In such instances, samples should be collected and appropriate tests conducted to determine whether herbicide failure is a result of resistance. Indicators of possible herbicide resistance include (1) failure to control a weed species normally controlled by the herbicide at the dose applied, especially if control is achieved on adjacent weeds; (2) a spreading patch of noncontrolled plants of a particular weed species; and (3) surviving plants mixed with controlled individuals of the same species. If herbicide resistance is suspected, seed production from all noncontrolled plants of the species concerned should be interrupted to prevent the perpetuation of the resistance problem, even, in extreme cases, if that means destroying the crop in the process. Timely scouting is key to making appropriate management decisions.

Challenges. Although thorough scouting of fields provides growers with valuable information about the level and spectrum of weed populations in their fields, there are several limitations. Field scouting is a time-consuming process, and any delay in scouting or implementation of control measures, including herbicide applications, will be costly. The efficacy of many of the herbicides used against rapidly growing HR weeds (e.g., amaranth species) becomes more limited as growth stage advances. Most labels recommend that specific rates be used until a particular weed growth stage is reached; after which, control will probably be only partial. The cost associated with proper field scouting can also be an obstacle. Further, the lack of suitable expertise to properly identify small weed seedlings (i.e., cotyledon to one-leaf stage) poses a significant challenge. There exist resources that can assist scouts in identifying weed species (e.g., Bryson and DeFelice 2009, 2010; Stubbendieck et al. 1994; Uva et al. 1997; Whitson et al. 2009), but greater education concerning proper weed identification and the critical characteristics that separate similar species will be required to adequately train field scouts.

BMP 6: Use Multiple, Effective MOAs against the Most Troublesome Weeds and Those Prone to Herbicide Resistance. Herbicides are often the strongest selection agents for weed species present within a cropping system (Booth and Swanton 2002). Use of herbicides across vast areas containing large, genetically diverse weed populations causes intense selection pressure, often resulting in the evolution of resistance in weed communities; repeated application of effective herbicides with the same MOA is the single greatest risk factor for herbicide-resistance evolution (Beckie 2006; Powles et al. 1997). Targeting the most troublesome and resistanceprone weeds within a field by using different herbicide MOAs in annual rotations, tank mixtures, and sequential applications can delay the evolution of resistance by minimizing the selection pressure imposed on those weed populations by a particular herbicide MOA. In an annual herbicide rotation, crops in two or more subsequent cropping seasons receive different herbicide MOAs. Mixtures and sequential applications can be used as a resistance management technique by applying different herbicides to the same crop during the same growing season, simultaneously, in the case of a mixture, and at different times for a herbicide sequence.

The occurrence of resistant individuals in a weed population not previously exposed to the target herbicide is rare (Gressel and Levy 2006; Gressel and Segel 1990). However, the proportion of resistant individuals will rapidly increase with repeated use of the same herbicide MOA. For example, Beckie (2006) showed that significant levels of resistance to ALS-inhibitor herbicides can evolve in weed populations with as few as five applications.

Combining recommended rates of different herbicide MOAs, simultaneously, sequentially, or annually, greatly reduces the likelihoods of survival and reproduction of the resistant individuals. In most weed populations, individuals 
naturally resistant to more than one herbicide MOA will be rare. In most cases investigated to date, herbicide resistance is conferred by a single dominant or semidominant allele (Jasieniuk et al. 1996; Vila-Aiub et al. 2009). If different resistance alleles are at unlinked loci, the probability of an individual plant being resistant to multiple MOAs can be estimated as the product of the frequencies of resistance to each single MOA (Gressel and Segel 1990; Wrubel and Gressel 1994). This assumes that no single allele confers crossresistance to multiple herbicides by mechanisms such as general detoxification or sequestration.

Modeling studies predict that strategies involving herbicide rotations or mixtures will be most effective at preventing resistance evolution in species with limited pollen movement, where recombination of resistance alleles transferred via pollen is limited, and with limited seed dispersal (Beckie et al. 2001; Diggle et al. 2003). Single-gene, target-site resistance evolves more slowly in weed populations with continuing establishment of susceptible individuals from persistent seedbanks, keeping the frequency of resistance at low levels (Powles et al. 1997). However, sequential applications in such cases may expose more than one weed cohort to different selection pressures, contributing to the longer-term evolution of genotypes resistant to multiple herbicide MOAs.

Rotations, Sequential Applications, and Mixtures to Mitigate Resistance. For any herbicide combination strategy to be effective in mitigating resistance, the herbicides must have different MOAs because minimizing herbicide selection pressure on the weed population is the key to delaying resistance. Annual herbicide rotations are useful but not sufficient because they subject a weed population to a single MOA at a time, potentially allowing the progeny of resistant individuals to survive and acquire additional resistance via gene flow before the next herbicide application. Annual rotations and sequential applications may, therefore, select for multiple resistance over time, especially if the interval between applications is long enough to accommodate more than one weed generation or if gene flow is high. In contrast, herbicide mixtures apply multiple selection pressures simultaneously, theoretically allowing only the survival of very rare individuals that have already evolved resistance to these multiple herbicide MOAs via mutations at multiple loci or gene flow. Modeling work by Diggle et al. (2003) predicted that the rate of herbicide-resistance evolution will be slowed more with herbicide tank mixtures than with annual herbicide rotations. Likewise, Powles et al. (1997) showed that mixing two herbicides with different MOAs delays resistance longer than rotating between them. Similarly, Beckie and Reboud (2009) reported that mixing an ALS herbicide with a photosystem II (PSII) inhibitor or auxinic herbicide is more effective than annual herbicide rotation in delaying resistance to ALSinhibiting herbicides. Wrubel and Gressel (1994) noted that mixtures containing triazine and chloroacetamide herbicides were effective in preventing triazine resistance during a $20-y \mathrm{r}$ period in lambsquarters (Chenopodium L.) and amaranth weed species, whereas a triazine herbicide applied alone resulted in widespread resistance in these species. However, herbicide mixtures are effective at delaying resistance only when the mixture components target, and are effective on, the same weed species. For example, a mixture in which one MOA acts on grass weeds and the other on broadleaf weeds may provide good broad-spectrum control, but will not reduce the rate of resistance evolution in either of the weed groups (Wrubel and Gressel 1994).

For maximum benefit, herbicide mixtures must not only have different MOAs, but also have similar efficacy and persistence, allowing them to act simultaneously on the same weed cohort. Efficacy is also improved when the mixture components are degraded differently (Powles et al. 1997; Wrubel and Gressel 1994). Some herbicide mixtures have synergistic action, in which the activity of the combined herbicides is greater than the additive effect of each. For instance, Woodyard et al. (2009) reported synergistic activity between HPPD inhibitors and PSII inhibitors on common lambsquarters (Chenopodium album L.), giant ragweed (Ambrosia trifida L.), and common waterhemp in corn.

Contact and systemic herbicides are often not effective tank-mix partners because of the contact herbicide antagonizing the activity of the systemic herbicide. When both types of herbicides are needed as part of a resistance-management strategy, sequential applications will be superior to mixtures for reducing the risks of resistance. For example, an effective sequential HR management strategy developed in Australia through simulation modeling and later successfully implemented is the "double knock" tactic, in which an application of glyphosate is followed by paraquat up to $7 \mathrm{~d}$ later to control rigid ryegrass plants that survived the glyphosate application (Neve et al. 2003b; Walsh and Powles 2007).

Using Rotations and Mixtures After Resistance Has Evolved. Although the most desirable strategy is to proactively use annual herbicide rotations, sequential applications, or tank mixtures before resistance evolves, that requires growers to apply multiple herbicides even if weed densities are low (Powles et al. 1997). More commonly, growers prefer to use one herbicide that still provides good control on susceptible weeds while adding a second product to control resistant plants. Jacquemin et al. (2009) found that applying mixtures to weed populations after resistance has evolved could be effective if the resistance mechanism imposes a significant fitness penalty via negative cross-resistance (i.e., resistance to one herbicide makes individuals more susceptible to a second herbicide). However, that scenario is not common. More research is needed on the use of combined herbicide strategies on already-resistant weed populations, as well as on the potential for such strategies to select for cross resistance (Preston 2004).

Rotating Crops with Different or Multiple Herbicide-Resistance Traits. Rotation of HR crops without the diversity of herbicide MOA (e.g., GR cotton followed by GR soybean) will have no effect on reducing the evolution of $\mathrm{HR}$ weeds (Reddy and Norsworthy 2010). However, rotating different herbicide-resistance crop traits (in the same, or a different, crop) is one more way of increasing herbicide MOA diversity within cropping systems, such as rotating GR crops with glufosinate- or auxin-resistant crops. Based on modeling studies by Neve et al. (2011b), rotating GR cotton with glufosinate-resistant or non-HR cotton reduces the number of glyphosate applications required in a single year during the course of the rotation. As a result, the predicted risk of GR Palmer amaranth evolving in cotton would diminish by approximately $50 \%$ and resistance would be delayed by 2 to 
3 yr. This prediction was partially validated in the field where large plots of continuous GR cotton were found to have high densities of GR Palmer amaranth after 4 yr of continuous sole use of glyphosate, unlike a system in which GR cotton was annually rotated with glufosinate-resistant cotton (Johnson et al. 2011). Another option for producers is to grow crops with multiple herbicide-resistance traits (i.e., stacked traits), allowing them to use multiple, often broad-spectrum herbicide simultaneously. Cotton cultivars and corn hybrids have been developed to confer high levels of resistance to glyphosate and glufosinate, and several other crop varieties are in commercial development with various combinations of resistance to glyphosate, glufosinate, ALS inhibitors, dicamba, 2,4-D, and HPPD-inhibiting herbicides (Green 2009). This has the added advantage of allowing the development of products with MOA mixes for application convenience and cost effectiveness.

Challenges. A challenge to using multiple MOAs for weeds prone to evolving herbicide resistance is the need to readily identify the MOA for each herbicide used. This may be difficult for weed managers because many herbicide labels do not include the MOA designations. Additionally, use of multiple herbicides increases the complexity of the weed management system and requires some level of expertise for properly matching herbicides and MOAs with target species. Finally, it is not clear whether there are enough different herbicide MOAs available to responsibly target different weed species in various crops, in part because of the increasing number of HR weeds.

Another key challenge is the paradigm shift that will be required in weed management, a change in the farmers' point of view. Before the evolution of HR weeds, an established priority of IWM was to maximize herbicide use efficiency and minimize the number and frequency of herbicide application, a goal aimed at mitigating off-target movement and the effect on the environment. In the wake of HR weed evolution, an increase in the diversity of herbicide MOAs is a vital component of stewardship programs aimed at conserving existing herbicide MOAs while managing HR weeds. Despite its potential, this strategy may incur additional costs to growers, which is often an impediment to adoption. Using more herbicides, or more expensive herbicides with different MOAs, may be perceived to reduce profitability in the short-term. However, recent evidence indicates yield increases associated with a diversity of herbicide MOAs result in equivalent economic benefits, even in the year of application, making this BMP economically viable in the medium to long term (Weirich et al. 2011a,b).

BMP 7: Apply the Labeled Herbicide Rate at Recommended Weed Sizes. In the 1990s, reduced herbicide rates were seen as an environmentally sound practice and were a part of many integrated approaches to weed management in crops (Bhowmik 1997; Buhler et al. 1992; Mickelson and Renner 1997; Steckel et al. 1990). This fit well with the concept of weed economic thresholds (i.e., weed density at which cost of control equals the financial return on the recovered crop yield) to optimize crop yield with submaximum weed control (O'Donovan 1996; Zhang et al. 2000). Weed management programs often integrate herbicide application at below-label rates with other control measures, such as tillage and enhancement of crop competitiveness, to keep weed densities below economic threshold levels as defined by crop yield loss models (Blackshaw et al. 2006; O'Donovan et al. 2007). The underlying assumption is that, although herbicide manufacturers' labeled application rates are set sufficiently high to control a range of weed species across different growth stages and site conditions, economically acceptable weed control at a given location can often be achieved with reduced herbicide rates, especially if weed pressure is low and weeds are smaller than sizes listed on the label. However, as suggested by Gressel $(1995,2002)$ and later established through studies (Busi and Powles 2009; Manalil et al. 2011; Neve and Powles 2005a), recurrent exposure to low herbicide doses that allow a proportion of the weed population to survive may have unintended evolutionary consequences. For example, recent evidence indicates that applying herbicides at below the labeled rate was a major contributing factor to the evolution of diclofop-resistant rigid ryegrass in an Australian wheat field (Manalil et al. 2011).

A weed population under selection from repeated low doses of a herbicide risks accumulation of minor genes, which individually confer only a slight increase in fitness but, when combined in one individual, provide agronomically significant levels of herbicide resistance. Manipulation of this type of polygenic phenotypic response in populations showing continuous trait variation is a long-established foundation of crop breeding, but few investigators have explored multigene herbicide resistance in weeds. A dominant or semidominant allele at a single locus has been found to confer herbicide resistance in most weed species investigated to date. This may only reflect that simple, major gene systems are the easiest to identify experimentally, although rapid adaptation to extreme environmental events (such as exposure to high doses of herbicide) is theoretically most likely to involve single genes with large phenotypic effects (Lande 1983; Macnair 1991). Population response to constant, but less-intense, selection pressure is more likely to involve selection in many minor genes, each with a small, individual effect, which accumulates over multiple generations to produce adapted phenotypes (Orr and Coyne 1992). This type of polygenic evolutionary-resistance response to sublethal drug or pesticide doses is well documented in bacteria (Olofsson and Cars 2007), insects (Roush and MacKenzie 1987), and fungi (Shaw 2006); evidence is emerging for a similar response in weeds, as described below.

Within-population variation for herbicide resistance has been reported in some weeds (Jasieniuk et al. 1996; Patzoldt et al. 2002), including significant survival differences among individuals at low herbicide doses, although they are uniformly susceptible to the labeled rate (Neve and Powles 2005a). Such variation may be attributed to different alleles at minor loci contributing to polygenic resistance or to different allele combinations at modifier loci affecting expression of a major resistance gene (Neve and Powles 2005a; Uyenoyama 1986). Regardless of the molecular mechanism, repeated exposure of these weed populations to reduced herbicide doses risks incremental enrichment of the gene pool with minor resistance alleles, a phenomenon termed creeping resistance by Gressel (1995).

In some weed species, individuals surviving below-label herbicide rates can initiate a rapid population response. Experimental exposure of rigid ryegrass populations to sublethal glyphosate doses resulted in a population shift to resistance in three to four cycles of selection (Busi and Powles 2009). Using low doses of the acetyl coenzyme A carboxylase 
(ACCase)-inhibitor diclofop-methyl in an initially susceptible rigid ryegrass population and then bulk-crossing survivors, Neve and Powles (2005a) showed that recurrent selection generated field-level resistance in only three generations. Increased levels of cross resistance to other ACCase inhibitors and to ALS-inhibiting herbicides were also reported in the selected populations, suggesting that gene pool enrichment had occurred for multiple alleles controlling nontarget siteresistance mechanisms (Neve and Powles 2005b). Enhanced herbicide detoxification as a widespread cross-resistance mechanism, as proposed by Preston (2004), is one possible outcome of repeated selection for minor resistance alleles.

Knowledge of reproductive biology as well as patterns of herbicide use can help identify weed populations that are more likely to evolve polygenic resistance through recurrent selection by low-dose applications. The risk is theoretically higher in outcrossing species that repeatedly recombine genotypes across family lineages and in populations that already possess a diverse array of minor resistance alleles or the capacity to acquire them from an external source via gene flow (Holsinger 2000; Manalil et al. 2011; Neve 2008). As such, threshold-driven weed management strategies using low-dose herbicide applications increase the risk of polygenic resistance evolution (Busi and Powles 2009; Neve and Powles 2005a,b). However, even when used at the registered rate, any volatile or slowly dissipating herbicide that repeatedly exposes a given weed cohort to a reduced dose could pose a selection risk. For example, slow-degrading, soil-applied herbicides may deliver sublethal doses to later-emerging weeds and allow for the gradual accumulation of resistance alleles, if the same residual herbicide is applied over multiple growing seasons (Maxwell and Mortimer 1994; Zhang et al. 2000). Other situations where weeds may be subjected to below-labeled rates include spraying plants larger than those recommended on the label; inadequate coverage of weeds because of size, density, or crop cover; and low rates caused by imprecise sprayer calibration or inaccurate mixing.

Challenges. The use of full-labeled doses of herbicides requires a change in the approach to weed control. There are perceived and real risks to using herbicides (i.e., unwanted environmental side-effects, adverse effects on human and animal health), which led to a concerted effort to reduce herbicide use in agroecosystems (Mortensen et al. 2000). In the Netherlands, there has been research to support the use of reduced herbicide doses for weed control (Kempenaar and Lotz 2004; Ketel and Lotz 1998), contrary to the recommendation in this document. The ability to reduce weed management costs also has been a prominent factor in grower adoption of reducedrate herbicide applications. Although there is a perception that reduced rates provide short-term economic benefits to the growers, especially on lands that are leased, the costs of evolving herbicide resistance exceed monetary savings achieved through reduced herbicide doses.

Another important limitation to the use of full-labeled rates is the potential for phytotoxicity to the crop. Before application of a herbicide, labels will need to be evaluated to ensure that recommended rates are consistent with soils and growing conditions that are integrated into extension recommendations among the states in which the crop is grown. This is of particular concern when different MOAs are combined in a single application.
Additionally, there are potentially serious consequences to adopting a full-rate application policy in minor-use crops (i.e., vegetables and fruits) where crop tolerances to various herbicides will vary within a region, depending on cultural practices and the use of other pesticides. The risks associated with registration of herbicides in minor-use crops are problematic; in response to this, the Interregional Project 4 (IR-4) program was created to mitigate some of the cost associated with pesticide registration in minor-use crops. With the elimination of methyl bromide use for preplant pest control in vegetable crops, herbicides have become an important weed control tool in these systems. Requiring the use of full-labeled rates in minor-use crops may increase the risk-to-benefit ratio for many registrants to the point that herbicide labels may be cancelled in these crops. This could cause significant problems for weed management in these high-value, fresh-market crops.

Although not typically viewed as such, herbicide applications will be below-rate if weeds exceed the growth stage or size listed on the registration label for a particular herbicide rate. Herbicide application to appropriate weed sizes is critical but can be a challenge because of the limited availability of an available skilled labor force or unfavorable weather conditions. In addition, large farm sizes make it difficult to thoroughly scout fields and to make timely herbicide applications. Under these circumstances, it is likely that at least some weeds may exceed labeled sizes before herbicides can be applied.

\section{BMP 8: Emphasize Cultural Management Techniques that} Suppress Weeds by Using Crop Competitiveness. Cultural practices can be directed to exploit crop competitiveness, thereby reducing weed emergence and growth. Some of these practices include cultivar selection (Jordan 1993; Wax and Pendleton 1968), narrow row spacing (Norsworthy and Frederick 2005; Wax and Pendleton 1968), high seeding rates (Norsworthy and Oliver 2001, 2002; Walsh and Powles 2007), adjusting planting dates (Gill and Holmes 1997; Walsh and Powles 2007; Webster et al. 2009), irrigation management (Walker and Buchanan 1982), crop rotation (Johnson and Coble 1986; Schreiber 1992; Schweizer and Zimdahl 1984), and judicial application of fertilizers with appropriate placement. By hampering weed emergence and growth, each of these practices lessens weed fecundity (Norsworthy et al. 2007b), which is critical to reducing the soil seedbank and risks of herbicide resistance (Neve et al. 2011a). Most of these practices also result in increased crop yields (Howe and Oliver 1987; Norsworthy and Frederick 2005; Norsworthy and Oliver 2001).

Cultivar Selection. Crop genotypes differ in competitive ability, as measured by the ability to suppress weeds (Jordan 1993; Monks and Oliver 1988; Norsworthy and Shipe 2006; Rose et al. 1984; Wax and Pendleton 1968). Suppression of weed growth is desirable in that limiting seed production of those weeds that escape control would diminish future weed problems, including HR weeds. For soybean, early-season growth rate is an important characteristic for competitive genotypes (Rose et al. 1984). Additionally, plant height, tillering, leaf angle, and canopy formation are other common criterion for cultivar selection for improved weed suppression. Hybrid rice lines with greater tillering and taller growth characteristics are more competitive with weedy rice than 
nonhybrids (Shivrain et al. 2009a). Additionally, choosing an HR crop cultivar that does not flower at the same time as, or is less cross-compatible with, the weed relative will prevent transfer of the resistance trait to the weedy species (Shivrain et al. 2009b). Selection of a full-season cultivar to maximize the period with crop cover will suppress weed emergence for prolonged periods, whereas planting an early maturing cultivar may broaden the window of postharvest seed production of escaped weeds that potentially contribute to seedbank persistence and herbicide-resistance evolution (Reddy and Norsworthy 2010)(see BMP 11). In the southern Rice Belt, late-emerging or late-maturing weedy rice that escapes in-season weed control tactics will continue to grow after rice harvest and produce seed before the first killing frost (Shivrain et al. 2010). In an ALS-resistant rice system, these escapes may be first-generation crosses with the HR crop, given the highly outcrossing nature of weedy rice with cultivated rice (Shivrain et al. 2007).

Planting Date. In some areas and for certain crops, planting dates can be manipulated to take advantage of lengthy frostfree growing periods without sacrificing optimum yields. In such environments, altering planting dates (early or late planting) may place the crop at a competitive advantage over specific weeds. For instance, a delay in crop planting may shift peak weed emergence before crop establishment, allowing for effective control before crop emergence. Controlling an early emerging cohort means an ultimate reduction in the soil seedbank and number of in-crop weeds that must be controlled. One such example is the implementation of a 2wk delay in planting of wheat in some regions of Australia (Gill and Holmes 1997; Walsh and Powles 2007). Delayed planting allows for control of a large proportion of rigid ryegrass that emerges after the initial spring rains, using nonselective herbicides before crop establishment. A similar tactic is employed in the southern United States with a double cropping of June-planted soybean following winter-wheat harvest, rather than planting soybean in May as is the most widely used system. The double-cropping system has been successful at reducing the density of GR Palmer amaranth in soybean because the 1-mo delay in planting and the suppressive nature of the preceding wheat crop greatly reduces Palmer amaranth emergence (DeVore et al. 2011).

Altering planting date, if possible, can mitigate the movement of resistant traits from crop to weedy relative, from weed to weed, and from weedy relative to the crop by minimizing the flowering synchrony between cross-compatible species. This is the case with red rice, which can acquire resistance to ALS-inhibiting herbicides from ALS-resistant rice and further spread resistance among compatible populations (Shivrain et al. 2009a,c). This principle may be applicable to other HR crop systems where gene flow to weedy relatives is a potential source for the introduction of HR weeds.

Narrow Rows and Seeding Rates. For many annual weed species, emergence ceases or diminishes as a result of crop canopy closure (Jha and Norsworthy 2009; Norsworthy 2004a; Norsworthy and Oliveira 2007c). Narrowing crop-row widths or increasing seeding rates hastens canopy closure and increases crop competitiveness, eventually suppressing the emergence and seed production of late-season weeds and cohorts (Bagavathiannan et al. 2011a; Howe and Oliver 1987;
Mickelson and Renner 1997; Norsworthy et al. 2007b; Webster 2007; Yelverton and Coble 1991). Although high seeding rates increase input costs, this tactic has proven beneficial for the management of HR weeds. One example is suppression of HR rigid ryegrass in Australia, where higher seeding rates have been readily adopted by wheat producers to achieve more-rapid crop canopy closure and increased crop competitiveness with ryegrass, in turn reducing ryegrass growth and number of seed returned to the seedbank (Walsh and Powles 2007).

Crop Rotation. Choice of crops in a rotation partially dictates the intensity of tillage and choice of planting dates and herbicides. In some experiments, crop rotation was less influential than tillage on the soil seedbank (Bárberi and Lo Cascio 2001), whereas in others, rotation was a stronger determinant of the soil seedbank density (Cardina et al. 2002). Lack of crop rotation results in a weed community with less diversity and hence reduces herbicide options for controlling those weeds. Risks of resistance are generally greater in systems with limited crop rotation compared with those where crop rotation (including rotation of HR traits) is regularly practiced (Neve et al. 2011b). For example, model simulations have shown that rotating GR cotton with corn can reduce the risk of GR Palmer amaranth by almost twofold vs. growing GR cotton alone (Neve et al. 2011b).

Nutrient Management. From a weed management perspective, nutrient management can be an essential tool. Factors such as timing, amount, and placement of fertilizers can be tailored to maximize crop growth and minimize weed growth. Inappropriate fertilization can be favorably exploited by weeds, leading to greater weed growth and competition with crops. In rice production, weedy rice takes up about $60 \%$ of applied $\mathrm{N}$ (Burgos et al. 2006), giving it a competitive advantage over the crop, leading to greater seed production and increased risk of herbicide-resistance evolution.

Irrigation Management. Irrigation before crop planting can be used to induce weed germination and allow use of tillage or a broad-spectrum herbicide to control emerged weeds (i.e., stale seed bed), reducing the germinable fraction of the soil seedbank that will otherwise emerge in the crop. Flooding has long been used as an effective way of managing weeds in rice (Smith 1979). Flooding rice fields as early as possible will improve control of many weed species, and flooding of fields is recommended immediately after a preflood herbicide application because the emergence of many weeds ceases after flooding (Baldwin and Slaton 2001). Furthermore, water-seeded rice culture, in which fields are flooded and pregerminated rice seed are spread over the field, is a technique that has been used for weed management, especially for control of red rice in conventional rice (Baldwin and Slaton 2001).

Challenges. Altering row width may require expensive equipment modifications. Increased seeding rates increase production costs and would be adopted only if producers see economic benefit. The ability of a grower to alter planting dates depends on the crop, the size of the farming operation, other crops produced, availability of labor, length of cropping season, and whether harvesting has to be scheduled. For 
agronomic crops planted on a large number of hectares, planting dates could be restricted by the scheduling of harvest if commercial harvesting is hired. Alteration of planting dates will likely be implemented only if there is a perceived weed control benefit and a lack of observable yield loss associated with this practice. The implementation of crop rotations may be challenged by crop price, crop preference of the landowner on leased farms, management costs, available land, appropriate soil, and availability of equipment among other challenges.

Integration of these cultural practices into current weed management programs does not guarantee an improvement in weed control or reduced weed fecundity. For instance, Norsworthy and Oliver (2002) often found poorer weed control in irrigated, than in dryland, soybean as a result of more rapid early season weed growth when soil moisture was not limited. However, dryland culture is often weedier because of reduced herbicide activation and reduced crop growth, which results in slow crop canopy coverage and allows weeds to thrive in between rows. In irrigated fields, control is reduced if herbicide application or mechanical practices are not timely, causing higher weed seed production. Ultimately, irrigation increases crop competitiveness, but the challenge is integrating irrigation with a timely, effective weed-control program. Furthermore, weeds respond differently to cultural management. For example, terrestrial weeds can be controlled by flooding, but some weeds are adapted and survive seasonal flooding.

BMP 9: Use Mechanical and Biological Management Practices Where Appropriate. Tillage. Tillage practices vary by cropping system and region, and even from grower to grower, with timing, intensity, and method of tillage influencing the size and composition of the weed seedbank (Bárberi and Lo Cascio 2001). Tillage practices must be regularly changed, in a manner similar to that of other production practices, to prevent buildup of any particular species or group of weeds in the soil seedbank. Perennial weeds and shallow-emerging annual grasses and small-seeded broadleaves are prominent in reduced-tillage systems (Buhler et al. 1994; Mt. Pleasant et al. 1990; Schreiber 1992), whereas annual large-seeded broadleaves are more prominent as tillage intensity increases (Bararpour and Oliver 1998).

The vertical distribution of weed seed in the soil profile and the rate of seedbank decline are influenced by tillage practices (Ball 1992; Bárbari and Lo Cascio 2001; Buhler et al. 1996, 1997; Cardina et al. 1991; Schreiber 1992). As soil disturbance decreases, there is generally an increase in the size and diversity of the soil seedbank (Cardina et al. 1991, 2002; Feldman et al. 1997). Warnes and Andersen (1984) studied the annual population of wild mustard (Sinapis arvensis L.) over a 7-yr period and reported that the final population size was reduced to $3 \%$ of its original size with mechanical cultivation three times each year but was reduced only by half in grass sod or chemical fallow. However, species shifts are affected less by tillage than by herbicides because herbicides are a stronger constraint than tillage on the assembly of communities (Booth and Swanton 2002; Derksen et al. 1998). When combined with proper timing of herbicide application, tillage or cultivation can effectively control perennial weeds such as bermudagrass [Cynodon dactylon (L.) Pers.](Etheredge et al. 2009), johnsongrass (Bruff et al. 1996), and redvine [Brunnichia ovata (Walt.) Shinners](Castello et al. 1998).
Tillage can be an effective means of weed control through burial of small weeds, disrupting roots leading to plant desiccation, and cutting or severely damaging broadleaf weeds below the apical region, leading to plant mortality. Historically, crops have been planted in rows mainly to allow for interrow cultivation as a means of weed management. Recent modeling efforts have shown the value of interrow cultivation in reducing the risks of herbicide-resistance evolution in row crops (Norsworthy et al. 2011a). For example, the risk of barnyardgrass evolving resistance to glyphosate in cotton was $68 \%$ over a $30-y r$ period when a continuous glyphosate system with no interrow cultivation was used; however, the risk was reduced to $38 \%$ over the same period when integrating a single midseason interrow cultivation into the existing system (Norsworthy et al. 2011a).

Tillage can also be used to reduce the soil seedbank by stimulating weed seed germination. In the absence of weed seed production, tillage results in more-rapid loss of weed seed from the soil seedbank compared with a no-till system (Bhowmik and Bekech 1993; Bridges and Walker 1985; Buhler 1995). With repeated tillage and no seed input, seed loss is initially rapid and continues over time, at a rather decreased rate (Gallandt 2006). In Australia, an early shallow cultivation, referred to as early tickle, before planting is used to increase weed emergence (Pannell et al. 2004). This strategy requires a delay in planting and any weed control benefit must be weighed against crop yield reduction. For example in wheat, the yield penalty was $5 \%$ for a 10 -d delay and $10 \%$ for a 20-d delay in planting. Using germination as a method of seed loss, however, requires that germinating weeds are effectively controlled (Gallandt 2006).

Deep-tillage implements that invert soil layers, such as a moldboard plow, bury weed seed deep enough to prevent successful germination and emergence (Bennett 2011). For instance, in a double-crop winter-wheat/soybean system that integrated a one-time use of a moldboard plow, the emergence of GR Palmer amaranth was reduced by at least $95 \%$ over two growing seasons (DeVore et al. 2011).

Cover Crops and Synthetic Mulches. Establishing a physical barrier or mulch (living or nonliving) between crop rows to reduce light availability and suppress weed growth is an effective weed management tool that has attracted increasing research attention, especially for organic production systems and for high-value crops grown on small areas (Bangarwa et al. 2011; Norsworthy et al. 2007c; Patterson 1998). In addition to their weed control benefits, compostable mulch materials, such as straw, hay, and stubbles, enhance soil nutrient status and organic matter content, provide nitrogen benefits if a leguminous cover cop is used, reduce loss of unused soil nitrogen from the crop root zone, improve soil structure and texture, and control soil erosion (Salmerón et al. 2010). Alternative compostable mulches that can be incorporated into the soil include wetted and rolled shredded paper, an expensive but good weed-control option that is effective for up to $2 \mathrm{yr}$ (Pellett and Heleba 1995), and cornstarch-based biodegradable film (Waterer 2010).

Black polyethylene sheet mulch is effective for high-value crops, especially against tough-to-control weeds, such as yellow nutsedge (Cyperus esculentus L.), reducing their shoot biomass by $72 \%$ (Webster $2005 \mathrm{a}$ ), but it may need to be combined with additional barrier layers for effective suppression of much more 
aggressive weeds (Daugovish and Mochizuki 2010). Translucent plastic sheets are less effective at suppressing weed growth than black polyethylene sheets (Chase et al. 1998). However, when used for soil solarization to raise soil temperature, clear plastic mulch has been shown to induce $97 \%$ mortality in kudzu [Pueraria montana var. lobata (Willd.) Maesen \& S.M. Almeida] crowns over two seasons in South Carolina (Newton et al. 2008). It has also been used to eradicate the seedbank of weedy golden wreath wattle [Acacia saligna (Labill.) Wendl. f.] in trials in Australia by inducing germination and then exposing the seedlings to lethal soil temperatures (Cohen et al. 2008). Polyethylene mulches have also been successfully integrated with herbicides for weed control in bell pepper (Capsicum annuum L.) and other high-value vegetable crops (Bangarwa et al. 2011; Culpepper et al. 2009; Grey et al. 2007, 2009).

For field crops, the use of synthetic mulches over a larger production area is impractical and not cost effective. However, cover crops can be effectively integrated into weed management programs. A cover crop can be interplanted or undersown within a cash crop (i.e., living mulch) or sown as a relay or double crop immediately after harvest and then terminated before the next cash crop is planted. The cover crop residue is then incorporated into the soil or left on the surface as a mulch. In addition to soil improvement and erosion prevention, cover crops suppress weeds for a substantial period into the cropping season, delaying the need for an early season herbicide application (Bergkvist et al. 2010; Kruidhof et al. 2009; Norsworthy et al. 2010b, 2011b; Teasdale et al. 1991; Yenish et al. 1996). In addition to competing with, or physically suppressing weeds, some cover crop species provide weed control through allelopathy (Ateh and Doll 1996; Hartwig and Ammon 2002; Putnam et al. 1983).

Allelopathy, the ability of a plant to influence growth of other plants through biochemicals (i.e., allelochemicals), has been noted in several cover crop species, including cereal rye (Secale cereale L.), oat (Avena sativa L.), sorghum [Sorghum bicolor (L.) Moench ssp. bicolor], wheat, common sunflower (Helianthus annuus L.), several legumes, and in several Brassicaceae species (Caamal-Maldonado et al. 2001; Leather 1987; Norsworthy 2004b; Norsworthy et al. 2010b, 2011b; Putnam and DeFrank 1983; Steinsiek et al. 1982). However, cover crops should be chosen carefully because some cover crops may have negative allelopathic effects on the main crop. For instance, cotton yields were reduced by turnip (Brassica rapa L. ssp. rapa) cover crop (Norsworthy et al. 2011b), and corn yields were reduced by oat (Norsworthy 2004b) and rye (Johnson et al. 1993) mulch. The level of allelopathic activity is also dependent on a number of factors, including location, environmental conditions, biomass, and management practices (Schomberg et al. 2006), again, suggesting the need to make a good cover crop choice for a particular set of conditions. In addition, some living mulches may adequately compete with the main crop for resources.

Mowing. Mowing is another mechanical option that can be used before seed set to prevent weed seed production (Pannell et al. 2004). Mowing is more effective on annual broadleaf weeds than it is on grasses and perennial broadleaf species because mowing effectively prevents propagation in annual broadleaf weeds by removing the growing point (Meiss et al. 2008); by contrast, many low-growing grasses escape mowing and will produce seed. Timing of mowing is critical. For example, mowing spotted knapweed (Centaurea stoebe L.) at early bolting or budding stages results in new seedhead production, whereas mowing at flowering greatly reduces subsequent seed set (Story et al. 2010).

Grazing. Grazing as a means of weed control is feasible in pasture systems. The effectiveness of grazing for weed control depends on pasture type, duration of grazing, preferences by grazing animals, and numbers of grazing animals (grazing intensity)(Lacey and Sheley 1996; Olson and Wallander 1998; Pannell et al. 2004). Sheep grazing has been shown to reduce the number of ryegrass plants setting seed by 60 to $80 \%$ or 90 to $95 \%$ after $3 \mathrm{yr}$ of standard or intense grazing, respectively (Pannell et al. 2004). An unintended result of grazing, however, is the likely changes in plant community composition because of preferential grazing by animals. For example, leafy spurge (Euphorbia esula L.) was grazed by sheep but not by cattle (Lacey and Sheley 1996). In general, cattle grazing can shift the plant community to weedy broadleaf species, whereas intensive grazing by sheep or goats can shift the community toward grass species (Lacey and Sheley 1996).

Challenges. Conservation-tillage practices that were established to prevent soil erosion and promote water conservation will restrict the incorporation of tillage for weed management. Use of mechanical methods of weed control will be limited by the availability of equipment and skilled labor and by the expense of implementing these practices. In addition, many U.S. Department of Agriculture (USDA) programs specifically discourage and, in some instances, prohibit, tillage operations on lands vulnerable to soil erosion. Other programs provide financial incentives for conservation tillage, creating an economic disincentive for incorporating tillage as a tool for resistance management. Once growers have adopted conservation tillage programs, they may no longer have a need for retaining tillage equipment.

Although synthetic mulches are effective in high-value crops, using that system is very expensive. The mulch could be reused for multiple crops, but some aggressive weeds deteriorate the integrity of the mulch and limit the number of seasons that it can be used (Webster 2005b). Further, removal and disposal of synthetic mulches are also expensive. For biological mulches, the mulch material itself may be a source of weed seed (see BMP 10)(Menalled et al. 2004).

Incorporating cover crops and living mulches into a weed management program can reduce selection for herbicide resistance, although herbicides may still be used for cover-crop burndown or to suppress a living mulch and reduce competition with the main crop (Hartwig and Ammon 2002). Repeated glyphosate treatment of horseweed, a winter annual weed present in many fields in the spring when cover crops are burned down, is thought to have led to the evolution of GR horseweed (Koger and Reddy 2005; Main et al. 2004). Cover crops can be used to inhibit early season weeds, but producers must be aware that herbicides used in the desiccation of the crop should be included in any herbicideresistance management plan.

Although the soil conservation benefits of cover crops are undeniable, there is often no direct cash return in the form of a marketable product to offset costs associated with establishment and termination. One exception is when winter wheat is planted before soybean, a routine practice in the southern United States. Additionally, determining the 
appropriate time for cover-crop termination is complex (Price et al. 2009) because it requires balancing the ease of killing the cover crop, amount of biomass produced, and amount of soil moisture that is being consumed by the cover crop. The optimum balance will be regional- and often farm-specific and will vary from year to year, depending on soil type, cover crop growth, and availability of supplemental irrigation. Thus, the greatest challenge to the use of any mulch or cover crop is the added complexity associated with integration into existing cropping systems.

Repeated use of mowing may lead to a shift in the weed spectrum, often to one comprising more grasses and lowgrowing broadleaf weeds. Furthermore, mowing all weed species present within a rangeland or pasture before seed set can be quite challenging, and mowing is not feasible for most agronomic or horticultural crops.

Grazing can be an effective way of managing weeds; however, mature seed of some weed species can pass through the digestive tract of grazing animals without losing viability and be redistributed (Lacey et al. 1992). In addition, because of the increasing specialization in farming operations, the number of farmers integrating field crops with animal production has declined, limiting the adoption of grazing between cash crops.

\section{BMP 10: Prevent Field-to-field and Within-Field Move-} ment of Weed Seed or Vegetative Propagules. The potential for field-to-field and farm-to-farm movement of weed propagules, resulting in introduction of new weed species or HR weeds into noninfested areas must be recognized. Preventative weed management incorporates practices that avoid introduction, infestation, or dispersion of weed species into areas currently free of those weeds. Natural seed dispersal in the absence of a specialized dispersal mechanism or agent is generally limited to less than $5 \mathrm{~m}$ from the mother plant (Verkaar et al. 1983), and often, human activities are an important means of weed seed dispersal (Burton et al. 2006; Gonzalez-Andujar et al. 2001). Hence, preventing the immigration of propagules or pollen movement from adjacent infested areas and preventing propagule dispersal from infested areas to noninfested areas should be an important consideration to all weed management programs.

Most weed populations exhibit an aggregated or patchy distribution (Wiles et al. 1992), attaining spatial stability over time (Beckie et al. 2005; Marshall and Brain 1999; Rew and Cussans 1997; Rew et al. 1996; Wilson and Brain 1991). The degree of spatial stability is more pronounced in perennial species and in large-seeded weeds, such as wild common sunflower and velvetleaf, which exhibit shattering and localized seed dispersal before crop harvest (Burton et al. 2005; Colbach et al. 2000; Dieleman and Mortensen 1999). Although short-distance, localized dispersal of any weed is still undesirable, the opportunities for long-distance dispersal events, followed by rapid colonization, even if less frequent, are of particular concern for herbicide-resistance management. In an effective herbicide-based weed management system, patches of low-density weed populations that do not form a persistent seedbank can be driven toward extinction (Humston et al. 2005). The key to successful eradication of an HR weed population is early recognition of resistance, when the infestation is still minor and manageable, with low seedbank density. However, when a few resistant plants survive within a field, their occurrence is often overlooked until the population builds up to a level that herbicide failure is recognizable; by which point, seed and pollen carrying resistance alleles may have dispersed great distances, exacerbating the problem from a single incidence for an individual producer to one that affects an entire county, state, or region.

Crop Residues, Manures, and Plant By-Products. Crop residues and by-products, including composts, organic mulches, straw, hay, harvest cleanings, or grass clippings, are sometimes used as amendments, mainly in vegetable crops or home gardens, to improve soil fertility or reduce weed emergence through physical suppression. Introduction of new weed species into fields that previously were free of certain weed species is possible with introduction of these weed seed-containing materials. One source of weed seed is livestock food pellets processed with crop residues (Cash et al. 1998). A crop byproduct that can carry viable weed seed is gin trash, a waste material from the cotton-ginning process, whereby the cotton fiber is separated from both the seed and other plant material adhering to the lint during harvest. Weed seed from plants remaining at cotton harvest are common components of gin trash (Norsworthy et al. 2009). In a survey of ginning facilities in the southern United States, raw gin trash was found to be routinely applied to crop fields as a disposal method, and it is likely that the gin trash contains seed from HR weeds present in cotton fields at harvest (Norsworthy et al. 2009). Additionally, gin trash is sometimes fed to livestock. A recent introduction and successful establishment of GR Palmer amaranth in Michigan is believed to have resulted from gin trash or hay purchased in the southern United States and then fed to cattle (C. Sprague, personal communication). Because the effects of composting gin trash are often variable, viable weed seed can survive composting (Gordon et al. 2001; Norsworthy et al. 2009). Therefore, caution should be used when applying these amendments.

Application of animal manure and open grazing are also important sources for the introduction of additional weeds to the soil seedbank, including weed seed with herbicide resistance (Blackshaw and Rode 1991; Mt. Pleasant and Schlather 1994; Wiese et al. 1998), because some weed seed can pass through the digestive tract of ruminants without losing viability. For example, about $52 \%$ of redroot pigweed (Amaranthus retroflexus L.) seed remained viable after digestion in the rumen of dairy cattle (Blackshaw and Rode 1991). Additionally, intraregional and interregional transport of animals that have consumed weed seed-contaminated feed or ingested weed seed through grazing may contribute to the movement of weed seed into new areas. For instance, it has been suspected that cross-state transportation of cattle has greatly contributed to the spread of tropical soda apple (Solanum viarum Dunal), a federally listed noxious weed capable of remaining viable in the rumen of cattle (Byrd et al. 2004). Weed seed dispersal by wildlife, such as deer, birds, and rodents, is also possible (Goddard et al. 2009; Traveset et al. 2001).

Manure spreading allows for movement of weed seed that lack specialized dispersal mechanisms (Thill and MallorySmith 1997). Menalled et al. (2005) reported an addition of up to 169 weed seed $\mathrm{m}^{-2}$ in the soil seedbank when composted swine manure was applied. Eberlein et al. (1992) found triazine-resistant Powell amaranth (Amaranthus powellii 
S. Wats.) in seven fields treated with manure from feedlots, whereas no resistance was observed in fields on the same farm that did not receive the manure, suggesting the possible source of contamination. Introduction of HR weed seed through manure could rapidly lead to future management problems for growers. As such, manure should be used cautiously considering the potential for long-distance dispersal of new weed species or HR weeds.

Challenges. Preventative weed management can be complex and challenging. As a result, farmers are often unwilling to adopt costly preventative practices, especially if the land is rented or leased (see section on General Challenges to Adoption of BMPs). In some cases, the cost of actions preventing the movement of weed seed and propagules in crop residues and by-products (e.g., straw, stubble) is prohibitive. As farms grow larger and machinery is moved greater distances, the importance of proper sanitation to limit the movement of weed seed, especially HR weed seed, is essential (Buhler et al. 1998). Effective sanitation of equipment between fields demands substantial amounts of time and labor, often affecting farm operations during critical times, such as during planting, tillage, and harvesting. It can also be difficult to confirm the effectiveness and quantify the cost-benefit ratio; only after a weed establishes will the presence of weed propagules in the machinery be apparent. In addition, some potential mechanisms for weed seed movement among fields are largely out of the growers' control, such as dispersal by wildlife (Goddard et al. 2009), wind (Dauer et al. 2009; Shields et al. 2006), and water (Kelley and Bruns 1975; Wilson 1980). In a survey of Ohio farmers, most of the respondents attributed the introduction of new weed seed to their farm to natural elements, including wind (97\%), wildlife (87\%), and birds (80\%)(Wilson et al. 2008).

\section{BMP 11: Manage Weed Seed at Harvest and Postharvest} to Prevent a Buildup of the Weed Seedbank. At Harvest. Unshed weed seed that are present at crop harvest are often retained in the harvested grain or expelled from the harvester along with the debris (i.e., straw, chaff, weed seed, among others)(Shirtliffe and Entz 2005; Walsh et al. 2012). Research in Australian wheat fields has demonstrated the value of collecting and destroying weed seed at harvest as a herbicideresistance management tactic (Walsh et al. 2012). However, the fraction of seed entering the harvester differs considerably by weed species, depending on maturity characteristics and on time of crop harvest relative to weed seed maturity. McCanny and Cavers (1988) found that only $45 \%$ of wild oat seed shatter before crop harvest, whereas about 30 to $45 \%$ are expelled from the harvester and about 11 to $25 \%$ are retained with the harvested grain. The fraction of seed expelled from the harvester along with the debris could be collected and destroyed, substantially reducing weed seed additions to the soil seedbank. Shirtliffe and Entz (2005) found that the chaff fraction of the debris contained about $74 \%$ of the wild oat seed that were expelled from the harvester, and for ryegrass, it was up to $95 \%$ (Walsh and Parker 2002), suggesting that the chaff needs greater attention.

Collecting and destroying weed seed at harvest is one of the most promising strategies to reduce the perpetuation of the soil seedbank (Maxwell and Ghersa 1992; Walsh et al. 2012; Westerman et al. 2006;). Maxwell and Ghersa (1992) suggested that a combine attachment acting as a weed seed "predator" would significantly reduce weed seed dispersal and limit new introductions. Since then, a number of tactics have been evaluated in wheat for destroying weed seed at harvest, the first being the collection of chaff using a cart attached to the rear of the harvester, which achieved up to $85 \%$ removal of rigid ryegrass from fields (Walsh and Powles 2007; Walsh et al. 2012). Another tactic involves the use of baling equipment attached to the rear of the harvester, allowing weed seed-containing straw and chaff to be baled directly as they exit the harvester (Walsh and Powles 2007; Walsh et al. 2012). The bales can later be fed to confined livestock. In Australia, equipment recently developed to destroy weed seed is the Harrington Seed Destructor, which uses a cage-mill device comprising bars spinning in opposite directions to grind weed seed-containing chaff as it exits the harvester (Walsh et al. 2012). Because up to 95\% of ryegrass seed that enter a harvester exit in the chaff fraction (Walsh and Parker 2002), this equipment has been highly effective in reducing the amount of HR ryegrass that reenters the soil seedbank. Similarly, in Oklahoma, hammer and roller mills were tested and proven effective in destroying the seed of cheat (Bromus secalinus L.) (Gossen et al. 1998).

After Harvest. After crop harvest, producers often allow weeds to grow uncontrolled. Such lapses in weed management can lead to increases in the soil seedbank if sufficient time elapses between harvest and a weed-killing frost, even if a high level of weed control was achieved during crop production. Postharvest weed-seed production must be prevented to effectively manage soil seedbanks for the long term (see BMP 2). In some weeds, such as common waterhemp, viable seed production can occur as early as $7 \mathrm{~d}$ after pollination (Bell and Tranel 2010), meaning that these weeds are capable of producing seed after crop harvest, especially in southern climates.

Burning of stubble or chaff that contains weed seed is a postharvest tactic that has been used effectively in Australia to reduce weed seed return to the soil seedbank (Walsh et al. 2012). Disengaging the chaff spreaders in harvesters allows expelled debris to be windrowed, reducing in-field dissemination of weed seed (Maxwell and Ghersa 1992) and, most importantly, concentrating weed seed in a narrow band of chaff that can be burned later. Harvesters in Australia have been fitted with chutes that direct the chaff into bands much narrower than those produced solely by disengaging the straw spreader (Walsh and Newman 2007). The narrow bands of chaff burn at much hotter temperatures over longer periods, resulting in greater weed seed mortality. For instance, up to $99 \%$ of annual ryegrass seed were killed by narrow, windrow burning, whereas burning of standing stubble was found to kill only $80 \%$ of the seed (Walsh and Newman 2007).

Encouraging postdispersal weed-seed herbivory and microbial decay is another important tactic for reducing seedbank replenishment. Understanding the effect of production practices on herbivory and microbial decay of weed seed is necessary to make informed management decisions that promote reductions in the soil seedbank. Degrees of herbivory may differ among weed species and may also be influenced by postharvest field management, such as tillage, residue cover, etc. Annual weed seed losses due to herbivory can exceed $80 \%$ (Harrison et al. 2003; Kremer and Spencer 1989). Although tillage does not always deleteriously affect seed herbivory 
(Cardina et al. 1996; Cromar et al. 1999), soil disturbance that buries weed seed can limit herbivory by surface-dwelling organisms (Hulme 1994). The amount and duration of vegetative cover can also affect herbivory rates (Chauhan et al. 2010), with systems having some degree of residue cover generally being more attractive to seed herbivores than are fully exposed fields (Povey et al. 1993; Reader 1991).

Factors that influence seed decay include tillage intensity, depth of burial, and interactions with seed herbivores (Kremer 1984). For example, greater numbers of foxtail species occurred near the soil surface in a no-till system, whereas the number of buried seed was greatest in a plowed system (Pitty et al. 1987). Additionally, microbial action on seed can interact with herbivory, especially when insect feeding leads to increased fungal infection of weed seed (Kremer and Spencer 1989).

Challenges. One challenge of targeting harvest and afterharvest seedbank replenishment is the need to know the growth and reproductive biology, including the duration of vegetative and reproductive stages, time of weed maturity, and initiation of seed shattering, of multiple weeds (Norris 2007). Such knowledge is currently lacking for many arable weed species in different crops and geographical regions. Although collection of weed seed at harvest is relatively easier, concentration of weed seed in windrows presents engineering challenges that have not been studied in U.S. cropping systems. In Australia, chaff carts or baling were not widely adopted for weed seed removal because of reduced harvest efficiency; machinery breakdowns; management costs of having to remove the residue, usually by burning; and increased capital costs (Walsh and Newman 2007). However, new engineering efforts have overcome several of these limitations (Walsh et al. 2012).

Adoption of stubble burning for weed seed removal may be limited by factors such as local or regional environmental regulations, the need for crop stubble to increase soil organic matter, and the potential reduction in herbicide efficiency by creating a carbon layer that can readily bind and limit herbicide activity (Banks and Robinson 1982; Potter et al. 2008). Postdispersal weed-seed herbivory is a potentially important, but often overlooked, component of preventing seed additions to the soil seedbank (Harrison et al. 2003; Jacob et al. 2006; Seaman and Marino 2003). Evaluation of factors that enhance seed herbivory is still a critical research need (Cromar et al. 1999; Gallandt 2006; Menalled et al. 2001). Likewise, a thorough ecological understanding of how production practices can be used to encourage microbial decay of soil seedbanks (Chee-Sanford et al. 2006), and the influence of management practices on the combined effects of herbivory and microbial decay has been limited. Research on enhancing herbivory and microbial decay as a weed management tool is still in the descriptive stage and yet to be extended to growers.

BMP 12: Prevent an Influx of Weeds into the Field by Managing Field Borders. Weeds in unmanaged habitats, including field margins, roadsides, ditchbanks, railroads, and riparian zones can serve as a corridor for the introduction and movement of new weed species (Boutin and Jobin 1998), including HR weeds. The density, diversity, and fecundity of wild and weedy plant populations are generally greatest along field edges and decrease with increasing distance into crop fields (Marshall 1989; Wilson and Aebischer 1995). Although research emphasis on field borders as a source of weed seed introduction is limited in the United States, there has been a wealth of research in this area in European countries, mainly as an opportunity for preserving farmland biodiversity (Kiss et al. 1997; Marshall 1989; Noordijk et al. 2011; Wilson and Aebischer 1995). In the context of herbicide-resistance management, allowing resistance-prone weeds to produce seed in field borders may exacerbate the risk of resistance.

Most crop producers in the United States place emphasis on maximizing crop yields by management for weed removal within fields but often neglect to manage field borders, from which some of the most invasive and noxious weeds can find ingress via seed dispersal or through gradual movement of vegetative propagules, especially in the absence of tillage. Allowing weed seed production in field borders can have longterm effects on the seedbank of crop production fields, especially when outcrossing occurs with resistant populations near a field, allowing spread of resistance through pollen and seed movement. Simulation models have shown that weeds with high dispersal potential located in or near field borders have greater potential to deleteriously affect crop yields across a field compared with more-competitive weeds that have a low potential for dispersal (Maxwell and Ghersa 1992). Several of the tactics discussed previously can be used to minimize weed entry from field borders, roadsides, and ditchbanks (see BMPs 1 and 2).

Sowing field borders to a less-weedy, preferred species that can be managed later is another tactic for reducing immigration of agriculturally important weeds from field edges. However, Noordijk et al. (2011) concluded that regular haying as a field-edge management tactic is more effective in preventing weed seed immigration than sowing wildflower mixtures along field margins. Planting and maintaining a dense grass cover in field borders may prevent the establishment of arable weed communities through shading and regular mowing. In many parts of the United States, roadsides and ditchbanks are managed by county and state entities through mowing, haying, and herbicide applications.

In the southern United States, where GR Palmer amaranth is a serious problem on many farms, weeds in ditchbanks and along roadsides cause serious concern because of potential seed entrance into adjacent crop fields (Bennett 2011). Glyphosate was traditionally used to manage field margins, but because of the widespread occurrence of resistant Palmer amaranth, other means, such as mowing, followed by repeat applications of paraquat or complete disking have been followed to prevent seed production in these populations.

Challenges. The willingness of producers to manage field borders is often limited by time constraints and added management costs for which there is no direct economic return. Additionally, the management programs used to control weeds in the adjacent habitats can hasten the selection pressure for herbicide resistance, if few herbicides are continually used. For instance, use of an ALS-inhibiting herbicide for grass weed control on roadsides (Goatley et al. 1998) increases selection pressure for the evolution of ALSresistant weeds that may coexist in managed rights-of-way and production fields in the vicinity. Although farmers diversify their approaches to weed management in field edges, they have limited knowledge of, or control over, such practices in 
ditchbanks and rights-of-way, railroads, power lines, and other similar habitats, which are usually managed by government entities or third parties. Coordination of control efforts with other owners, local or state governments, and third parties is difficult to achieve.

A detrimental effect of managing field borders can be a reduction in farmland biodiversity (Noordijk et al. 2011). Field borders could greatly contribute to the preservation of biological diversity, particularly as sanctuaries for beneficial insects and rare plants and as food sources for birds and other organisms (Wilson and Aebischer 1995). It appears that the goals of herbicide-resistance management to encourage prevention of weed seed production in field borders may be incompatible. As such, management decisions will be discretionary, depending on the specific goals of the grower.

\section{General Challenges to Adoption of BMPs}

Patterns of Land Ownership. The long-term economic benefits of BMPs are certain; however, many growers, out of necessity, focus on immediate economic benefits. Nationwide, approximately $38 \%$ of U.S. farmland is operated by tenants, and in parts of the Midwest and Mississippi Delta regions of the United States, more than $50 \%$ of the farms are tenant operated (USDA-NASS 2007), creating an enormous challenge for promoting BMPs with a long-term view. Farmers usually approach weed management on these rented farms differently than they do on land they own and plan to farm for many years (Soule et al. 2000). Growers on rented land often focus their attention on the economic returns of the current crop and are much less concerned with the long-term effects of management decisions on land they may not farm the following year. Also confounding the issue of rented land are restrictions imposed by the landlord on the tenant concerning crop rotations or, more specifically, concerning a particular crop to be grown annually without rotation. Educational programs that target landowners could be beneficial in altering that behavior; however, there may be economic issues involving vertical integration and investment of infrastructure of the farming operation that facilitates those management decisions. For instance, a land owner who operates a cotton-ginning facility will often rent only to tenants who will grow cotton to supply the raw materials for that business. Regardless of the motivation behind this practice, weed management strategies available to the tenant because of these stipulations can be significantly hampered in a monoculture system.

\section{Grower Perceptions of Future Technology and Effective-} ness of Current Practices. There are at least two additional factors that may hinder the adoption of practices that contribute to herbicide stewardship: (1) the expectation that the release of a new technology to solve the HR weed problems is imminent, and (2) the belief that resistancemanagement strategies will be futile (Webster and Sosnoskie 2010). In Australia, a survey revealed that growers who believed new herbicide chemistries would be available soon were less likely to adopt strategies designed to delay the occurrence of HR weeds, compared with those who were uncertain about those alternatives (Llewellyn et al. 2007). The basis for this belief is rooted in recent history (Webster and Sosnoskie 2010). For instance, triazine-resistant weeds were effectively managed with ALS-inhibitor herbicides following their release. Once weeds subsequently evolved resistance to ALS-inhibitors and ACCase inhibitors, GR crop technologies allowed growers to effectively manage those $\mathrm{HR}$ species, and many farmers believe that this trend will continue.

Although it is a common perception that new herbicides or herbicide technologies will be developed to combat HR weeds, there has not, unfortunately, been a new herbicide MOA introduced commercially since 1998. In fact, the dominance of glyphosate and GR crops resulted in less investment in research and development from agrichemical companies (Duke 2011). A significant decline in herbicidediscovery research occurred during the period from 1995 through 2010 (Gerwick 2010).

The assessment that herbicide-resistance management strategies will be unsuccessful is based on the belief that herbicide resistance in weeds occurs randomly and cannot be contained. Not only can resistance traits be moved through seed dispersal by natural elements (e.g., water, wind, and fauna) and agricultural equipment, but they can also be transferred through pollen movement (Busi et al. 2008; Hidayat et al. 2006; Murray et al. 2002; Sosnoskie et al. 2009). Transfer of herbicide-resistance genes among weed populations through pollen or seed movement has significant implications for resistance prevention and management. In a survey conducted in Australia, about $70 \%$ of the growers suspected that their neighbors were the ultimate source of HR weeds currently on their farms, through either the movement of seed or the movement of pollen (Llewellyn and Allen 2006). Given the potential for the movement of herbicideresistance traits among weedy populations, many growers reject the assumption that investment in resistance management programs will delay the occurrence of herbicide resistance on their farm (Llewellyn and Allen 2006).

Hardin (1968) first proposed the concept of the "tragedy of the commons," whereby a commonly held resource is depleted by those who exploit it for individual gain, even though the ultimate loss of the resource is collectively disadvantageous. This idea has been expanded and applied to agricultural settings by others (Gould 1995; Webster and Sosnoskie 2010). Hardin provides the example of a shared resource, such as a body of water, spoiled by individuals or businesses who found discharging wastes into that water was more economical for them than the costly treatment of the waste. Likewise, indiscriminate herbicide use leading to the rapid evolution of herbicide resistance in weeds may result in the loss of herbicide options for all growers, especially if resistance spreads rapidly across a region. Spoiling of the common resource of pesticide susceptibility by some growers can make others reluctant to spend time and money to implement management programs that deter the evolution of pesticide resistance (Gould 1995). Additionally, it is expected that the adoption of BMPs for resistance management will be slow because of the steep learning curve associated with proficient use of new and often complex technologies and because of the challenge of clearly demonstrating the benefit of practices involving short-term costs for longer-term prevention. The key challenge is to develop and implement a sustained education and awareness campaign to overcome the various deterrents to adoption of resistance-management practices and to establish or strengthen local networks of farmers willing to work in concert. 
Table 1. National trends in weed management for soybean, cotton, and corn. ${ }^{\text {a,b }}$

\begin{tabular}{|c|c|c|c|c|c|c|c|c|c|c|c|c|c|c|c|}
\hline \multirow[b]{2}{*}{ Practice } & \multicolumn{5}{|c|}{ Soybean } & \multicolumn{5}{|c|}{ Cotton } & \multicolumn{5}{|c|}{ Corn } \\
\hline & 1996 & 1998 & 2000 & 2002 & 2006 & 1997 & 1999 & 2000 & 2003 & 2007 & 1996 & 1998 & 2000 & 2001 & 2005 \\
\hline & & & & & & $\%$ & & & 1 & & & & & & \\
\hline GM HR seed & $7(13)$ & $44(4)$ & $59(4)$ & $81(6)$ & $97(5)$ & NA & $40(6)$ & $58(10)$ & $67(3)$ & $90(2)$ & $\mathrm{NA}^{\mathrm{d}}$ & $11(12)$ & $11(7)$ & $9(45)$ & $31(6)$ \\
\hline Field scouted for weeds & $79(1)$ & $85(1)$ & $85(2)$ & $82(12)$ & $91(1)$ & $71(3)$ & $80(3)$ & $82(3)$ & $85(2)$ & $92(1)$ & $81(2)$ & $85(1)$ & $83(2)$ & $50(19)$ & $89(1)$ \\
\hline Burndown herbicide used & $33(8)$ & $27(11)$ & $27(9)$ & $27(96)$ & $31(3)$ & $6(27)$ & $10(15)$ & $23(14)$ & $56(16)$ & $41(6)$ & $9(8)$ & $9(15)$ & $12(14)$ & $15(21)$ & $18(10)$ \\
\hline PRE weed control & $67(3)$ & $58(5)$ & $46(4)$ & $16(24)$ & $28(4)$ & $90(2)$ & $89(2)$ & $79(1)$ & $71(3)$ & $73(2)$ & $78(2)$ & $78(2)$ & $71(4)$ & $54(27)$ & $61(4)$ \\
\hline POST weed control & $78(2)$ & $79(2)$ & $87(2)$ & $91(4)$ & $95(1)$ & $62(5)$ & $70(3)$ & $76(3)$ & $79(3)$ & $89(2)$ & $59(5)$ & $62(2)$ & $63(2)$ & $58(6)$ & $66(3)$ \\
\hline Cultivated for weed control & $29(4)$ & $26(8)$ & $17(10)$ & $13(25)$ & $\mathrm{NA}^{\mathrm{d}}$ & $89(2)$ & $77(2)$ & $63(8)$ & $54(5)$ & $38(6)$ & $33(16)$ & $42(5)$ & $38(6)$ & $37(21)$ & $15(8)$ \\
\hline
\end{tabular}

a Abbreviations: RSE, relative standard error; GM, genetically modified; HR, herbicide resistant; USDA, U.S. Department of Agriculture.

b Source: Agricultural Resource Management Survey, USDA; http://www.ers.usda.gov/Data/BiotechCrops and http://www.ers.usda.gov/Data/ARMS/app/default. aspx? survey= CROP\#startForm.

${ }^{c}$ The RSE is the standard error of the estimate expressed as a percentage of the estimate; the larger the RSE, the less precise the estimate.

${ }^{\mathrm{d}}$ Estimate does not comply with the USDA-Economic Research Service disclosure limitation practices, is not available, or is not applicable.

\section{Current Levels of Adoption of BMPs}

Given the growing number of confirmed HR weeds in crop production systems and the BMPs that can be used to delay the evolution of resistance, it is important to assess the extent to which growers are adopting BMPs. Unfortunately, there is no single national database available that addresses this question directly. It is possible to infer levels of grower adoption of some BMPs from published sources, but, for many BMPs, no accessible data exist. Although the BMPs described above apply to managing resistance regardless of the herbicide in question, most of the available information on grower implementation of resistance management practices focuses on glyphosate because of the magnitude of its use in row-crop agriculture and the consequent concern about the growing problem of weed resistance to glyphosate. However, these data still provide insights into the current state of adoption of BMPs for herbicide-resistance mitigation and management by growers in the United States.

The USDA Agricultural Resource Management Survey (ARMS) provides data on trends in adoption of HR seed varieties and weed control practices for cotton, corn, and soybean in the United States. The most recent survey years for which results are available for those crops are 2005, 2006, and 2007. Data recorded for each crop include whether (1) HR varieties were planted, (2) fields were scouted for weeds, (3) a burndown herbicide was used, (4) PRE herbicides were used, (5) POST herbicides were used, and (6) tillage was employed for weed control. Collectively, this information provides some insight into the adoption of BMPs for herbicide-resistance management, especially in HR crops, and the extent of diversification implemented in weed management programs. However, some caveats apply when interpreting these data, as indicated by the following examples.

The USDA-ARMS data indicate that field scouting was carried out for weeds on $89 \%$ of the corn hectares planted in $2005,91 \%$ of the soybean hectares planted in 2006, and $92 \%$ of the cotton hectares planted in 2007 (Table 1). Although these appear to be high levels of scouting in all three crops, it should not be assumed they represent a widespread adoption of BMP 5. First, details on whether the scouting was carried out before, after, or both before and after herbicide applications were not recorded. As noted previously, field scouting has little utility in detecting emerging resistance problems unless it is carried out following the herbicide use. Second, the high levels of scouting may simply reflect a move from preventive weed management to a curative approach, one that greatly depends on POST herbicide treatments. An increase in POST herbicide use promoted by a parallel increase in the adoption of HR cultivars is shown for soybean and cotton in Table 1. That trend in adoption of HR cultivars was less apparent for corn (Table 1), where HR cultivars constituted only $31 \%$ of total corn hectares in 2005, much lower than it was for soybean or cotton (97 and 90\%, respectively) in that year. USDA-ARMS data are only available up to 2005 , but HR seed in corn is now estimated at 70\% for 2010 (USDA 2011).

Use of a burndown herbicide indicates that producers are attempting to plant into a weed-free field, although burndown treatments are employed in the Mississippi Delta preceding spring tillage as well (BMP 3). This practice is used extensively in reduced tillage systems where the burndown herbicide replaces preplant tillage to control existing weeds. Burndown herbicides were used on $31 \%$ of the soybean hectares planted in $2006,41 \%$ of the cotton hectares planted in 2007 , and $18 \%$ of the corn hectares planted in 2005 (Table 1). Concurrent with the expansion of conservation tillage in cotton, use of burndown treatments increased dramatically, expanding from 6 to $41 \%$, reflecting the adoption of transgenic $\mathrm{HR}$ varieties and reduced tillage systems in this crop. There was little change in the use of burndown herbicides in soybean and corn over the reported period. Unfortunately, burndown herbicide use is not an effective component of resistance management if the same herbicide is used for both burndown and later POST applications, which is likely to be the case in GR crops because glyphosate has been the preferred choice for both of these applications. In GR crops, growers typically make more than one application of glyphosate and, in some areas, make more than three applications (Norsworthy 2003; Norsworthy et al. 2007d; Wilson et al. 2011). Repeated use of the same herbicide in the same season is not consistent with weed management diversification (BMP 2) or the use of multiple herbicide MOAs (BMP 6).

Cultivation for weed control adds diversity to a herbicidebased weed management system (BMP 2). Cultivation was practiced on $38 \%$ of U.S. cotton hectares in 2007 and on $15 \%$ of the corn hectares in 2005 (Table 1). The last reliable estimate of cultivation for weed control in soybean was 13\% in 2002. Weed management through cultivation has steadily decreased with the adoption of transgenic HR varieties of soybean, cotton, and corn and is now less than half the levels reported in the late 1990s. This reduction reflects the efficacy of current herbicide-based weed control systems and the increased adoption of reduced-tillage systems that this efficacy has allowed. 
Table 2. Regional trends in weed management for soybean and cotton. ${ }^{a-c}$

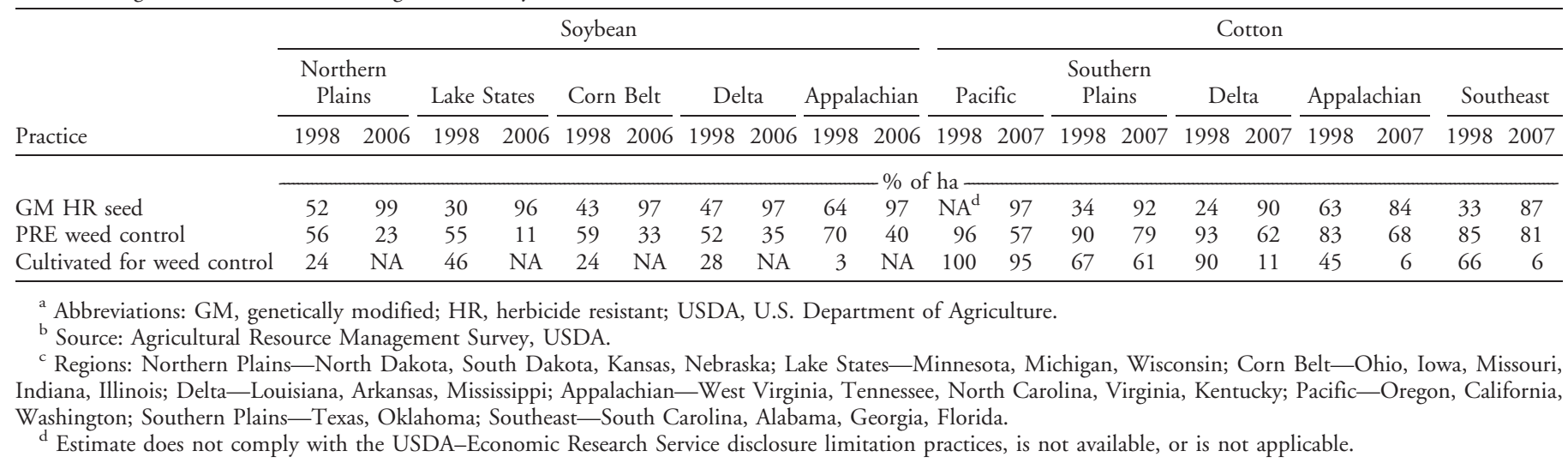

The data from Table 1 indicate that a combination of all five weed management practices (scouting, burndown, PRE and POST herbicide applications, and tillage) were used on less than $10 \%$ of the hectares in any of these crops. Weed control on an estimated $25 \%$ of the soybean hectares in $2006,25 \%$ of the cotton hectares in 2007, and 8\% of the corn hectares in 2005 combined scouting, PRE herbicide use, and cultivation. Use of PRE and POST herbicides on the same land occurred on approximately $28 \%$ of the soybean, $65 \%$ of the cotton, and $40 \%$ of the corn hectares at the last reporting period for each crop. Based on those estimates, it appears that most of the U.S. hectares planted to those three crops were not under a diversified weed management program (BMP 2) that integrates multiple herbicide MOAs (BMP 6). Both of those BMPs are foundations for herbicide-resistance management.

A closer examination of weed management trends in major soybean- and cotton-producing regions (Table 2) shows a dramatic decrease in the use of PRE herbicides and cultivation with the post-1996 advent of GR crops. For example, in the Lake States in 1998, 55\% of the soybean hectares were treated with a PRE herbicide and 46\% were cultivated. By 2006, the hectares had dropped to 11 and $0 \%$ (acreage too low to estimate accurately), respectively; however, there has been a recent upward trend in the use of PRE herbicides in areas were GR weeds are prominent. In 1998, 93\% of cotton hectares in the U.S. Delta region were treated with a PRE herbicide and $90 \%$ were cultivated to control weeds. These dropped to 62 and $11 \%$, respectively, by 2007 . The adoption of HR seed in soybean and cotton was accompanied by widespread discontinuation of cultivation and PRE herbicide use and a shift to predominantly POST herbicide-based weed management programs. Such programs initially provided high levels of control, and their efficacy-including the decreased need for cultivation-allowed the adoption of conservation tillage in areas where weed problems had previously prevented its use. However, that shift has greatly reduced the diversity of weed management practices. As previously noted, the current (2010) estimate of HR seed use in corn $(70 \%$ of national hectares) is equal to that of cotton and $70 \%$ of that in soybean (USDA 2011). As described below, recent grower surveys show that weed management practices in HR corn are becoming less diverse, mirroring the trend already seen in soybean and cotton. A variety of practices are still being used in the Pacific and Southern Plains regions, and the occurrence of herbicide resistance appears lower in those regions.

An alternative approach to assessing the diversity of weed management programs is to examine the range of herbicides being used in a crop. Table 3 lists the major herbicide families and their MOAs used in 1996 and 2006 in soybean, in 1996 and 2007 in cotton, and in 1996 and 2005 in corn. For all three crops, there was a reduction in MOA diversity between the earlier and later dates. In soybean and cotton, there was a dramatic shift to dominance of glyphosate over that period, whereas the use of several other herbicide families with different MOAs effectively ceased. Glyphosate (WSSA group 9) was used on $19 \%$ of the treated corn acres in 2005 , less than soybean or cotton. Between 1996 and 2005, the use of several other herbicide families on corn, notably the amides, benzoics, and sulfonylureas, declined sharply, whereas the use of triazine herbicides increased from 38 to $48 \%$ of the herbicide-treated corn acres. Overall, with the exception of triazine use in corn, there has been a marked trend toward reduced diversity of herbicide MOAs being used in soybean, corn, and cotton. That contravenes BMP 6 and greatly increases the selection pressure for resistance.

Surveys of grower practices provide another vehicle for examining levels of adoption of BMPs for herbicide-resistance management. Shaw et al. (2009) and Givens et al. (2009) described the results of a 2005 survey of 1,050 producers from Illinois, Indiana, Iowa, Mississippi, Nebraska, and North Carolina. Survey participants were selected from a list of corn, soybean, and cotton growers who had signed agreements to use Roundup Ready (Monsanto Company, St. Louis, MO 63167) technology incorporating transgenic GR crop varieties into their cropping systems. When producers were questioned about changes in herbicide use on their farms, it was found that nonglyphosate-based weed management programs were being replaced in corn or had already been replaced in soybean and cotton by glyphosate as the foundational, if not the only, herbicide used to manage weeds. Furthermore, in a single season, glyphosate was applied three times by between 30 and $40 \%$ of the GR cotton growers and two or additional times by 66 to $74 \%$ of the GR soybean producers (Givens et al. 2009). Follow-up surveys in 2006 and 2007 found that GR cotton growers were using glyphosate on fewer hectares (13\%), whereas $83 \%$ of GR cotton land was treated with residual herbicides either PRE or POST. In contrast, weed management was dependent on glyphosate alone on $62 \%$ of the hectares in a GR corn-GR soybean rotation, 55\% of the hectares in continuous GR soybean, and $49 \%$ of the hectares in continuous GR corn (Shaw et al. 2011; Wilson et al. 2011). Together, these data indicate failure to follow either BMP 2 or BMP 6 in those crops by a substantial proportion of growers. 
Table 3. Herbicides, by herbicide family, applied to soybean, cotton, and corn by percentage of total treated area. ${ }^{a}$

\begin{tabular}{|c|c|c|c|c|c|c|c|}
\hline \multirow[b]{2}{*}{ Herbicide family } & \multirow{2}{*}{$\begin{array}{c}\text { Herbicide group } \\
\text { based on mechanism } \\
\text { of action }\end{array}$} & \multicolumn{2}{|c|}{ Soybean } & \multicolumn{2}{|c|}{ Cotton } & \multicolumn{2}{|c|}{ Corn } \\
\hline & & 1996 & 2006 & 1996 & 2007 & 1996 & 2005 \\
\hline Amides & 15 & $4(18)$ & $2(12)$ & $\mathrm{NA}^{\mathrm{d}}$ & NA & $27(2)$ & $4(10)$ \\
\hline Aryloxyphenoxy propionic acid & 1 & $7(7)$ & $\mathrm{NA}^{\mathrm{c}}$ & NA & NA & NA & NA \\
\hline Benzoic & 4 & NA & NA & NA & NA & $10(6)$ & $2(18)$ \\
\hline Benzothiadiazole & 6 & $4(24)$ & NA & $3(12)$ & $1(20)$ & NA & NA \\
\hline Dinitroaniline & 3 & $20(8)$ & $3(9)$ & $26(7)$ & $14(4)$ & NA & NA \\
\hline Diphenyl ether & 14 & $8(9)$ & $1(24)$ & NA & NA & NA & NA \\
\hline Imidazolinone & 2 & $21(5)$ & $2(12)$ & NA & NA & NA & NA \\
\hline Organic arsenical & 9 & NA & NA & $12(9)$ & $1(18)$ & NA & NA \\
\hline Oxime & 1 & $7(11)$ & $1(17)$ & NA & NA & NA & NA \\
\hline Phenoxy & 4 & $5(14)$ & $5(9)$ & NA & NA & $5(7)$ & $3(14)$ \\
\hline Phosphinic acid & 9 & $10(8)$ & $77(1)$ & $3(10)$ & $60(2)$ & $2(21)$ & $19(5)$ \\
\hline Pyridine & 12 & NA & NA & NA & NA & $0(37)$ & $6(9)$ \\
\hline Sulfonylurea & 2 & $9(6)$ & NA & NA & NA & $11(7)$ & $5(18)$ \\
\hline Triazine & 5 & $4(18)$ & $1(17)$ & $13(8)$ & $2(15)$ & $38(2)$ & $48(3)$ \\
\hline Urea & 7 & NA & NA & $20(5)$ & $6(8)$ & NA & NA \\
\hline Other herbicides & & $2(13)$ & $6(6)$ & $23(7)$ & $17(4)$ & $8(6)$ & $9(8)$ \\
\hline
\end{tabular}

a Source: Agricultural Resource Management Survey, U.S. Department of Agriculture; http://www.ers.usda.gov/Data/ARMS/app/default.aspx?survey=CROP\# startFor.

b The number is the Weed Science Society of America classification (Herbicide Handbook 2007).

${ }^{c}$ The relative standard error (RSE) is the standard error of the estimate expressed as a percentage of the estimate; the larger the RSE, the less precise the estimate.

${ }^{\mathrm{d}}$ Estimate does not comply with the U.S. Department of Agriculture-Economic Research Service disclosure limitation practices, is not available, or is not applicable.

A follow-up survey to Shaw et al. (2009) was conducted in 2010 to measure changes in attitudes, perceptions, and practices between 2005 and 2010 (Prince et al. 2012a). Growers were more likely to see glyphosate resistance as a problem in the 2010 survey (Prince et al. 2012b), particularly in the southern United States. Growers were also able to identify specific GR weeds in their state or county (Prince et al. 2012c). As a result, more growers reported using MOAs other than glyphosate in the 2010 survey (Prince et al. 2012d). Growers also had a greater recognition that tillage and residual herbicides were effective herbicide-resistance management tools (Prince et al. 2012e).

Frisvold et al. (2009) described a 2007 survey of more than 1,000 corn, cotton, and soybean producers who were asked about their use of the following 10 BMPs for HR weeds: (1) scouting fields before applying herbicides; (2) scouting fields after applying herbicides; (3) starting with a clean field, accomplished either by a burndown herbicide or tillage; (4) controlling weeds when they were relatively small; (5) controlling weed escapes and preventing weeds from setting seed; (6) cleaning equipment before moving it to a new field to minimize weed seed spread; (7) planting new seed that is as weed free as possible; (8) using multiple herbicides with different MOAs; (9) supplementing herbicides with tillage; and (10) using the label-recommended herbicide rate. Most growers reported always or often practicing six of the BMPs (scouting before or after herbicide application or both, planting into a clean field, controlling weeds early and preventing escapes, planting new weed-free seed, and applying herbicide at the labeled rate) (Table 4). However, a significant proportion of participating growers reported rarely or never cleaning equipment before moving between fields (54\%), rarely or never using multiple herbicides with different MOAs (28\%), and rarely or never using supplemental tillage (53\%).

Adoption patterns were similar across producer groups: the same seven most widely adopted BMPs were practiced by $71 \%$ or more of corn, cotton, or soybean producers (Frisvold et al. 2009). Use of multiple herbicides with different MOAs, cleaned equipment, and supplemental tillage were used infrequently by the three producer groups: fewer than half of any of those producers practiced these three BMPs often or

Table 4. Frequency of herbicide-resistance best management practice implementation as percentage of all respondents from a 2007 survey of 1,000 U.S. corn, cotton, and soybean growers. ${ }^{\mathrm{a}, \mathrm{b}}$

\begin{tabular}{lccr}
\hline BMP & Often or always & Sometimes & Rarely or never \\
\hline & & $\%$ & 5 \\
Scout before herbicide application & 1 & 11 & 4 \\
Scout after herbicide application & 81 & 15 & 13 \\
Plant into clean field & 75 & 9 & 2 \\
Control weeds early & 89 & 15 & 6 \\
Control escapes & 79 & 20 & 3 \\
Clean equipment & 25 & 33 & 2 \\
Plant new weed-free seed & 94 & 26 & 28 \\
Use different herbicide MOAs & 39 & 4 & 53 \\
Supplemental tillage & 21 & 93 & 1 \\
Apply herbicide at labeled dose & & & 5 \\
\end{tabular}

a Abbreviation: BMP, best management practice; MOA, mechanism of action.

${ }^{\mathrm{b}}$ Adapted from Frisvold et al. 2009. 
always. More corn producers used multiple herbicides with different MOAs often or always (49\%) than did either cotton $(38 \%)$ or soybean $(28 \%)$ growers.

In summary, most corn, soybean, and cotton growers in the United States are using at least some herbicide-resistance BMPs. However, a significant fraction of growers are not practicing adequate, proactive herbicide-resistance management. The fields of these growers are likely to be the places where HR weeds are evolving, and that lack of stewardship may discourage other growers from being more diligent about resistance management. In particular, diversifying weed management practices (BMP 2) and using multiple herbicide MOAs (BMP 6) are key resistance-management recommendations that need to be more widely implemented. Recent survey data suggest a shift from sole reliance on glyphosate to the reintroduction of residual herbicides with more-diverse MOAs into weed management programs among U.S. cotton growers. Unfortunately, that may reflect a reactive response to the emergence of hard-to-control GR weeds in cotton fields, rather than a proactive attempt to prevent resistance evolution. Whether this pattern will be repeated in corn, soybean, and other crops remains to be seen.

There is also a clear need for more-extensive and moresystematic surveys of grower adoption of herbicide-resistance BMPs; those data will be vital for determining the effectiveness of educational and other measures encouraging their use.

\section{Recommendations for Adoption of BMPs}

Recommendation One: Reduce the Weed Seedbank through Diversified Programs that Minimize Weed Seed Production. Sustainable herbicide-resistance management requires a much longer-term perspective than that of a single season. Maintaining low weed-seed numbers in the soil seedbank reduces the number of plants that will be exposed to future herbicide treatment and can substantially reduce resistance risk (Neve et al. 2011a). Thus, there are advantages to controlling weed seed production even if such management might not lead to direct economic benefits in the current season.

For herbicide-resistance management, preventing viable weed seed production is necessary. Occasionally, there will be failures, and weeds capable of producing seed may not be controlled. In situations in which initial weed management efforts are unsuccessful, producers must take appropriate action to prevent weed seed production or vegetative propagation, including postharvest weed control.

Although model data show that weed seed added to the soil seedbank increases the risk of resistant weeds, research is needed on more weed species, locales, and production scenarios to confidently incorporate vital weed-seed reduction strategies into weed resistance BMPs. Additionally, preventing seed production, including after the harvest, must be strongly emphasized by extension educators, local distributors, and others communicating these BMPs to producers and encouraging their use.

Recommendation Two: Implement a Herbicide-MOA Labeling System for All Herbicide Products, and Conduct an Awareness Campaign. Given the number of different herbicide MOAs, the unfamiliarity of MOA specification to nonspecialists, the frequent use of mixed MOA herbicide products, frequent changes in herbicide products in the market, and the complexity of herbicide chemistry and MOA biochemistry, there is a need for the introduction of clear, standard herbicide-MOA labeling on herbicide use instructions (labels) and containers. To reduce overreliance on particular herbicide MOAs and to enable diversity in herbicide use, there must be an easy and consistent identification of product MOAs. All herbicide products should be clearly identified by standard MOA designations. The inclusion of MOAs on labels is essential for basic communication and will facilitate programs to better inform producers and their advisors of the importance of herbicide diversity. This recommendation is supported by the positive experience of establishing MOA labeling in Australia and Canada, where MOA labeling has facilitated awareness and adoption of herbicide-MOA rotation as a resistance management strategy (Beckie 2006; Shaner et al. 1999). Currently, some herbicide manufacturers in the United States voluntarily provide MOA labeling on their products.

To be successful, MOA labeling must be implemented and supported by manufacturers. However, given the diversity of manufacturers, suppliers, products, and product names, some form of industry-wide coordination and compliance will be needed to ensure comprehensive implementation. In countries that have adopted the practice, the herbicide industry selfregulated to ensure MOA labeling appeared on all herbicide products and associated materials (Beckie 2006; Shaner et al. 1999). Should self-regulation not be implemented or not be effective, regulatory authorities could mandate MOA labeling. Ideally, the herbicide industry and the scientific community would work together with regulators to achieve MOA labeling. In Australia, mandatory herbicide MOA labeling was cooperatively achieved 15 yr ago. Establishing a similar requirement, whether by agreement among companies or through a regulatory agency, is essential to the implementation of herbicide-resistance management in the United States. Both the Weed Science Society of America (WSSA) and the Herbicide Resistance Action Committee have developed simple, clear MOA designations. Because only the WSSA MOA designations are approved in the United States and Canada for use on herbicide labels, the WSSA system should be used for this application.

We propose MOA labeling with a unified program of education jointly developed, supported, and espoused by the WSSA, pesticide manufacturers and their trade association, and the purveyors of HR cultivars. We also propose that herbicide MOAs for each recommended herbicide be included and easily referenced in all state recommendation guides and websites.

Recommendation Three: Communicate that Discovery of New, Highly Effective Herbicide MOAs Is Rare and that the Existing Herbicide Resource Is Exhaustible. The international herbicide-discovery industry has been spectacularly successful in producing new herbicides in the second half of the 20th century. Producers are aware of this success and, consequently, have high expectations that new herbicides capable of overcoming resistance issues will continue to enter the market (Llewellyn et al. 2002; Wilson et al. 2008). However, the reality is that herbicide discovery has slowed dramatically in recent years, as is evident in the reduction in the number of herbicide patents issued (Ruegg et al. 2007). 
Therefore, to encourage crop producers to achieve herbicide sustainability, current optimistic expectations about new herbicide introductions will need to be addressed. Dampening high expectations will be difficult because of the successful record of herbicide technology, the confidential nature of the development pipeline, and the unpredictability of new herbicide discovery. Achieving consensus on this matter in a highly competitive herbicide industry may also be difficult. However, focusing on important and unique herbicide examples, such as glyphosate, may be an effective way to illustrate the potential for losing valuable herbicide resources and to communicate the need to use products in a sustainable manner so as to retain their utility. Should there be a widespread reduction in the weed control spectrum of a dominant herbicide, such as glyphosate, it will be important to stress the sustainability of strategies and technologies that would replace it.

Recommendation Four: Demonstrate the Benefits and Costs of Proactive, Diversified Weed Management Systems for the Mitigation of HR Weeds. Because of their relative advantages in cost efficiency, reliability, and ease of use, herbicides will remain central to weed control strategies. Such reliance means that the case for reducing dependence on a preferred herbicide option must be strong and clearly communicated. Where the sustainability of a key herbicide is threatened, practices to sustain its use must be emphasized.

The most effective means of conserving herbicide MOAs is diversifying weed management programs by combining herbicides with different MOAs and incorporating nonchemical control tools. Diversification reduces direct selection pressure by reducing the number of applications of a single herbicide, especially the number of consecutive applications of a single MOA. Application of two MOAs in sequence tends to conserve the efficacy of both, but particularly that of the first applied because the second application may control weeds that escaped the first by reason of incipient resistance. Growers may be reluctant to replace simple weed management programs that rely on a single or very few herbicides with more diverse weed management programs because the complexity of such programs is a deterrent (Jordan et al. 2003; Liebman and Gallandt 1997; Swanton et al. 2008).

Making alternative weed management programs as simple and as cost effective as possible will be required if preemptive herbicide-resistance management is to be widely adopted. The rapid and extensive adoption of GR crops illustrates that simplicity and convenience in weed control are highly valued by modern crop producers (Dill et al. 2008; Marra et al. 2004; Piggott and Marra 2008; Shaw et al. 2009). Complexity consumes management time, attention, and labor (Kingwell 2010; Pardo et al. 2010), and those costs must be clearly addressed when promoting herbicide sustainability through adoption of diversity in weed management strategies.

A persuasive argument for adoption of diverse resistancemanagement practices may be that costs of control after herbicide resistance has evolved are often higher than the cost of a program for reducing the risk of resistance in the first place (Mueller et al. 2005; Orson 1999). A successful example of preemptive adoption of a resistance risk-averting practice is the campaign to encourage glyphosate sustainability in Australia using a "double knock" treatment. The doubleknock treatment incorporates an application of a second herbicide MOA, other than glyphosate, shortly after the glyphosate preseeding application (Neve et al. 2003b; Weersink et al. 2005).

Recommendation Five: Foster the Development of Incentives by Government Agencies and Industry that Conserve Critical Herbicide MOAs as a Means to Encourage Adoption of Best Practices. Herbicides are the most costeffective means of weed control in most cropping systems. Growers may accept the risk of herbicide resistance and overuse a single or a few herbicide MOAs when competitive diversified programs are not readily apparent. Diversification may occur in three ways:

1. An alternative herbicide program with more than one MOA becomes available and is perceived by the grower to be more effective or less costly than the former program that had high risks of generating resistance. In such a situation, little or no inducement is needed because growers will use programs that are most effective and least costly.

2. An alternative program is available that is as effective and economical as one that has a high risk of resistance, but it is underused. In this case, education by the cooperative extension service, distributors, and manufacturers' representatives can be effective in conveying to growers the advantage of conserving valuable MOAs by using diversified programs.

3. Alternative programs exist but are less effective or more costly than the standard program. In this scenario, it will be difficult to convince growers to use the less effective or more costly approach because it is difficult to estimate future economic consequences. Consequently, growers tend to choose short-term advantages. In this scenario, economic incentives may be needed for conservation of products with broad utility for the public good.

We recommend the expansion of the USDA Natural Resources Conservation Service (NRCS) program, which supports producers by creating positions for technical service providers to assist in the development and implementation of sustainable herbicide-resistance management programs. USDA-NRCS is also developing plans for cost-share incentives for producers to help reduce the risks of resistance on farms, or to contend with weeds that have already evolved resistance (Robinson 2011). Support for soil-conservation farming systems and improved environmental outcomes could be a focus for conserving valuable herbicide MOAs (D'Emden et al. 2008; Givens et al. 2009; Gray et al. 1996; Marsh et al. 2006).

Recommendation Six: Promote the Application of Full, Labeled Rates at the Appropriate Weed and Crop Growth Stage. When tank mixtures are employed to control the range of weeds present in a field, each product should be used at the specified label rate appropriate for the weeds present. Repeated use of rates below those recommended on labels increases the probability of resistance (Neve and Powles 2005a,b; Norsworthy 2012). Below-labeled rates allow more weeds to survive treatment, and those weeds produce seed in the survivors that will lead to an accumulation of genes that confer resistance via multigenic mechanisms. Although producers can avoid knowingly applying a reduced herbicide 
rate, they must also be aware that rates can be unintentionally reduced by poor spray coverage or by applying a herbicide to weeds larger than those recommended.

It is in the herbicide manufacturers' interest to specify the manner of use of a proprietary herbicide because of probable adverse market consequences from misuse or complaints of product failure. Such stipulations are standard in herbicide labeling where specific off-label uses are not permitted, e.g., those that have a high likelihood of failure or of off-target damage. All herbicide labels give quite specific information on the application rates, weed sizes, conditions, and other factors that may affect activity of that herbicide. We recommend the crop-protection industry draft herbicide labels with mandatory minimum-use rates so the state regulatory agencies can enforce compliance. Although a pesticide label is a legal document, it may contain both mandatory and advisory statements. Minimum use rates can be made mandatory if correctly written, and that would require users to comply with those specifications to avoid increasing the risks of resistance evolution.

Recommendation Seven: Identify and Promote Individual BMPs that Fit Specific Farming Segments with the Greatest Potential Impact. We recognize that there are substantial gaps in research knowledge of herbicide-resistance BMPs. We also recognize that a BMP for a specific weed in one locale may not be the best practice in another locale or under different crop management practices. For example, tillage may offer a viable management strategy in some areas, whereas in areas susceptible to wind or water erosion, tillage would be a poor option. Likewise, herbicide use varies among locales because of differences in soils, weather, and general production practices. Weed scientists, including extension specialists, industry personnel, and producers must work cooperatively to establish and verify BMPs for problem weeds in various regions. In some cases, computer modeling can be used to predict outcomes without the need for numerous long-term field studies (Neve et al. 2011a). However, field studies are needed to collect data to parameterize models and validate model predictions. General BMPs, whether developed by model simulation or field experience, should be used as a base recommendation, allowing local weed scientists and producers to refine programs to fit individual management needs. IWM to reduce the risk of resistance combines multiple BMPs, and the path to reducing resistance risk is likely to be achieved in incremental steps from simple to more complex practices as producers gain confidence about adopting new strategies (Byerlee and Polanco 1986).

Information flow to producers occurs through private crop consultants, herbicide retailers, popular media, university research and extension systems, and other producers (Givens et al. 2009; Norsworthy et al. 2007d). Therefore, the first step in encouraging producers to adopt BMPs for herbicide sustainability in a particular state or region is to understand and access those same information pathways, using educational materials that include practices suitable for local situations and farming practices. A wide range of factors affects producer decisions regarding IWM and herbicide resistance (Shaw et al. 2009; Wilson et al. 2008, 2009). Identifying those factors at a local level allows targeted information delivery to improve decision-making (Llewellyn 2007). Many aspects of herbicide management, including managing for sustainability, require region-specific decisionmaking and, therefore, regional research.

Many of the BMPs offer benefits to the farming system beyond weed control, and those benefits will give producers extra incentive to adopt the practices (Llewellyn et al. 2004, 2005). Relative cost-benefit predictions for various BMPs should be presented in educational materials and programs and should be based on local farming economics. Practices that offer the greatest relative advantage in the short term are more likely to be adopted preemptively. At present, adoption of complex and costly practices is more likely with increased producer awareness of herbicide resistance, presence, or risk on their farms. However, area-wide promotion of preemptive BMPs developed to fit local production problems may encourage producers to realize the importance of these practices and increase their confidence that resistance management can be successful for their operation.

Recommendation Eight: Engage the Public and Private Sectors in the Promotion of BMPs, Including Those Concerning Appropriate Herbicide Use. The weed resistance crisis provides an excellent opportunity for partnerships between public- and private-sector consultants and scientists. The potential to reach growers and their advisors can be greatly increased when a science-based recommendation gains the support of the communication resources of a manufacturer. The double-knock concept in Australia (Walsh and Powles 2007) is one example that led to high levels of preemptive adoption of a practice.

Herbicide manufacturers should not constrain sales in any way as a part of a cooperative effort with the public sector to promote herbicide diversity in resistance management programs. However, given the realities of resistance evolution, we recommend that herbicide manufacturers unequivocally state and promote on the label and in all advertising material that the herbicide be used in a manner that embraces the principles of sustainable weed management. In this way, herbicide manufacturers are promoting a message that is consistent with public- and private-sector educational efforts.

Recommendation Nine: Direct Federal, State, and Industry Funding to Research Addressing the Substantial Knowledge Gaps in BMPs for Herbicide Resistance and Support Cooperative Extension Services as Vital Agents in Education for Resistance Management. Our current knowledge of best practices for managing herbicide resistance is incomplete. Much of the research on developing herbicide-based management strategies in cropping systems is funded by herbicide manufacturers, who are primarily interested in approaches that benefit their bottom line. Federal and state funds are, therefore, needed to meet additional research needs. Weed management is local and requires specific solutions that do not rely on one technique or one herbicide. Agriculture needs a diversity of weed management tools and strategies for every crop, including resistance management programs that use more than one herbicide or management technique in each cropping scenario. Although industry support will likely continue for some research, federal and state funding must be available and be substantial enough to support resistance-management projects for which private funding is not available or insufficient.

A vital aspect of developing and implementing successful resistance-management BMPs is information transfer to 
consumers of those practices. A great deal of this information is articulated through state and local extension specialists. These professionals, in addition to private crop consultants, are at the forefront of introducing producers to new information and strategies through one-on-one communication, grower and consultant meetings, cooperation in field demonstrations at research station field days, popular press news releases, and technical brochures and websites. In some states, weed resistance has compelled extraordinary cooperation among academia, extension specialists, consultants, industry personnel, and producers to develop solutions to urgent problems. However, it is vital that resistancemanagement research and education be supported by both private and public sectors. The need for public funding is necessary and justified given the dependence of our society on the agricultural community and its crop production.

\section{Acknowledgments}

Improvements made to this document by Marilyn McClelland, Muthukumar Bagavathiannan, James Anderson, and two anonymous reviewers are gratefully appreciated. Support for preparation of this document was provided to the WSSA by the USDA Animal and Plant Health Inspection Service. This publication was supported in part by the United States Department of Agriculture's (USDA) Animal and Plant Health Inspection Service Agreement Number 092000-0050-CA.

\section{Literature Cited}

Ateh, C. M. and J. D. Doll. 1996. Spring-planted winter rye (Secale cereale) as a living mulch to control weeds in soybean (Glycine max). Weed Technol. 10:347-353.

Bagavathiannan, M. V., J. K. Norsworthy, and K. L. Smith. 2011a. Growth and reproduction of barnyardgrass (Echinochloa crus-galli) under different soybean densities and distances from soybean rows. Proc. South. Weed Sci. Soc. 64:298.

Bagavathiannan, M. V., J. K. Norsworthy, K. L. Smith, and N. Burgos. 2011b. Seedbank size and emergence pattern of barnyardgrass (Echinochloa crus-galli) in Arkansas. Weed Sci. 59:359-365.

Baldwin, F. and N. Slaton. 2001. Rice weed control. Pages 37-46 in N. Slaton, ed. Rice Production Handbook. Little Rock, AR: Arkansas Cooperative Extension Service, University of Arkansas Misc. Publ. 192.

Ball, D. A. 1992. Weed seedbank response to tillage, herbicides, and crop rotation sequence. Weed Sci. 40:654-659.

Bangarwa, S. K., J. K. Norsworthy, E. E. Gbur, J. Zhang, and T. Habtom. 2011. Allyl isothiocyanates: a methyl bromide replacement in polyethylene-mulched bell pepper. Weed Technol. 25:90-96.

Banks, P. A. and E. L. Robinson. 1982. The influence of straw mulch on the soil reception and persistence of metribuzin. Weed Sci. 30:164-168.

Bararpour, M. T. and L. R. Oliver. 1998. Effect of tillage and interference on common cocklebur (Xanthium strumarium) and sicklepod (Senna obtusifolia) population, seed production, and seedbank. Weed Sci. 46:424-431.

Bárberi, P. and B. Lo Cascio. 2001. Long-term tillage and crop rotation effects on weed seedbank size and composition. Weed Res. 41:325-340.

Barrett, S.C.H. 1983. Crop mimicry in weeds. Econ. Bot. 37:255-282.

Baskin, J. M. and C. C. Baskin. 1987. Temperature requirements for afterripening in buried seeds of four summer annual weeds. Weed Res. 27:385-389.

Baskin, J. M. and C. C. Baskin. 1977. Role of temperature in the germination ecology of three summer annual weeds. Oecologia 30:377-382.

Bauer, T. A. and D. A. Mortensen. 1992. A comparison of economic and economic optimum thresholds for two annual weeds in soybeans. Weed Technol. 6:228-235.

Beckie, H. J. 2006. Herbicide-resistant weeds: management tactics and practices. Weed Technol. 20:793-814.

Beckie, H. J. and X. Reboud. 2009. Selecting for weed resistance: herbicide rotation and mixture. Weed Technol. 23:363-370.

Beckie, H. J., L. M. Hall, and B. Schuba. 2005. Patch management of herbicideresistant wild oat (Avena fatua). Weed Technol. 19:697-705.
Beckie, H. J., L. M. Hall, and F. J. Tardif. 2001. Impact and management of herbicide-resistant weeds in Canada. Pages 747-754 in Proceedings of the Brighton Crop Protection Conference-Weeds. Farnham, UK: British Crop Protection Council.

Bell, M. S. and P. J. Tranel. 2010. Time requirement from pollination to seed maturity in waterhemp (Amaranthus tuberculatus). Weed Sci. 58:167-173.

Benech-Arnold, R. L., C. M. Ghersa, R. A. Sanchez, and A. E. Garcia Fernandez. 1988. The role of fluctuating temperatures in the germination and establishment of Sorghum halepense (L.) Pers. regulation of germination under leaf canopies. Funct. Ecol. 2:311-318.

Bennett, D. 2011. Pigweeds: Chopping Costs, Burning Fields and Moldboard Plows. http://southwestfarmpress.com/print/management/pigweeds-choppingcosts-burning-fields-and-moldboard-plows. Accessed: January 14, 2011.

Bergkvist, G., A. Adler, M. Hansson, and M. Weih. 2010. Red fescue undersown in winter wheat suppresses Elytrigia repens. Weed Res. 50:447-455.

Bhowmik, P. C. 1997. Weed biology: importance to weed management. Weed Sci. 45:349-356.

Bhowmik, P. C. and M. M. Bekech. 1993. Horseweed (Conyza canadensis) seed production, emergence, and distribution in no-tillage and conventional-tillage corn (Zea mays). Agron. Trends Agric. Sci. 1:67-71.

Blackshaw, R. E. and L. M. Rode. 1991. Effect of ensiling and rumen digestion by cattle on weed seed viability. Weed Sci. 39:104-108.

Blackshaw, R. E., J. T. O’Donovan, K. N. Harker, G. W. Clayton, and R. N. Stougaard. 2006. Reduced herbicide doses in field crops: a review. Weed Biol. Manag. 6:10-17.

Booth, B. D. and C. J. Swanton. 2002. Assembly theory applied to weed communities. Weed Sci. 50:2-13.

Boutin, C. and B. Jobin. 1998. Intensity of agricultural practices and effects on adjacent habitats. Ecol. Appl. 8:544-557.

Bridges, D. C. and R. H. Walker. 1985. Influence of weed management and cropping systems on sicklepod (Cassia obtusifolia) seed in the soil. Weed Sci. 33:800-804.

Brookes, G. and P. Barfoot. 2011. GM crops: global socio-economic and environmental impacts 1996-2009. www.pgeconomics.co.uk/pdf/ 2011globalimpactstudy.pdf. Accessed: July 20, 2011.

Brown, J. and A. P. Brown. 1996. Gene transfer between canola (Brassica napus L. and B. campestris L.) and related weed species. Ann. Appl. Biol. 129:513-522.

Bruff, S. A., J. L. Griffin, and E. P. Richard, Jr. 1996. Johnsongrass (Sorghum halepense) control as influenced by timing of asulam and fertilizer/cultivation applications. Weed Technol. 10:134-139.

Bryson, C. T. and M. S. De Felice, eds. 2009. Weeds of the South. Athens: University of Georgia Press. 468 p.

Bryson, C. T. and M. S. De Felice, eds. 2010. Weeds of the Midwestern United States and Central Canada. Athens: University of Georgia Press. 427 p.

Buhler, D. D. 1995. Influence of tillage systems on weed population dynamics and management in corn and soybean production in the central USA. Crop Sci. 35:1247-1257.

Buhler, D. D., J. L. Gunsolus, and D. F. Ralston. 1992. Integrated weed management techniques to reduce herbicide inputs in soybean. Agron. J. 84:973-978.

Buhler, D. D., R. G. Hartzler, and F. Forcella. 1997. Implications of weed seedbank dynamics to weed management. Weed Sci. 45:329-336.

Buhler, D. D., R. G. Hartzler, and F. Forcella. 1998. Weed seed bank dynamics: implications to weed management. J. Crop Prod. 1:145-168.

Buhler, D. D., T. C. Mester, and K. A. Kohler. 1996. Effect of tillage and maize residue on the emergence of four annual weed species. Weed Res. 40:153-165.

Buhler, D. D., D. E. Stoltenberg, R. L. Becker, and J. L. Gunsolus. 1994. Perennial weed populations after 14 years of variable tillage and cropping systems. Weed Sci. 42:205-209.

Burgos, N. R., R. J. Norman, D. R. Gealy, and H. Black. 2006. Competitive N uptake between rice and weedy rice. Field Crops Res. 99:96-105.

Burnside, O. C., R. S. Moomaw, F. W. Roeth, G. A. Wicks, and R. G. Wilson. 1986. Weed seed demise in soil in weed-free corn (Zea mays) production across Nebraska. Weed Sci. 34:248-251.

Burton, M. G., D. A. Mortensen, and D. B. Marx. 2005. Environmental characteristics affecting Helianthus annuus distribution in a maize production system. Agric. Ecosyst. Environ. 111:30-40.

Burton, M. G., E. P. Prostko, T. M. Webster, A. S. Culpepper, and J. K. Norsworthy. 2006. Local and regional dispersal of tropical spiderwort (Commelina benghalensis). Proc. South. Weed Sci. Soc. 59:211.

Busi, R. and S. B. Powles. 2009. Evolution of glyphosate resistance in a Lolium rigidum population by glyphosate selection at sublethal doses. Heredity 103:318-325.

Busi, R., Q. Yu, R. Barrett-Lennard, and S. Powles. 2008. Long distance pollenmediated flow of herbicide resistance genes in Lolium rigidum. Theor. Appl. Genet. 117:1281-1290. 
Byerlee, D. and E. H. de Polanco. 1986. Farmers' stepwise adoption of technological packages: evidence from the Mexican Altiplano. Am. J. Agric. Econ. 68:519-527.

Byrd, J. D., C. T. Bryson, and R. G. Westbrooks. 2004. Tropical Soda Apple (Solanum viarum Dunal) Identification and Control. http://www.mdac.state. ms.us/n_library/departments/bpi/pdf/bpi_tsa_fact_sheet.pdf. Accessed July 29, 2011.

Caamal-Maldonado, J. A., J. J. Jimenez-Osornio, A. Torres-Barragan, and A. L. Anaya. 2001. The use of allelopathic legume cover and mulch species for weed control in cropping systems. Agron. J. 93:27-36.

Cardina, J. and H. M. Norquay. 1997. Seed production and seed bank dynamics in subthreshold velvetleaf (Abutilon theophrasti) populations. Weed Sci. 45:85-90.

Cardina, J., C. P. Herms, and D. J. Doohan. 2002. Crop rotation and tillage system effects on weed seedbanks. Weed Sci. 50:448-460.

Cardina, J., C. P. Herms, D. A. Herms, and F. Forcella. 2007. Evaluating phenological indicators for predicting giant foxtail (Setaria faberi) emergence. Weed Sci. 55:455-464.

Cardina, J., E. Regnier, and K. Harrison. 1991. Long-term tillage effects on seed banks in three Ohio soils. Weed Sci. 39:186-194.

Cardina, J., H. M. Norquay, B. R. Stinner, and D. A. McCartney. 1996. Postdispersal predation of velvetleaf (Abutilon theophrasti) seeds. Weed Sci. 44:534-539.

Carey, V. F., III., R. E. Hoagland, and R. E. Talbert. 1995. Verification and distribution of propanil-resistant barnyardgrass (Echinochloa crus-galli) in Arkansas. Weed Technol. 9:366-372.

Cash, S. D., D. L. Zamora, and A. W. Lenssen. 1998. Viability of weed seeds in feed pellet processing. J. Range Manag. 51:181-185.

Castello, T. A., T. K. Keisling, and L. R. Oliver. 1998. Cultural and chemical redvine (Brunnichia ovata) control in soybean. Little Rock, AR: Arkansas Agricultural Experiment Station Special Rep. 186. Pp. 16-18.

Chase, C. A., T. R. Sinclair, D. G. Shilling, J. P. Gilreath, and S. J. Lo Cascio. 1998. Light effects on rhizome morphogenesis in nutsedges (Cyperus spp.): implications for control by soil solarization. Weed Sci. 46:575-580.

Chauhan, B. S., T. Migo, P. R. Westerman, and D. E. Johnson. 2010. Postdispersal predation of weed seeds in rice fields. Weed Res. 50:553-560.

Chee-Sanford, J. C., M. M. Williams, III., A. S. Davis, and G. K. Sims. 2006. Do microorganisms influence seed-bank dynamics? Weed Sci. 54:575-587.

Clay, S. and G. Johnson. 2002. Scouting for weeds [published online December 6, 2002]. Crop Manag. Netw. doi:10.1094/CM-2002-1206-01-MA.

Coble, H. D. and C. A. Mortensen. 1992. The threshold concept and its application to weed science. Weed Technol. 6:191-195.

Cohen, O., J. Riov, J. Katan, A. Gamliel, and P. Bar (Kutiel). 2008. Reducing persistent seed banks of invasive plants by soil solarization — the case of Acacia saligna. Weed Sci. 56:860-865.

Colbach, N., F. Forcella, and G. A. Johnson. 2000. Spatial and temporal stability of weed populations over five years. Weed Sci. 48:366-377.

Cousens, R. 1987. Theory and reality of weed control thresholds. Plant Prot. Q. 2:13-20.

Cromar, H. E., S. D. Murphy, and C. J. Swanton. 1999. Influence of tillage and crop residue on postdispersal predation of weed seeds. Weed Sci. 47:184-194.

Culpepper, A. S., J. T. Flanders, A. C. York, and T. M. Webster. 2004. Tropical spiderwort (Commelina benghalensis) control in glyphosate-resistant cotton. Weed Technol. 18:432-436.

Culpepper, A. S., T. L. Grey, W. K. Vencill, J. M. Kichler, T. M. Webster, S. M. Brown, A. C. York, J. W. Davis, and W. W. Hanna. 2006. Glyphosateresistant Palmer amaranth (Amaranthus palmeri) confirmed in Georgia. Weed Sci. 54:620-626.

Culpepper, A. S., T. L. Grey, and T. M. Webster. 2009. Vegetable response to herbicides applied to low-density polyethylene mulch prior to transplant. Weed Technol. 23:444-449.

Culpepper, A. S., T. M. Webster, L. M. Sosnoskie, and A. C. York. 2010. Glyphosate-resistant Palmer amaranth in the US. Pages 195-212 in V. K. Nandula, ed. Glyphosate Resistance: Evolution, Mechanisms, and Management. Hoboken, N.J: John Wiley.

Dale, P. J. 1994. The impact of hybrids between genetically modified crop plants and their related species: general considerations. Mol. Ecol. 3:31-36.

Dauer, J. T., E. C. Luschei, and D. A. Mortensen. 2009. Effects of landscape composition on spread of a herbicide-resistant weed. Landsc. Ecol. 24: 735-747.

Dauer, J. T., D. A. Mortensen, and M. J. VanGessel. 2007. Temporal and spatial dynamics of long-distance Conyza canadensis seed dispersal. J. Appl. Ecol. 44:105-114.

Daugovish, O. and N. J. Mochizuki. 2010. Barriers prevent emergence of yellow nutsedge (Cyperus esculentus) in annual plasticulture strawberry (Fragaria $\times$ ananassa). Weed Technol. 24:478-482.
D’Emden, F. H., R. S. Llewellyn, and M. P. Burton. 2008. Factors influencing adoption of conservation tillage in Australian cropping regions. Aust. J. Agric. Res. Econ. 52:169-182.

Derksen, D. A., P. R. Watson, and H. A. Loeppky. 1998. Weed community composition in seed banks, seedling, and mature plant communities in a multi-year trial in western Canada. Asp. Appl. Biol. 51:43-50.

DeVore, J. D., J. K. Norsworthy, D. B. Johnson, C. E. Starkey, M. J. Wilson, and G. M. Griffith. 2011. Palmer amaranth emergence as influenced by soybean production system and deep tillage. Proc. South. Weed Sci. Soc. 64:239.

Dewey, S. A. and R. E. Whitesides. 1990. Weed seed analysis from four decades of Utah small grain drillbox surveys. Proc. Western Soc. Weed Sci. 43:69.

Dieleman, J. A. and D. A. Mortensen. 1999. Characterizing the spatial pattern of Abutilon theophrasti seedling patches. Weed Res. 39:455-467.

Diggle, A. J., P. B. Neve, and F. P. Smith. 2003. Herbicides used in combination can reduce the probability of herbicide resistance in finite weed populations. Weed Res. 43:371-382.

Dill, G. M., C. A. CaJacob, and S. R. Padgette. 2008. Glyphosate-resistant crops: adoption, use and future considerations. Pest Manag. Sci. 64:326-331.

Duke, S. O. 2011. Why are there no new herbicide modes of action in recent years [published online ahead of print December 22, 2011]? Pest Manag. Sci.. doi: $10.1002 / \mathrm{ps} 2333$.

Duke, S. O. and S. B. Powles. 2008. Glyphosate: a once-in-a-century herbicide. Pest Manag. Sci. 64:319-325.

Eberlein, C. V., K. Al-Khatib, M. J. Guttieri, and E. P. Fuerst. 1992. Distribution and characteristics of triazine-resistant Powell amaranth (Amaranthus powellii) in Idaho. Weed Sci. 40:507-512.

Egley, G. H. 1976. Germination of developing prickly sida seeds. Weed Sci. 24:239-243

Egley, G. H. 1999. Reflections on my career in weed seed germination research. Seed Sci. 9:3-12.

Egley, G. H. and J. M. Chandler. 1983. Longevity of weed seeds after 5.5 years in the Stoneville 50-year buried-seed study. Weed Sci. 31:264-270.

Etheredge, L. M., Jr., J. L. Griffin, and M. E. Salassi. 2009. Efficacy and economics of summer fallow conventional and reduced-tillage programs for sugarcane. Weed Technol. 23:274-279.

Feldman, S. R., C. Alzugaray, P. S. Torres, and P. Lewis. 1997. The effect of different tillage systems on the composition of the seedbank. Weed Res. 37:71-76.

Finnoff, D., J. F. Shogren, B. Leung, and D. Lodge. 2007. Take a risk: preferring prevention over control of biological invaders. Ecol. Econ. 62:216-222.

Forcella, F. 1993. Seedling emergence model for velvetleaf. Agron. J. 85:929-933.

Forcella, F., R. L. Benech Arnold, R. Sanchez, and C. M. Ghersa. 2000. Modeling seedling emergence. Field Crops Res. 67:123-139.

Forcella, F., K. Dekker, R. G. Harvey, C. A. Alm, D. D. Buhler, and J. Cardina. 1992. Weed seedbanks of the U.S. Corn Belt: magnitude, variation, emergence, and application. Weed Sci. 40:636-644.

Forcella, F., K. Eradat-Oskoui, and S. W. Wagner. 1993. Application of weed seedbank ecology to low-input crop management. Ecol. Appl. 3:74-83.

Forcella, F., R. G. Wilson, and J. Dekker, et al. 1997. Weed seed bank emergence across the Corn Belt. Weed Sci. 45:67-76.

Foresman, C. and L. Glasgow. 2008. US grower perceptions and experiences with glyphosate-resistant weeds. Pest Manag. Sci. 64:388-391.

Frisvold, G. B., T. M. Hurley, and P. D. Mitchell. 2009. Adoption of best management practices to control weed resistance by corn, cotton, and soybean growers. Agbioforum 12:370-381.

Gallagher, R. S. and J. Cardina. 1998a. Phytochrome-mediated Amaranthus germination I: effect of seed burial and germination temperature. Weed Sci. 46:48-52.

Gallagher, R. S. and J. Cardina. 1998b. Phytochrome-mediated Amaranthus germination II: development of very low fluence activity. Weed Sci. 46:53-58.

Gallandt, E. R. 2006. How can we target the weed seedbank? Weed Sci. 54:588-596.

Gerwick, C. G. 2010. Thirty years of herbicide discovery: surveying the past and contemplating the future. Chapters VII-IX in Agrow Report. (Silver Jubilee Edition). London, UK: Informa.

Gill, G. S. and J. E. Holmes. 1997. Efficacy of cultural control methods for combating herbicide-resistant Lolium rigidum. Pestic. Sci. 51:352-358.

Givens, W. A., D. R. Shaw, G. R. Kruger, W. G. Johnson, S. C. Weller, B. G. Young, R. G. Wilson, M.D.K. Owen, and D. Jordan. 2009. Survey of tillage trends following the adoption of glyphosate-resistant crops. Weed Technol. 23:150-155.

Goatley, J. M., V. L. Maddox, and R. M. Watkins. 1998. Bahiagrass response to a plant growth regulator as affected by mowing interval. Crop Sci. 38:196-200.

Goddard, R. H., T. M. Webster, J. R. Carter, and T. L. Grey. 2009. Resistance of Benghal dayflower (Commelina benghalensis) seeds to harsh environments and 
the implications for dispersal by mourning doves (Zenaida macroura) in Georgia, U.S.A. Weed Sci. 57:603-612.

Gold, H. J., J. Bay, and G. G. Wilkerson. 1996. Scouting for weeds, based on the negative binomial distribution. Weed Sci. 44:504-510.

Gonzalez-Andujar, J. L., R. E. Plant, and C. Fernandez-Quintanilla. 2001. Modeling the effect of farmers' decisions on the population dynamics of winter wild oat in an agricultural landscape. Weed Sci. 49:414-422.

Gordon, E., T. C. Keisling, L. R. Oliver, and C. Harris. 2001. Two methods of composting gin trash. Commun. Soil Sci. Plant Anal. 32:491-507.

Gossen, R.R.S., R. J. Tyrl, M. Hauhouot, T. F. Peeper, P. L. Claypool, and J. B. Solie. 1998. Effects of mechanical damage on cheat (Bromus secalinus) caryopsis anatomy and germination. Weed Sci. 46:249-257.

Gould, F. 1995. Comparisons between resistance management strategies for insects and weeds. Weed Technol. 8:830-839.

Gray, R. S., W. J. Taylor, and J. S. Brown. 1996. Economic factors contributing to the adoption of reduced tillage technologies in central Saskatchewan. Can. J. Plant Sci. 76:661-668.

Green, J. M. 2009. Evolution of glyphosate-resistant crop technology. Weed Sci. $57: 108-117$

Green, J. M., C. B. Hazel, D. R. Forney, and L. M. Pugh. 2008. New multipleherbicide crop resistance and formulation technology to augment the utility of glyphosate. Pest. Manag. Sci. 64:332-339.

Gressel, J. 1995. Creeping resistances: the outcome of using marginally effective or reduced rates of herbicides. Pages 587-590 in Proceedings of the Brighton Crop Protection Conference-Weeds. Farnham, UK: British Crop Protection Council.

Gressel, J. 2002. Molecular Biology of Weed Control. London: Taylor and Francis. $520 \mathrm{p}$.

Gressel, J. and A. A. Levy. 2006. Agriculture: the selector of improbable mutations. Proc. Natl. Acad. Sci. U. S. A. 103:12215-12216.

Gressel, J. and L. A. Segel. 1990. Modeling the effectiveness of herbicide rotations and mixtures as strategies to delay or preclude resistance. Weed Technol. 4:186-198.

Grey, T. L., W. K. Vencill, T. M. Webster, and A. S. Culpepper. 2009. Herbicide dissipation from low density polyethylene mulch. Weed Sci. 57:351-356.

Grey, T. L., T. M. Webster, and A. S. Culpepper. 2007. Autumn vegetable response to residual herbicides applied the previous spring under low-density polyethylene mulch. Weed Technol. 21:496-500.

Griffith, G. M., J. K. Norsworthy, and T. Griffin. 2010. Cotton yield reduction associated with spatial movement of glyphosate-resistant Palmer amaranth. Ark. Crop Prot. Assoc. 14:11.

Hardin, G. 1968. The tragedy of the commons. Science 162:1243-1248.

Harper, J. C. 1956. The evolution of weeds in relation to herbicides. Proc. Brit. Weed Contr. Conf. 3:179-188.

Harrison, S. K., E. E. Regnier, and J. T. Schmoll. 2003. Postdispersal predation of giant ragweed (Ambrosia trifida) seed in no-tillage corn. Weed Sci. 51:955-964.

Hartwig, N. L. and H. U. Ammon. 2002. Cover crops and living mulches. Weed Sci. 50:688-699.

Hartzler, R. G. 1996. Velvetleaf (Abutilon theophrasti) population dynamics following a single year's seed rain. Weed Technol. 10:581-586.

Hartzler, R. G. and G. W. Roth. 1993. Effect of prior year's weed control on herbicide effectiveness in corn (Zea mays). Weed Technol. 7:611-614.

Hartzler, R. G., B. A. Battles, and D. Norby. 2004. Effect of common waterhemp (Amaranthus rudis) emergence date on growth and fecundity in soybean. Weed Sci. 52:242-245.

Hartzler, R. G., D. D. Buhler, and D. E. Stoltenberg. 1999. Emergence characteristics of four annual weed species. Weed Sci. 47:578-584.

Harvey, S. J. and F. Forcella. 1993. Vernal seedling emergence model for common lambsquarters (Chenopodium album). Weed Sci. 41:309-316.

Hausman, N. E., S. Singh, P. J. Tranel, D. E. Riechers, S. S. Kaundun, N. D. Polge, D. A. Thomas, and A. G. Hager. 2011. Resistance to HPPD-inhibiting herbicides in a population of waterhemp (Amaranthus tuberculatus) from Illinois, United States. Pest Manag. Sci. 67:258-261.

Heap, I. 2011a. Top 10 worst herbicide resistant weeds globally. Page 319 in 51st Meeting of the Weed Science Society of America. Lawrence, KS: WSSA.

Heap, I. 2011b. International Survey of Herbicide-Resistant Weeds. http://www. wssa.net/Weeds/Resistance/ResistanceLinks.htm. Accessed July 29, 2011

Heatherly, L. C., A. Blaine, H. F. Hodges, R. A. Wesley, and N. Buehring. 1999 Variety selection, planting date, row spacing, and seeding rate. Pages 41-51 in L. G. Heatherly and H. F. Hodges, eds. Soybean Production in the Midsouth. Boca Raton, FL: CRC.

Hidayat, I., J. Baker, and C. Preston. 2006. Pollen-mediated gene flow between paraquat-resistant and susceptible hare barley (Hordeum leporinum). Weed Sci. 54:685-689.

Holsinger, K. E. 2000. Reproductive systems and evolution in vascular plants. Proc. Natl. Acad. Sci. U. S. A. 97:7037-7042.
Honek, A., Z. Martinkova, and V. Jarosik. 1999. Annual cycles of germinability and differences between primary and secondary dormancy in buried seeds of Echinochloa crus-galli. Weed Res. 39:69-79.

Howe, O. W., III. and L. R. Oliver. 1987. Influence of soybean (Glycine max) row spacing on pitted morningglory (Ipomoea lacunosa) interference. Weed Sci. 35:185-193.

Hulme, P. E. 1994. Post-dispersal seed predation in grassland: its magnitude and sources of variation. J. Ecol. 81:645-652.

Humston, R., D. A. Mortensen, and O. N. Bjornstad. 2005. Anthropogenic forcing on the spatial dynamics of an agricultural weed: the case of the common sunflower. J. Appl. Ecol. 42:863-872.

Hurley, T. M., P. D. Mitchell, G. B. Frisvold, and G. B. 2009. Weed management costs, weed best management practices, and the Roundup Ready weed management program. Agbioforum 12:281-290.

Isaacs, M. A., E. C. Murdock, J. E. Toler, and S. U. Wallace. 1989. Effects of late-season herbicide applications on sicklepod (Cassia obtusifolia) seed production and viability. Weed Technol. 37:761-765.

Jacob, H. A., D. M. Minkey, R. S. Gallagher, and C. P. Borger. 2006. Variation in postdispersal weed seed predation in a crop field. Weed Sci. 54:148-155.

Jacquemin, B., J. Gasquez, and X. Reboud. 2009. Modeling binary mixtures of herbicides in populations resistant to one of the components: evaluation for resistance management. Pest Manag. Sci. 65:113-121.

Jalaludin, A., J. Ngim, B.H.J. Bakar, and Z. Alias. 2010. Preliminary findings of potentially resistant goosegrass (Eleusine indica) to glufosinate-ammonium in Malaysia. Weed Biol. Manag. 10:256-260.

Jasieniuk, M., A. L. Brule-Babel, and I. N. Morrison. 1996. The evolution and genetics of herbicide resistance. Weed Sci. 44:176-193.

Jha, P. and J. K. Norsworthy. 2009. Soybean canopy and tillage effects on emergence of Palmer amaranth (Amaranthus palmeri) from a natural seed bank. Weed Sci. 57:644-651.

Jha, P., J. K. Norsworthy, M. B. Riley, and W. Bridges, Jr. 2010. Annual changes in temperature and light requirements for Palmer amaranth (Amaranthus palmeri) seeds retrieved from soil. Weed Sci. 58:426-432.

Jha, P., J. K. Norsworthy, W. Bridges, Jr., and M. B. Riley. 2008. Influence of glyphosate timing and row width on Palmer amaranth (Amaranthus palmeri) and pusley (Richardia spp.) demographics in glyphosate-resistant soybean. Weed Sci. 56:408-415.

Johnson, C. W. and H. D. Coble. 1986. Crop rotation and herbicide effects on the population dynamics of annual grasses. Weed Sci. 34:452-456.

Johnson, D. B., J. K. Norsworthy, and G. M. Griffith. 2011. Weed populations after four years of Liberty Link and Roundup Ready cotton [behind pay wall]. In Proceedings of the Beltwide Cotton Conference. Atlanta, GA: National Cotton Council of America.

Johnson, G. A., M. S. DeFelice, and Z. R. Helsel. 1993. Cover crop management and weed control in corn (Zea mays). Weed Technol. 7:425-430.

Jones, R. E. and R. W. Medd. 2000. Economic thresholds and the case for longer term approaches to population management of weeds. Weed Technol. 14:337-350.

Jordan, N. 1993. Prospects for weed control through crop interference. Ecol. Appl. 3:84-91.

Jordan, N., R. Becker, J. Gunsolus, S. White, and S. Damme. 2003. Knowledge networks: an avenue to ecological management of invasive weeds. Weed Sci. 51:271-277.

Keeley, P. E., C. H. Carter, and R. J. Thullen. 1987. Influence of planting date on growth of Palmer amaranth (Amaranthus palmeri). Weed Sci. 35:199-204.

Kelley, A. D. and V. F. Bruns. 1975. Dissemination of weed seeds by irrigation water. Weed Sci. 23:486-493.

Kempenaar, C. and L.A.P. Lotz. 2004. Reduction of herbicide use and emission by new weed control methods and strategies. Water Sci. Technol. 49:135-138.

Ketel, D. H. and L.A.P. Lotz. 1998. Influence of allocation and detoxification of metribuzin in Chenopodium album on the reliability of prediction of the minimum lethal herbicide dose rate. Weed Res. 38:267-274.

King, C. A. and L. R. Oliver. 1994. A model for predicting large crabgrass (Digitaria sanguinalis) emergence as influenced by temperature and water potential. Weed Sci. 42:561-567.

Kingwell, R. S. 2010. Managing complexity in modern farming. Abstract 59090 in Proceeding of Australian Agricultural and Resource Economics Society Conference, Adelaide, NSW: Australian Agricultural and Resource Economics Society. http://EconPapers.repec.org/RePEc:ags:aare10:59090. Accessed July 30, 2011.

Kiss, J., K. Penksza, F. Tóth, and F. Kádár. 1997. Evaluation of fields and field margins in nature production capacity with special regard to plant protection. Agric. Ecosyst. Environ. 63:227-232.

Koger, C. H. and K. N. Reddy. 2005. Role of absorption and translocation in the mechanism of glyphosate resistance in horseweed (Conyza canadensis). Weed Sci. 53:84-89. 
Kremer, R. J. 1984. Management of weed seed banks with microorganisms. Ecol. Appl. 3:42-52.

Kremer, R. J. and N. R. Spencer. 1989. Impact of a seed-eating insect and microorganisms on velvetleaf (Abutilon theophrasti) seed viability. Weed Sci. $37: 211-216$

Kruidhof, H. M., L. Bastiaans, and M. J. Kropff. 2009. Cover crop residue management for optimizing weed control. Plant Soil 318:169-184.

Lacey, J. R. and R. L. Sheley. 1996. Leafy spurge and grass response to picloram and intensive grazing. J. Range Manag. 49:311-314.

Lacey, J. R., R. Wallander, and K. Olson-Rutz. 1992. Recovery, germinability, and viability of leafy spurge (Euphorbia esula) seeds ingested by sheep and goats. Weed Technol. 6:599-602.

Lande, R. 1983. The response to selection on major and minor mutations affecting a metrical trait. Heredity 50:47-65.

Leather, G. R. 1987. Weed control using allelopathic sunflowers and herbicide. Plant Soil 98:17-23.

Legleiter, T. R. and K. W. Bradley. 2008. Glyphosate and multiple herbicide resistance in common waterhemp (Amaranthus rudis) populations from Missouri. Weed Sci. 56:582-587.

Legleiter, T. R., K. W. Bradley, and R. E. Massey. 2009. Glyphosate-resistant waterhemp (Amaranthus rudis) control and economic returns with herbicide programs in soybean. Weed Technol. 23:54-61.

Leon, R. G., D. C. Basshami, and M.D.K. Owen. 2007. Thermal and hormonal regulation of the dormancy-germination transition in Amaranthus tuberculatus seeds. Weed Res. 47:335-344.

Liebman, M. and E. R. Gallandt. 1997. Many little hammers: Ecological management of crop-weed interactions. Pages 291-343 in L. E. Jackson, ed. Ecology in Agriculture. San Diego, CA: Academic.

Llewellyn, R. S. 2007. Information quality and effectiveness for more rapid adoption decisions by producers. Field Crops Res. 104:148-156.

Llewellyn, R. S. and D. M. Allen. 2006. Expected mobility of herbicide resistance via weed seeds and pollen in a Western Australian cropping region. Crop Prot. 25:520-526.

Llewellyn, R. S., R. K. Lindner, D. J. Pannell, and S. B. Powles. 2002. Resistance and the herbicide resource: perceptions of Western Australian grain growers. Crop Prot. 21:1067-1075.

Llewellyn, R. S., R. K. Lindner, D. J. Pannell, and S. B. Powles. 2004. Grain grower perceptions and use of integrated weed management. Aust. J. Exp. Agric. 44:993-1001

Llewellyn, R. S., R. K. Lindner, D. J. Pannell, and S. B. Powles. 2007. Herbicide resistance and the adoption of integrated weed management by Western Australian grain growers. Agric. Econ. 36:123-130.

Llewellyn, R. S., D. J. Pannell, R. K. Lindner, and S. B. Powles. 2005. Targeting key perceptions when planning and evaluating extension. Aust. J. Exp. Agric. 45:1627-1633.

Macnair, M. R. 1991. Why the evolution of resistance to anthropogenic toxins normally involves major gene changes: the limits to natural selection. Genetica 84:213-219.

Main, C. L., T. C. Mueller, R. M. Hayes, and J. B. Wilkerson. 2004. Response of selected horseweed [Conyza canadensis (L.) Cronq.] populations to glyphosate. J. Agric. Food Chem. 52:879-883.

Mallory-Smith, C. A. and M. Zapiola. 2008. Gene flow from glyphosate-resistant crops. Pest Manag. Sci. 64:428-440.

Mallory-Smith, C. A., D. C. Thill, and M. J. Dial. 1990. Identification of sulfonylurea herbicide-resistant prickly lettuce (Lactuca serriola). Weed Technol. 4:163-168.

Manalil, S., R. Busi, M. Benton, and S. Powles. 2011. Rapid evolution of herbicide resistance by low herbicide dosages. Weed Sci. 59:210-217.

Marra, M. C., N. E. Piggott, and G. A. Carlson. 2004. The net benefits, including convenience, of Roundup Ready soybeans: results from a national survey. NSF Center for IPM Technical Bulletin 2004-3. Raleigh, NC: National Science Foundation. 39 p.

Marsh, S. P., R. S. Llewellyn, and S. B. Powles. 2006. Social costs of herbicide resistance: the case of resistance to glyphosate. Abstract 25413 in Proceedings of the International Association of Agricultural Economists Conference. http:// econpapers.repec.org/RePEc:ags:iaae06:25413. Accessed July 30, 2011.

Marshall, E.J.P. 1989. Distribution patterns of plants associated with arable field edges. J. Appl. Ecol. 26:247-257.

Marshall, E.J.P. and P. Brain. 1999. The horizontal movement of seeds in arable soil by different soil cultivation methods. J. Appl. Ecol. 36:443-454.

Masin, R., M. C. Zuin, D. W. Archer, F. Forcella, and G. Zanin. 2005. WeedTurf: a prediction model to aid control of annual summer weeds in turf. Weed Sci. 53:193-201.

Matthews, J. M. 1994. Management of herbicide resistant populations. Pages 317-336 in S. B. Powles and J.A.M. Holtum, eds. Herbicide Resistance in Plants. Boca Raton, FL: CRC.
Maxwell, B. D. and C. Ghersa. 1992. The influence of weed seed dispersal versus the effect of competition on crop yield. Weed Technol. 6:196-204.

Maxwell, B. D. and A. M. Mortimer. 1994. Selection for herbicide resistance. Pages 1-26 in S. B. Powles and J.A.M. Holtum, eds. Herbicide Resistance in Plants. Boca Raton, FL: CRC

Maxwell, B. D., M. L. Roush, and S. R. Radosevich. 1990. Predicting the evolution and dynamics of herbicide resistance in weed populations. Weed Technol. 4:2-13.

McCanny, S. J. and P. B. Cavers. 1988. Spread of proso millet (Panicum miliaceum L.) in Ontario, Canada, II: dispersal by combines. Weed Res. 28:67-72

McMullan, P. and J. M. Green. 2011. Identification of a tall waterhemp (Amaranthus tuberculatus) biotype resistant to HPPD-inhibiting herbicides, atrazine, and thifensulfuron in Iowa. Weed Technol. 25:514-518.

Medd, R. W., M. G. McMillan, and A. S. Cook. 1992. Spray-topping of wild oats (Avena spp.) in wheat with selective herbicides. Plant Prot. 7:62-65.

Meiss, H., N. Munier-Jolain, F. Henriot, and J. Caneill. 2008. Effects of biomass, age and functional traits on regrowth of arable weeds after cutting. J. Plant Dis. Plant Prot. 21(SI XXI):493-499.

Menalled, F. D., K. A. Kohler, D. D. Buhler, and M. Liebman. 2005. Effects of composted swine manure on weed seedbank. Agric. Ecosyst. Environ. 111:63-69.

Menalled, F. D., J. C. Lee, and D. A. Landis. 2001. Herbaceous filter strips in agroecosystems: implications for ground beetle (Coleoptera: Carabidae) conservation and invertebrate weed seed predation. Gt. Lakes Entomol. 34:77-91.

Menalled, F. D., M. Liebman, and D. D. Butler. 2004. Impact of composted swine manure and tillage on common waterhemp (Amaranthus rudis) competition with soybean. Weed Sci. 20:56-59.

Michael, P. J., M. J. Owen, and S. B. Powles. 2010. Herbicide-resistant weed seeds contaminate grain sown in the Western Australian grainbelt. Weed Sci. 58:466-472.

Mickelson, J. A. and K. A. Renner. 1997. Weed control using reduced rates of postemergence herbicides in narrow and wide row soybean. J. Prod. Agric. $10: 431-437$.

Monks, D. W. and L. R. Oliver. 1988. Interactions between soybean (Glycine max) cultivars and selected weeds. Weed Sci. 36:770-774.

Mortensen, D. A., L. Bastiaans, and M. Sattin. 2000. The role of ecology in the development of weed management systems: an outlook. Weed Res. 40:49-62.

Mt. Pleasant, J. and K. J. Schlather. 1994. Incidence of weed seed in cow (Bos sp.) manure and its importance as a source for cropland. Weed Technol. 8:304-310.

Mt. Pleasant, J., R. E. McCollum, and H. D. Coble. 1990. Weed population dynamics and weed control in the Peruvian Amazon. Agron. J. 82:102-112.

Mueller, T. C., P. D. Mitchell, B. G. Young, and A. S. Culpepper. 2005. Proactive versus reactive management of glyphosate-resistant or tolerant weeds. Weed Technol. 19:924-933.

Murray, B. G., I. N. Morrison, and L. F. Friesen. 2002. Pollen-mediated gene flow in wild oat. Weed Sci. 50:321-325.

Neve, P. 2008. Simulation modeling to understand the evolution and management of glyphosate resistance in weeds. Pest Manag. Sci. 64:392-401.

Neve, P. and S. B. Powles. 2005a. Recurrent selection with reduced herbicide rates results in the rapid evolution of herbicide resistance in Lolium rigidum. Theor. Appl. Genet. 110:1154-1166.

Neve, P. and S. B. Powles. 2005b. High survival frequencies at low herbicide use rates in populations of Lolium rigidum result in rapid evolution of herbicide resistance. Heredity 95:485-492.

Neve, P., A. J. Diggle, F. P. Smith, and S. B. Powles. 2003a. Simulating evolution of glyphosate resistance in Lolium rigidum I: population biology of a rare resistance trait. Weed Res. 43:404-417.

Neve, P., A. J. Diggle, F. P. Smith, and S. B. Powles. 2003b. Simulating evolution of glyphosate resistance in Lolium rigidum II: past, present and future glyphosate use in Australian cropping. Weed Res. 43:418-427.

Neve, P., J. K. Norsworthy, K. L. Smith, and I. A. Zelaya. 2011a. Modelling evolution and management of glyphosate resistance in Amaranthus palmeri. Weed Res. 51:99-112.

Neve, P., J. K. Norsworthy, K. L. Smith, and I. A. Zelaya. 2011b. Modelling glyphosate resistance management strategies for Palmer amaranth in cotton. Weed Technol. 25:335-343.

Newton, C. H., L. R. Nelson, S. J. Dewalt, E. A. Mikhailova, C. J. Post, M. A. Schlautman, S. K. Cox, W. C. Bridges, and K. C. Hall. 2008. Solarization for the control of Pueraria montana (kudzu). Weed Res. 48:394-397.

Nichols, R. L., J. Bond, and A. S. Culpepper, et al. 2009. Glyphosate-resistant Palmer amaranth (Amaranthus palmeri) spreads in the Southern United States. Resist. Pest Manag. Newsl. 18:8-10.

Nichols, R., L. May, and F. Bourland. 2003. Special symposium-transgenic pest-resistant crops: status and testing issues. Crop Sci. 43:1582-1583. 
Noordijk, J., C.J.M. Musters, J. van Dijk, and G. R. de Snoo. 2011. Vegetation development in sown field margins and on adjacent ditch banks. Plant Ecol. 212:157-167.

Norris, R. F. 1999. Ecological implications of using thresholds for weed management. Pages 31-58 in D. D. Buhler, ed. Expanding the Context of Weed Management. New York: Haworth.

Norris, R. F. 2007. Weed fecundity: current status and future needs. Crop Prot. 26:182-188.

Norsworthy, J. K. 2003. Use of soybean production surveys to determine weed management needs of South Carolina farmers. Weed Technol. 17:195-201.

Norsworthy, J. K. 2004a. Soybean canopy formation effects on pitted morningglory (Ipomoea lacunosa), common cocklebur (Xanthium strumarium), and sicklepod (Senna obtusifolia) emergence. Weed Sci. 52:954-960.

Norsworthy, J. K. 2004b. Small-grain cover crop interaction with glyphosateresistant corn (Zea mays L.). Weed Technol. 18:52-59.

Norsworthy, J. K. 2012. Repeated selection with sublethal rates of glyphosate lead to decreased sensitivity in Palmer amaranth. Crop Manag. In press.

Norsworthy, J. K. and J. R. Frederick. 2005. Integrated weed management strategies for maize (Zea mays) production on the southeastern coastal plains of North America. Crop Prot. 24:119-126.

Norsworthy, J. K. and M. J. Oliveira. 2007a. Light and temperature requirements for common cocklebur (Xanthium strumarium) germination during afterripening under field conditions. Weed Sci. 55:227-234.

Norsworthy, J. K. and M. J. Oliveira. 2007b. Role of light quality and temperature on pitted morningglory (Ipomoea lacunosa) germination with after-ripening. Weed Sci. 55:111-118.

Norsworthy, J. K. and M. J. Oliveira. 2007c. A model for predicting common cocklebur (Xanthium strumarium) emergence in soybean. Weed Sci. 55:341-345.

Norsworthy, J. K. and L. R. Oliver. 2001. Effect of seeding rate of drilled glyphosate-resistant soybean (Glycine max) on seed yield and gross profit margin. Weed Technol. 15:284-292.

Norsworthy, J. K. and L. R. Oliver. 2002. Effect of irrigation, soybean (Glycine max) density, and glyphosate on hemp sesbania (Sesbania exaltata) and pitted morningglory (Ipomoea lacunosa) interference in soybean. Weed Technol. 16:7-17.

Norsworthy, J. K. and E. Shipe. 2006. Evaluation of glyphosate-resistant Glycine max genotypes for competitiveness at recommended seeding rates in wide and narrow rows. Crop Prot. 25:362-368.

Norsworthy, J. K., M. V. Bagavathiannan, P. Neve, K. Smith, and I. Zelaya 2011a. Integrating nonchemical practices into simulation modeling for herbicide resistance. a proactive strategy. WSSA Abstr. In press.

Norsworthy, J. K., N. R. Burgos, R. C. Scott, and K. L. Smith. 2007a. Consultant perspectives on weed management needs in Arkansas rice. Weed Technol. 21:832-839.

Norsworthy, J. K., P. Jha, and W. Bridges, Jr. 2007b. Sicklepod (Senna obtusifolia) survival and fecundity in wide- and narrow-row glyphosateresistant soybean. Weed Sci. 55:252-259.

Norsworthy, J. K., M. S. Malik, P. Jha, and M. B. Riley. 2007c. Suppression of Digitaria sanguinalis and Amaranthus palmeri using autumn-sown glucosinolate-producing cover crops in organically grown bell pepper. Weed Res. 47:425-432.

Norsworthy, J. K., M. S. Malik, M. B. Riley, and W. Bridges, Jr. 2010a. Time of emergence affects survival and development of wild radish (Raphanus raphanistrum) in South Carolina. Weed Sci. 58:402-407.

Norsworthy, J. K., M. McClelland, G. Griffith, S. Bangarwa, and J. Still. 2010b. Evaluation of legume cover crops and weed control programs in conservationtillage, enhanced glyphosate-resistant cotton. Weed Technol. 24:269-274.

Norsworthy, J. K., M. McClelland, G. Griffith, S. Bangarwa, and J. Still. 2011b. Evaluation of cereal and Brassicaceae cover crops in conservation-tillage, enhanced glyphosate-resistant cotton. Weed Technol. 25:6-13.

Norsworthy, J. K., K. L. Smith, R. C. Scott, and E. E. Gbur. 2007d. Consultant perspectives on weed management needs in Arkansas cotton. Weed Technol. 21:825-831.

Norsworthy, J. K., K. L. Smith, L. E. Steckel, and C. H. Koger. 2009. Weed seed contamination of cotton gin trash. Weed Technol. 23:574-580.

O’Donovan, J. T. 1996. Weed economic thresholds: Useful agronomic tool or pipe dream? Phytoprotection 77:13-28.

O’Donovan, J. T., R. E. Blackshaw, K. N. Harker, G. W. Clayton, J. R. Moyer, L. M. Dosdall, D. C. Maurice, and T. K. Turkington. 2007. Integrated approaches to managing weeds in spring-sown crops in western Canada. Crop Prot. 26:390-398.

Olofsson, S. K. and O. Cars. 2007. Optimizing drug exposure to minimize selection of antibiotic resistance. Clin. Infect. Dis. 45:129-136.

Olson, B. E. and R. T. Wallander. 1998. Effect of sheep grazing on a leafy spurge-infested Idaho fescue community. J. Range Manag. 51:247-252.
Omami, E. N., A. M. Haigh, R. W. Medd, and H. I. Nicol. 1999. Changes in germination, dormancy and viability of Amaranthus retroflexus as affected by depth and duration of burial. Weed Res. 39:345-354.

Orr, H. A. and J. A Coyne. 1992. The genetics of adaptation: a reassessment. Am. Nat. 105:725-742.

Orson, J. H. 1999. The cost to the producer of herbicide resistance. Weed Technol. 13:607-611.

Owen, M.D.K. 2008. Weed species shifts in glyphosate-resistant crops. Pest Manag. Sci. 64:377-387.

Owen, M.D.K. and I. A. Zelaya. 2005. Herbicide-resistant crops and weed resistance to herbicides. Pest Manag. Sci. 61:301-311.

Pannell, D. J., V. Stewart, A. Bennett, M. Monjardino, C. Schmidt, and S. B. Powles. 2004. RIM: a bioeconomic model for IWM of Lolium rigidum in Western Australia. Agric. Syst. 79:305-325.

Pardo, G., M. Riravololona, and N. M. Munier-Jolain. 2010. Using a farming system model to evaluate cropping system prototypes: are labour constraints and economic performances hampering the adoption of Integrated Weed Management? Eur. J. Agron. 33:24-32.

Patterson, D. T. 1998. Suppression of purple nutsedge (Cyperus rotundus) with polyethylene film mulch. Weed Technol. 12:275-280.

Patzoldt, W. L., P. J. Tranel, and A. G. Hager. 2002. Variable herbicide responses among Illinois waterhemp (Amaranthus rudis and A. tuberculatus) populations. Crop Prot. 21:707-712.

Pellett, N. E. and D. A. Heleba. 1995. Chopped newspaper for weed control in nursery crops. J. Environ. Hortic. 13:77-81.

Perez-Jones, A., K. W. Park, J. Colquhoun, C. Mallory-Smith, and D. Shaner. 2005. Identification of glyphosate-resistant Italian ryegrass (Lolium multiflorum) in Oregon. Weed Sci. 53:775-779.

Piggott, N. and M. C. Marra. 2008. Bt convenience biotechnology adoption over time in the presence of nonpecuniary characteristics that directly affect utility. Agbioforum 11:58-70.

Pitty, A., D. W. Staniforth, and L. H. Tiffany. 1987. Fungi associated with caryopses of Setaria species from field-harvested seeds from soil under two tillage systems. Weed Sci. 35:319-323.

Pollard, J. M., B. A. Sellers, and R. J. Smeda. 2004. Differential response of common ragweed to glyphosate. Proc. North. Cent. Weed Sci. Soc. 59:27.

Potter, T. L., C. C. Truman, T. C. Strickland, D. D. Bosch, and T. M. Webster. 2008. Herbicide incorporation by irrigation and tillage impact on runoff loss. J. Environ. Qual. 37:839-847.

Povey, F. D., H. Smith, and T. A. Watt. 1993. Predation of annual grass weed seeds in arable field margins. Ann. Appl. Biol. 122:323-328.

Powles, S. B. and Q. Yu. 2010. Evolution in action: plants resistant to herbicides. Annu. Rev. Plant Biol. 61:317-347.

Powles, S. B., C. Preston, I. B. Bryan, and A. R. Jutsum. 1997. Herbicide resistance: impact and management. Adv. Agron. 58:57-93.

Powles, S. B., E. S. Tucker, and T. W. Morgan. 1992. Eradication of paraquatresistant Hordeum glaucum Steud. by prevention of seed production for 3 years. Weed Res. 32:207-211.

Preston, C. 2004. Herbicide resistance in weeds endowed by enhanced detoxification: complications for management. Weed Sci. 52:448-453.

Price, A. J., F. J. Arriaga, R. L. Raper, K. S. Balkcom, T. S. Komecki, and D. W. Reeves. 2009. Comparison of mechanical and chemical winter cereal cover crop termination systems and cotton yield in conservation agriculture. J. Cotton Sci. 13:238-245.

Prince, J. M., D. R. Shaw, W. A. Givens, M.D.K. Owen, S. C. Weller, B. G. Young, R. G. Wilson, and D. L. Jordan. 2012a. Benchmark study: I-a survey to assess changes in grower perceptions of benefits and challenges of glyphosate-resistant cropping systems. Weed Technol. In press.

Prince, J. M., D. R. Shaw, W. A. Givens, M.D.K. Owen, S. C. Weller, B. G. Young, R. G. Wilson, and D. L. Jordan. 2012b. Benchmark study: II—a 2010 survey to assess grower awareness of and attitudes toward glyphosate resistance. Weed Technol. DOI: 10.1614/WT-D-11-00091.1.

Prince, J. M., D. R. Shaw, W. A. Givens, M.D.K. Owen, S. C. Weller, B. G. Young, R. G. Wilson, and D. L. Jordan. 2012c. Benchmark study: III-trends in problematic weeds in glyphosate-resistant cropping systems. Weed Technol. DOI: dx.doi.org/10.1614/WT-D-11-00093.1.

Prince, J. M., D. R. Shaw, W. A. Givens, M.D.K. Owen, S. C. Weller, B. G. Young, R. G. Wilson, and D. L. Jordan. 2012d. Benchmark study: IVchanging herbicide use patterns in glyphosate-resistant cropping systems. Weed Technol. DOI: dx.doi.org/10.1614/WT-D-11-00094.1.

Prince, J. M., D. R. Shaw, W. A. Givens, M.D.K. Owen, S. C. Weller, B. G. Young, R. G. Wilson, and D. L. Jordan. 2012e. Benchmark study: IV-Survey of grower practices for managing glyphosate-resistant weed populations. Weed Technol. In press.

Putnam, A. R. and J. DeFrank. 1983. Use of phytotoxic plant residues for selective weed control. Crop Prot. 2:173-181. 
Putnam, A. R., J. DeFrank, and J. P. Barnes. 1983. Exploitation of allelopathy for weed control in annual and perennial cropping systems. J. Chem. Ecol. 9:1001-1010.

Reader, R. J. 1991. Control of seeding emergence by ground cover: a potential mechanism involving seed predation. Can. J. Bot. 69:2084-2087.

Reddy, K. N. and J. K. Norsworthy. 2010. Glyphosate-resistant crop production systems: impact on weed species shifts. Pages 165-184 in V. K. Nandula, ed. Glyphosate Resistance in Crops and Weeds: History, Development, and Management. Singapore: J. Wiley.

Rew, L. J. and G. W. Cussans. 1997. Horizontal movement of seeds following tine and plough cultivation: implications for spatial dynamics of weed infestations. Weed Res. 37:247-256.

Rew, L. J., R. J. Froud-Williams, and N. D. Boatman. 1996. Dispersal of Bromus sterilis and Anthriscus sylvestris seed within arable field margins. Agric. Ecosyst. Environ. 59:107-114.

Robinson, E. 2011. NRCS to Offer Assistance for Managing Weed Resistance. http://deltafarmpress.com/government/nrcs-offer-assistance-managing-weedresistance Accessed: April 4, 2011.

Rose, S. J., O. C. Burnside, J. E. Specht, and B. A. Swisher. 1984. Competition and allelopathy between soybeans and weeds. Agron. J. 76:523-528.

Roush, R. T. and J. A. MacKenzie. 1987. Ecological genetics of insecticide and acaricide resistance. Annu. Rev. Entomol. 32:361-380.

Roux, F., M. Paris, and X. Reboud. 2008. Delaying weed adaptation to herbicide by environmental heterogeneity: a simulation approach. Pest Manag. Sci. 64:16-29.

Ruegg, W. T., M. Quadranti, and A. Zoschke. 2007. Herbicide research and development: challenges and opportunities. Weed Res. 47:271-275.

Ryan, G. F. 1970. Resistance of common groundsel to simazine and atrazine. Weed Sci. 18:614-616.

Salmerón, M., J. Carvero, D. Quilez, and R. Isla. 2010. Winter cover crops affect monoculture maize yield and nitrogen leaching under irrigated Mediterranean conditions. Agron. J. 102:1700-1709.

Sattin, M., G. Zanin, and A. Berti. 1992. Case history for weed competition/ population ecology: Velvetleaf (Abutilon theophrasti) in corn (Zea mays). Weed Technol. 6:213-219.

Schomberg, H. H., R. G. McDaniel, E. Mallard, D. M. Endale, D. S. Fisher, and M. L. Cabrera. 2006. Conservation tillage and cover crop influences on cotton production on a southeastern U.S. coastal plain soil. Agron. J. 98:1247-1256.

Schreiber, M. M. 1992. Influence of tillage, crop rotation, and weed management on giant foxtail (Setaria faberi) population dynamics and corn yield. Weed Sci. 40:645-653

Schweizer, E. E. and R. L. Zimdahl. 1984a. Weed seed decline in irrigated soil after rotation of crops and herbicides. Weed Sci. 32:84-89.

Seaman, R. E. and P. C. Marino. 2003. Influence of mound building and selective seed predation by the red imported fire ant (Solenopsis invicta) on an old-field plant assemblage. J. Torrey Bot. Soc. 130:193-201.

Seefeldt, S. S., R. Zemetra, F. L. Young, and S. S. Jones. 1998. Production of herbicide-resistant jointed goatgrass (Aegilops cylindrica) $\times$ wheat (Triticum aestivum) hybrids in the field by natural hybridization. Weed Sci. 46:632-634.

Seng, C. T., L. V. Lun, C. T. San, and I. B. Sahid. 2010. Initial report of glufosinate and paraquat multiple resistance that evolved in a biotype of goosegrass (Eleusine indica) in Malaysia. Weed Biol. Manag. 10:229-233.

Shaner, D. L., S. Howard, and I. Chalmers. 1999. Effectiveness of mode of action labeling for resistance management: survey of Australian farmers. In Proceedings of the Brighton Crop Protection Conference-Weeds. Farnham, UK: British Crop Protection Council. http://www.plantprotection.org/ HRAC/effectiveness.htm. Accessed July 30, 2011.

Shaw, D. R., W. A. Givens, and L. A. Farno, et al. 2009. Using a grower survey to assess the benefits and challenges of glyphosate-resistant cropping systems for weed management in U.S. corn, cotton, and soybean. Weed Technol. 23:134-149.

Shaw, D. R., M.D.K. Owen, P. M. Dixon, S. C. Weller, B. G. Young, R. G. Wilson, and D. L. Jordan. 2011. Benchmark study on glyphosate-resistant cropping systems in the United States, part 1: introduction to 2006-2008. Pest. Manag. Sci. 67:741-746.

Shaw, M. W. 2006. Is there such a thing as a fungicide resistance strategy? a modeler's perspective. Asp. Appl. Biol. 78:37-44.

Shields, E. J., J. T. Dauer, M. J. VanGessel, and G. Neumann. 2006. Horseweed (Conyza canadensis) seed collected in the planetary boundary layer. Weed Sci. 54:1063-1067.

Shimono, Y., Y. Takiguchi, and A. Konuma. 2010. Contamination of internationally traded wheat by herbicide-resistant Lolium rigidum. Weed Biol. Manag. 10:219-228.

Shirtliffe, S. J. and M. H. Entz. 2005. Chaff collection reduces seed dispersal of wild oat (Avena fatua) by a combine harvester. Weed Sci. 53:465-470.

Shivrain, V. K., N. R. Burgos, M. M. Anders, S. N. Rajguru, J. Moore, and M. A. Sales. 2007. Gene flow between Clearfield ${ }^{\mathrm{TM}}$ rice and red rice. Crop Prot. 26:349-356.

Shivrain, V. K., N. R. Burgos, D. R. Gealy, K. L. Smith, R. C. Scott, A. Mauromoustakos, and H. Black. 2009a. Red rice (Oryza sativa) emergence characteristics and influence on rice yield at different planting dates. Weed Sci. 57:94-102.

Shivrain, V. K., N. R. Burgos, M. A. Mauromoustakos, D. R. Gealy, K. L. Smith, H. L. Black, and M. Jia. 2009b. Factors affecting the outcrossing rate between Clearfield $^{\mathrm{TM}}$ rice and red rice (Oryza sativa). Weed Sci. 57:394-403.

Shivrain, V. K., N. R. Burgos, M. A. Sales, A. Mauromoustakos, D. R. Gealy, K. L. Smith, H. L. Black, and M. Jia. 2009c. Factors affecting the outcrossing rate between Clearfield rice and red rice (Oryza sativa). Weed Sci. 57:394-403.

Shivrain, V. K., N. R. Burgos, R. C. Scott, E. E. Gbur, L. E. Estorninos, Jr., and M. R. McClelland. 2010. Diversity of weedy red rice (Oryza sativa L.) in Arkansas, U.S.A. in relation to weed management. Crop Prot. 29:721-730.

Shrestha, A. 2004. Weed Seed Return and Their Role in Future Weed Management. http://www.weedbiology.uckac.edu/kacspecies/PDF/weed-seedbanks.pdf. Accessed March 9, 2011.

Shrestha, A. and C. J. Swanton. 2007. Parameterization of the phenological development of select annual weeds under noncropped field conditions. Weed Sci. 55:446-454.

Simarmata, M., S. Bughrara, and D. Penner. 2005. Inheritance of glyphosate resistance in rigid ryegrass (Lolium rigidum) from California. Weed Sci. 53:615-619

Smith, D. T., R. V. Baker, and G. L. Steele. 2000. Palmer amaranth (Amaranthus palmeri) impacts on yield, harvesting, and ginning in dryland cotton. Weed Technol. 14:122-126.

Smith, R. J., Jr. 1979. How to control the hard-to-kill weeds in rice. Weeds Today 10:12-14.

Sosnoskie, L. M., T. M. Webster, D. Dales, G. C. Rains, T. L. Grey, and A. S. Culpepper. 2009. Pollen grain size, density, and settling velocity for Palmer amaranth (Amaranthus palmeri). Weed Sci. 57:404-409.

Soule, M. J., A. Tegene, and K. D. Wiebe. 2000. Land tenure and the adoption of conservation practices. Am. J. Agric. Econ. 82:993-1005.

Steadman, K. J., D. M. Easton, J. A. Plummer, D. G. Ferris, and S. B. Powles. 2006. Late-season nonselective herbicide application reduces Lolium rigidum seed numbers, seed viability, and seedling fitness. Aust. J. Agric. Res. 57:133-141.

Steckel, L. E., M. S. Defelice, and B. D. Sims. 1990. Integrating reduced rates of postemergence herbicides and cultivation for broadleaf weed-control in soybeans (Glycine max). Weed Sci. 38:541-545.

Steinsiek, J. W., L. R. Oliver, and F. C. Collins. 1982. Allelopathic potential of wheat (Triticum aestivum) straw on selected weed species. Weed Sci. 30:495-497.

Story, J. M., J. G. Corn, and L. J. White. 2010. Compatibility of seed head biological control agents and mowing for management of spotted knapweed. Environ. Entomol. 39:164-168.

Stubbendieck, J., G. Y. Friisoe, and M. R. Bolick. 1994. Weeds of Nebraska and the Great Plains. Lincoln, NE: Nebraska Department of Agriculture. 589 p.

Sutherland, S. 2004. What makes a weed a weed: life history traits of native and exotic plants in the USA. Oecologia 141:24-39.

Swanton, C. J., K. J. Mahoney, K. Chandler, and R. H. Gulden. 2008. Integrated weed management: knowledge-based weed management systems. Weed Sci. $56: 168-172$.

Swanton, C. J., S. Weaver, P. Cowan, R. Van Acker, W. Deen, and A. Shrestha. 1999. Weed thresholds: theory and applicability. J. Crop Prod. 2:9-29.

Switzer, C. M. 1957. The existence of 2,4-D-resistant strains of wild carrot. Proc. Northeast. Weed Control Conf. 11:315-318.

Talbert, R. E. and N. R. Burgos. 2007. History and management of herbicideresistant barnyardgrass (Echinochloa crus-galli) in Arkansas rice. Weed Technol. 21:324-331.

Taylor, S. E. and L. R. Oliver. 1997. Sicklepod (Senna obtusifolia) seed production and viability as influenced by late-season postemergence herbicide applications. Weed Sci. 45:497-501.

Teasdale, J. R., C. E. Beste, and W. E. Potts. 1991. Response of weeds to tillage and cover crop residue. Weed Sci. 39:195-199.

Thill, D. C. and C. A. Mallory-Smith. 1997. The nature and consequence of weed spread in cropping systems. Weed Sci. 45:337-342.

Traveset, A., N. Riera, and R. E. Mas. 2001. Passage through bird guts causes interspecific differences in seed germination characteristics. Funct. Ecol. 15:669-675.

[USDA] U.S. Department of Agriculture. 2011. Adoption of Genetically Engineered Crops in the U.S. http://www.ers.usda.gov/Data/BiotechCrops. Accessed: March 2, 2012.

[USDA-NASS] U.S. Department of Agriculture-National Agricultural Statistics Service. 2007. 2007 Census of Agriculture-Demographics. http://www. agcensus.usda.gov/Publications/2007/Online_Highlights/Fact_Sheets/demographics.pdf. Accessed October 25, 2010.

Uva, R. H., J. C. Neal, and J. M. DiTomaso. 1997. Weeds of the Northeast. Ithaca, NY: Cornell University Press. 396 p.

Uyenoyama, M. K. 1986. Pleiotropy and the evolution of genetic systems conferring resistance to pesticides. Pages $207-221$ in R. L. Metcalf and W. H. 
Luckmann, eds. Pesticide Resistance: Strategies and Tactics for Management. Washington, DC: National Academy.

Vander Wall, S. B., K. M. Kuhn, and M. J. Beck. 2005. Seed removal, seed predation, and secondary dispersal. Ecology 86:801-806.

VanGessel, M. J. 2001. Glyphosate-resistant horseweed in Delaware. Weed Sci. 49:703-705.

Verkaar, H. J., A. J. Schenkeveld, and M. P. Van de Klashorst. 1983. The ecology of short-lived forbs in chalk grasslands: dispersal of seeds. New Phytol. 95:335-344.

Vila-Aiub, M. M., P. Neve, and S. B. Powles. 2009. Fitness costs associated with evolved herbicide resistance in plants. New Phytol. 184:751-767.

Walker, E. R. and L. R. Oliver. 2008. Weed seed production as influenced by glyphosate applications at flowering. Weed Technol. 22:318-325.

Walker, R. H. and G. A. Buchanan. 1982. Crop manipulation in integrated weed management systems. Weed Sci. 30(Suppl.):17-24.

Walsh, M. and P. Newman. 2007. Burning narrow windrows for weed seed destruction. Field Crops Res. 104:24-30.

Walsh, M. and W. Parker. 2002. Wild radish and ryegrass seed collection at harvest: chaff carts and other devices. Perth, WA: Department of Agriculture Western Australia Agribusiness Crop Updates. Pp. 37-38.

Walsh, M. J. and S. B. Powles. 2007. Management strategies for herbicideresistant weed populations in Australian dryland crop production systems. Weed Technol. 21:332-338.

Walsh, M., R. Harrington, and S. Powles. 2012. Harrington Seed Destructor: a new non-chemical weed control tool for global grain crops. Crop Sci. In press.

Warnes, D. D. and R. N. Andersen. 1984. Decline of wild mustard (Brassica kaber) seeds in soil under various cultural and chemical practices. Weed Sci. 32:214-217.

Warwick, S. I., H. J. Beckie, and E. Small. 1999. Transgenic crops: new weed problems for Canada? Phytoprotection 80:71-84.

Warwick, S. I., A. Legere, M.-J. Simard, and T. James. 2008. Do escaped transgenes persist in nature? the case of a herbicide resistance transgene in a weedy Brassica rapa population. Mol. Ecol. 17:1387-1395.

Waterer, D. 2010. Evaluation of biodegradable mulches for production of warmseason vegetable crops. Can. J. Plant Sci. 90:737-743.

Wax, L. M. and J. W. Pendleton. 1968. Effect of row spacing on weed control in soybeans. Weed Sci. 16:462-465.

Webster, T. M. 2005a. Mulch type affects growth and tuber production of yellow nutsedge (Cyperus esculentus) and purple nutsedge (Cyperus rotundus). Weed Sci. 53:834-838.

Webster, T. M. 2005b. Patch expansion of purple nutsedge (Cyperus rotundus) and yellow nutsedge (Cyperus esculentus) with and without polyethylene mulch. Weed Sci. 53:839-845.

Webster, T. M. 2007. Cotton row spacing and plant population affect weed seed production. Pages 1-21 in Proceedings of World Cotton Research Conference IV. Lubbock, TX: International Cotton Advisory Committee.

Webster, T. M. and L. M. Sosnoskie. 2010. The loss of glyphosate efficacy: a changing weed spectrum in Georgia cotton. Weed Sci. 58:73-79.

Webster, T. M., M. G. Burton, A. S. Culpepper, A. C. York, and E. P. Prostko, 2005. Tropical spiderwort (Commelina benghalensis): a tropical invader threatens agroecosystems of the southern United States. Weed Technol. 19:501-508.

Webster, T. M., T. L. Grey, J. T. Flanders, and A. S. Culpepper. 2009. Cotton planting date affects the critical period of Benghal dayflower (Commelina benghalensis) control. Weed Sci. 57:81-86.

Weersink, A., Llewellyn, R. S., and Pannell, D. J. 2005. Economics of preemptive management to avoid weed resistance to glyphosate in Australia. Crop Prot. 24:659-665.

Weirich, J. W., D. R. Shaw, K. H. Coble, M.D.K. Owen, P. M. Dixon, S. C. Weller, B. G. Young, R. G. Wilson, and D. L. Jordan. 2011a. Benchmark study on glyphosate-resistant cropping systems in the United States, part 6 timeliness of economic decision-making in implementing weed resistance management strategies. Pest Manag. Sci. 67:785-789.

Weirich, J. W., D. R. Shaw, M.D.K. Owen, P. M. Dixon, S. C. Weller, B. G. Young, R. G. Wilson, and D. L. Jordan. 2011b. Benchmark study on glyphosate-resistant cropping systems in the United States, part 5: effects of glyphosate-based weed management programs on farm level profitability. Pest Manag. Sci. 67:781-784.

Westerman, P. R., M. Liebman, A. H. Heggenstaller, and F. Forcella. 2006 Integrating measurements of seed availability and removal to estimate weed seed losses due to predation. Weed Sci. 54:566-574.

Whitehead, C. W. and C. M. Switzer. 1967. The differential response of strain of wild carrot to 2,4-D and related herbicides. Can. J. Plant Sci. 43: 255-262.

Whitson, T. D., L. C. Burrill, and S. A. Dewey, et al. 2009. Weeds of the West, 10th ed. Jackson, WY: Color World Printers. 628 p.

Wiese, A. F., J. M. Sweeten, B. W. Bean, C. D. Salisbury, and E. W. Chenault. 1998. High temperature composting of cattle feedlot manure kills weed seed. Appl. Eng. Agric. 14:377-380.

Wiles, L. J., G. W. Oliver, A. C. York, H. J. Gold, and G. G. Wilkerson. 1992 Spatial distribution of broadleaf weeds in North Carolina soybean (Glycine max) fields. Weed Sci. 40:554-557.

Wilson, B. J. and P. Brain. 1991. Long-term stability of distribution of Alopecurus myosuroides Huds. within cereal fields. Weed Res. 31:367-373.

Wilson, P. J. and N. J. Aebischer. 1995. The distribution of dicotyledonous arable weeds in relation to distance from the field edge. J. Appl. Ecol. 32:295-310.

Wilson, R. G. 1980. Dissemination of weed seeds by surface irrigation water in Western Nebraska. Weed Sci. 28:87-92.

Wilson, R. G. 1988. Biology of weed seed in the soil. Pages 25-39 in M. A. Altieri and M. Liebman, eds. Weed Management in Agroecosystems: Ecological Approaches. Boca Raton, FL: CRC.

Wilson, R. G., B. G. Young, J. L. Mathews, S. C. Weller, W. G. Johnson, D. L. Jordan, M.D.K. Owen, P. M. Dixon, and D. R. Shaw. 2011. Benchmark study on glyphosate-resistant cropping systems in the United States, part 4: weed populations and soils seedbanks. Pest. Manag. 67:771-780.

Wilson, R. S., M. A. Tucker, N. H. Hooker, J. T. LeJeune, and D. Doohan 2008. Perceptions and beliefs about weed management: perspectives of Ohio grain and produce farmers. Weed Technol. 22:339-350.

Woodyard, A. J., J. A. Hugie, and D. E. Riechers. 2009. Interactions of mesotrione and atrazine in two weed species with different mechanisms for atrazine resistance. Weed Sci. 57:369-378.

Wrubel, R. P. and J. Gressel. 1994. Are herbicide mixtures useful for delaying evolution of resistance? a case study. Weed Technol. 8:635-648.

Yelverton, F. H. and H. D. Coble. 1991. Narrow row spacing and canopy formation reduces weed resurgence in soybeans (Glycine max). Weed Technol. 5:169-174.

Yenish, J. P., A. D. Worsham, and A. C. York. 1996. Cover crops for herbicide replacement in no-tillage corn (Zea mays). Weed Technol. 10:815-821.

Young, B. G. 2006. Changes in herbicide use patterns and production practices resulting from glyphosate-resistant crops. Weed Technol. 20:301-307.

Zapiola, M. L., C. K. Campbell, M. D. Butler, and C. A. Mallory-Smith. 2008. Escape and establishment of transgenic glyphosate-resistant creeping bentgrass Agrostis stolonifera in Oregon, USA: a 4-year study. J. Appl. Ecol. 45: 486-494.

Zhang, J., S. E. Weaver, and A. S. Hamill. 2000. Risks and reliability of using herbicides at below-labeled rates. Weed Technol. 14:106-115.

Received September 16, 2011, and approved January 24, 2012. 